Portland State University

PDXScholar

Fall 1-4-2013

\title{
Empowerment in Community-Based Participatory Research with Persons with Developmental Disabilities: Perspectives of Community Researchers
}

Erin Elizabeth Stack

Portland State University

Follow this and additional works at: https://pdxscholar.library.pdx.edu/open_access_etds

Part of the Community Health Commons, Other Medical Sciences Commons, and the Social Work Commons

Let us know how access to this document benefits you.

\section{Recommended Citation}

Stack, Erin Elizabeth, "Empowerment in Community-Based Participatory Research with Persons with Developmental Disabilities: Perspectives of Community Researchers" (2013). Dissertations and Theses. Paper 550.

https://doi.org/10.15760/etd.550

This Thesis is brought to you for free and open access. It has been accepted for inclusion in Dissertations and Theses by an authorized administrator of PDXScholar. Please contact us if we can make this document more accessible: pdxscholar@pdx.edu. 
Empowerment in Community-Based Participatory Research with Persons with Developmental Disabilities: Perspectives of Community Researchers

\author{
by
}

Erin Elizabeth Stack

\begin{abstract}
requirements for the degree of
Master of Science

in Psychology

Thesis Committee:

Cynthia Mohr, Chair

Ann Curry- Stevens

Lauren Lichty

Katherine E. McDonald
\end{abstract}

A thesis submitted in partial fulfillment of the

Portland State University

2012 


\begin{abstract}
Community-based participatory research (CBPR) is a research approach that benefits from the expertise of community members being involved in the research along all stages of a project (Israel et al., 2003). CBPR is often utilized with marginalized populations in order to amplify a community's voice on important issues in their lives (Bastida, Tseng, McKeever, \& Jack, 2010; Minkler \& Wallerstein, 2008). In the past, persons with disability have been excluded from research in order to protect them from exploitation. This practice of exclusion undermines opportunities for persons with disabilities to be independent and make decisions that are important for themselves and their communities. Exclusion also limits the generation of new knowledge that can benefit them (McDonald \& Keys, 2008). Through involvement on a CBPR project, persons with disabilities are given the opportunity to become empowered within the context of the project (Atkinson, 2004; Oden, Hernandez, \& Hidalgo, 2010). This study examined empowerment definitions, evolution of empowerment definitions, and facilitators and barriers to community partners with and without disabilities becoming empowered through their work on a CBPR project. Overall, community partners' definitions of empowerment related to individual and setting-level characteristics. Individual-level empowerment was defined as self-efficacy, self-esteem, control over decision-making, and disability rights advocacy. Facilitators to empowerment within the CBPR process were promoting inclusion, promoting an accessible partnership, sharing of power within and between groups, and actively sharing and gaining knowledge within and between groups. Inaccessible communication, inaccessible language, and lack of
\end{abstract}


project ownership were identified as possible barriers to empowerment. In most cases, empowerment definitions remained stable across one's work on this project, but there were instances of positive change in the lives of some community partners who expressed being empowered through the partnership. CBPR provides an opportunity for persons with developmental disabilities to be included in the research processes as well as possibly gain important qualities throughout, such as empowerment. This study situated the individual's empowerment beliefs and behaviors within the CBPR setting, identifying both facilitators and barriers, and provides support that a CBPR process can be empowering for community partners. Future research in collaboration with community partners should continue to focus on empowerment in all stages of the research project, local collaborations, and continued diversity of community engagement in research. Engaging in a formal reflection process and documenting the process for other researchers to learn from diverse barriers and facilitators to empowerment is encouraged 


\section{Acknowledgements}

I would like to share my appreciation for all those who have assisted me in the development and evolution of my Master's Thesis. I would like to thank all the academic and community partners working on the Partnering with People with Developmental Disabilities to Address Violence project. Their willingness to engage and learn from this evaluation has been stimulating and valued. I would like to thank my advisor, Dr.

Katherine McDonald for her commitment to the inclusion of persons with disabilities in research that continually inspires me. Also, I would like to thank the other members of my thesis committee, Dr. Ann Curry-Stevens, Dr. Lauren Lichty, and Dr. Cynthia Mohr for challenging me and providing support throughout this process. 
Table of Contents

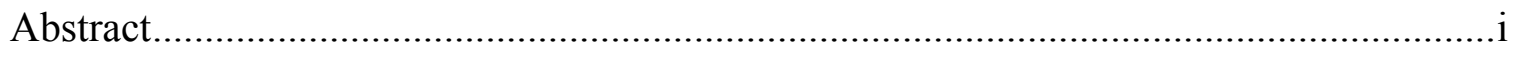

Acknowledgements ............................................................................................. ii

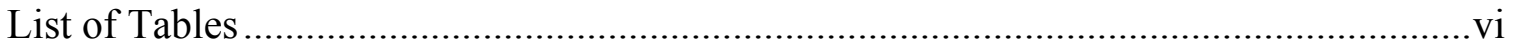

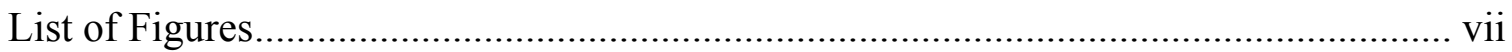

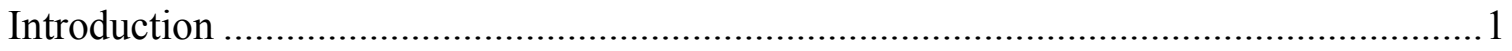

Community-Based Participatory Research: Theory \& Principles.................................... 3

Challenges of Putting CBPR into Practice .............................................................. 12

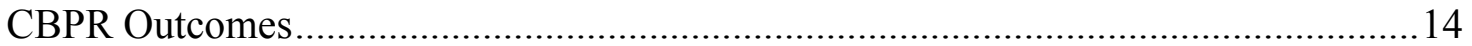

CBPR and People with Developmental Disabilities .....................................................16

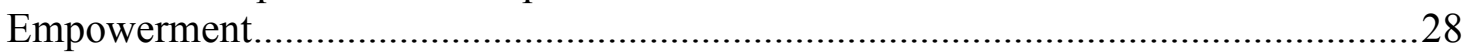

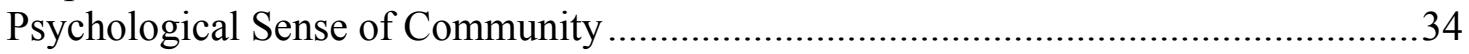

The Focal CBPR Project: Partnering with People with Developmental Disabilities to

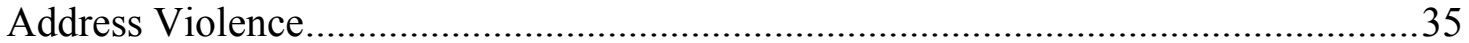

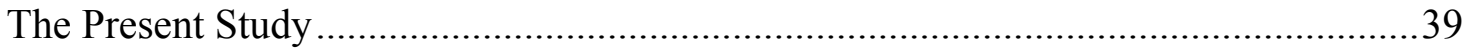

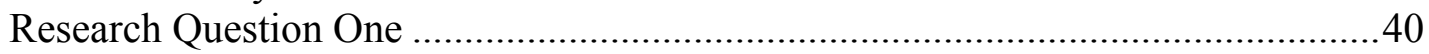

Research Question Two.................................................................................

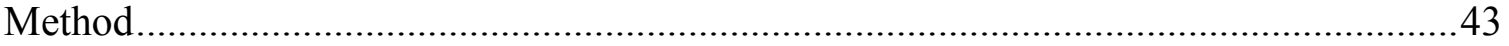

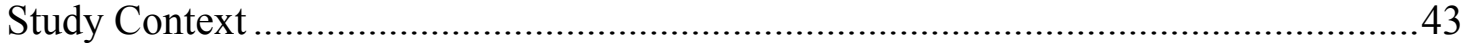

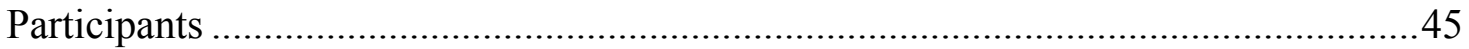

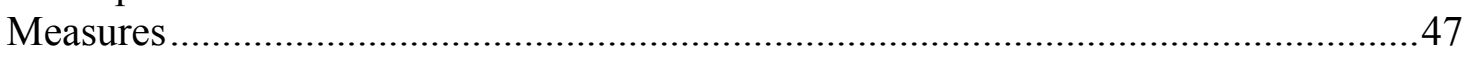

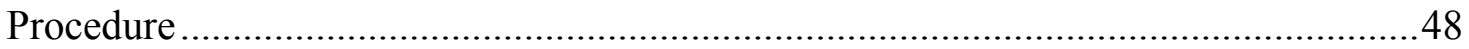

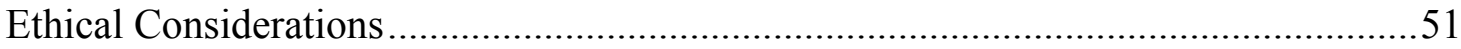

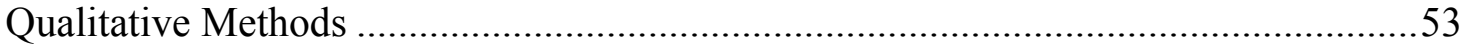

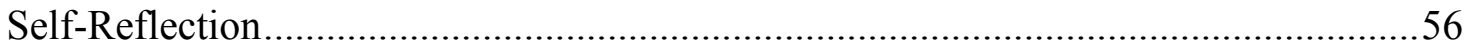

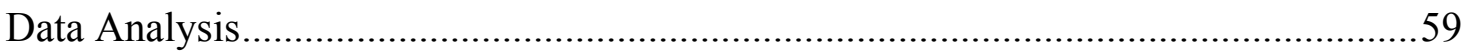

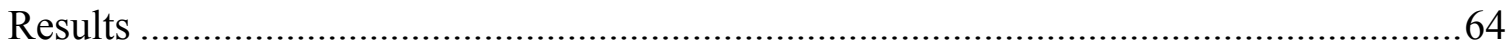

Community members' definitions of empowerment...............................................65

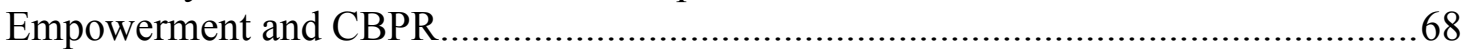

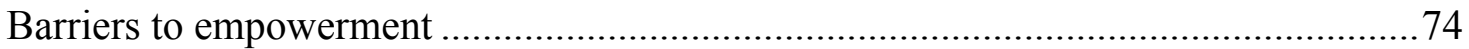

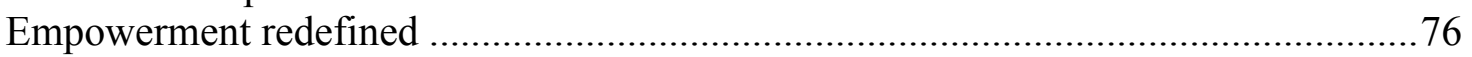

Secondary data: Academic partners and empowerment..............................................77

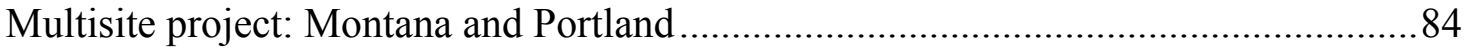

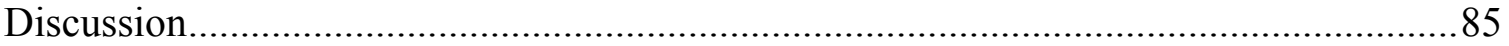

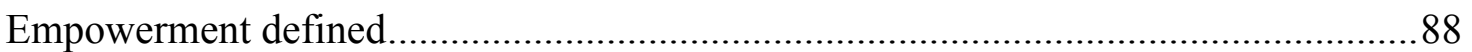

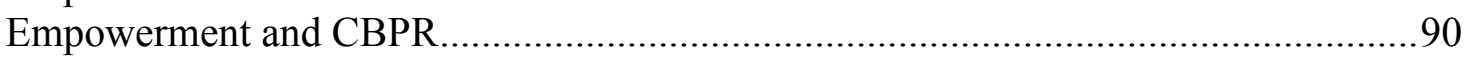

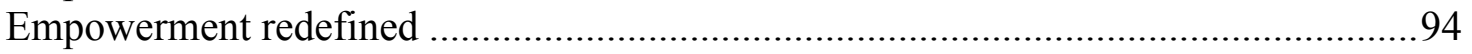

Multisite project: Montana and Portland ...................................................................94

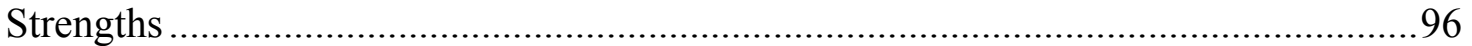

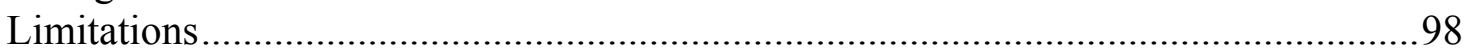

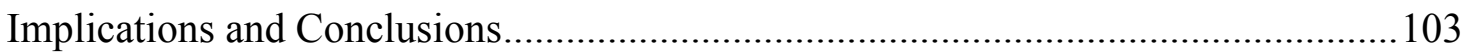




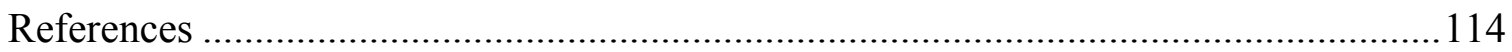

Appendix A: Israel et al. nine principles of Community-Based Participatory Research 131

Appendix B: Individual Interview Guide - Community Research Partners .............. 132

Appendix D: Individual Interview Consent Forms ................................................ 145

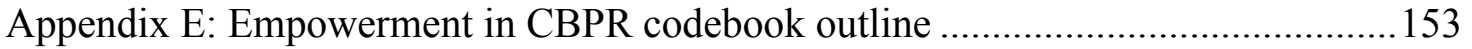

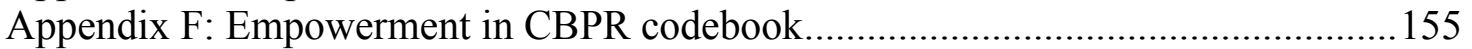

Appendix G: Empowerment in CBPR Member Check Summary .............................159

Appendix H: Empowerment in CBPR Member Check Summary (Redo) .................. 163 
List of Tables

Table 1: The Partnering Project Demographic Information....................... 107 


\section{List of Figures}

Figure 1: The Partnering CBPR process model (adapted from AASPIRE) ........... 108

Figure 2: CBPR Conceptual Logic Model........................................109

Figure 3: Community-Based Participatory Research with Persons with Developmental

Disabilities Concept Model ..................................................110

Figure 4: Partnering Project Infrastructure Model...............................111

Figure 5: Ecological model of Empowerment in CBPR: Expressions of and Influences on Empowerment within CBPR..............................................112

Figure 6: Setting Barriers and Facilitators in Individual Empowerment...............113 


\section{Introduction}

Persons with disabilities are often marginalized and decisions are made for them instead of with or by them. As a reaction against persons with developmental disabilities being left out of many important areas of their lives, the popular slogan "Nothing about us with us" has come to define one of the core values of the disability rights movement (Charlton, 1998). "Nothing about us with us" represents the belief that persons with disabilities should be included in decisions, laws, policies, research, and other things that affect their community. The inclusion of persons with developmental disabilities in research is necessary as they are the experts on their own lives. As such, the inclusion of persons with developmental disabilities allows for them to have an active, strong voice about the changes they hope to see in their communities (Walmsley, 2004a). Community-based participatory research (CBPR) and other participatory research approaches have been seen as tools to promote inclusion and allow persons with developmental disabilities the chance to voice their perspective and provide an opportunity to influence what they feel is important to be researched (Atkinson, 2004; Bigby \& Frawley, 2010; Ham et al., 2004; Nicolaidis et al., 2011; Oden, Hernandez, \& Hidalgo, 2010; Sample, 1996).

This study examines how one's involvement on a CBPR project can promote personal benefits for community partners as they engage with academic partners to address relevant social issues within their community. Empowerment of community partners involved on a CBPR projects has been noted by many scholars (Atkinson, 2004;

Balcazar, Keys, Kaplan, \& Suarez-Balcazar, 2006; Brydon-Miller, 1997; Chappell, 2001; 
Cocks \& Cockram, 1995; Israel et al., 2003; Minkler \& Wallerstein, 2008), but rarely has this phenomenon been evaluated or expressed by community partners with disabilities themselves (Atkinson, 2004; March, Steingold, Justice, \& Mitchell, 1997; Oden et al., 2010).). This project specifically examines the question of whether CBPR promote concepts of empowerment that are evident in community partners' experiences within the research project? And, what components of the collaboration do community partners note as helping or hindering their empowerment? As CBPR becomes more widely used, its theory, structure, and methods need to be studied and shared so the benefits and associated effective characteristics of CBPR can be better understood (Cook, 2008). Involving community members in research allows voices to be heard that have previously been silenced (Ham et al., 2004). Within the domain of the CBPR project of focus here, this study's aim is to examine ways in which community members with and without developmental disabilities have become empowered. Empowerment is a complex construct with many different interpretations. Therefore, part of this research includes exploring what empowerment means to community partners. Empowerment seen as ideas of autonomy, involvement, and power shared between academics and community partners inside the context of the CBPR project are expected to be experienced.

In this study, I discuss CBPR and CBPR with persons with disabilities in order to fully outline the similarities and differences that exist in a CBPR approach across populations. Next, the literature about the concept of empowerment is presented. I then highlight the similarities that exist between concepts of the group process of an effective CBPR project and psychological sense of community (PSOC), such as mutual 
relationships, communication, and trust. I approached this study with the belief that the shared decision-making, equal partnerships, and co-learning aspects of CBPR would create a sense of community, which in turn allows project members a space to become empowered. After providing background concepts I examined in this study, I share information about the CBPR project of focus and the details of the present study.

\section{Community-Based Participatory Research: Theory \& Principles}

Community-based participatory research (CBPR) is a research approach that promotes the inclusion of individuals whose communities are the focus of the study being involved in all steps of the research process. Despite the absence of much empirical study, some central principles of CBPR have emerged and are explained and celebrated by academics in the field (Israel et al., 2003; Israel et al., 2008; Minkler \& Wallerstein, 2008). As explained by Israel and colleagues (2003), these principles include: CBPR as participatory, a cooperation which engages community members equally, a co-learning experience, a development of systems and the building of community, an empowering process for community members to establish or re-establish control over choices in their

lives, and a focus on a balance between research and community action (See Appendix A for a complete list of these principles).

CBPR falls under the broader umbrella of action research. Action research was made popular by Kurt Lewin in the mid-1940s. At the time, Lewin (1946) was writing out of frustration on how data on intergroup relations had previously been collected. First, at the time, intergroup relations had mostly been studied by conducting surveys. Lewin felt this approach lacked insight into motivations and sentiments. Second, and 
more important to what action research has developed into today, Lewin was not satisfied with simply pointing out prevalence and diagnosis of phenomenon. He felt social change needed to be a goal and, ultimately, an expected outcome of any research (Lewin, 1946).

There exist many different names for action research. The different names exist because these approaches have developed through diverse theoretical and disciplinary traditions; however, the main characteristics and desired outcomes are highly similar. There essentially are applications of similar ideas present in different fields (Boog, 2003). Some of the names of the different participatory approaches similar to CBPR that exist are participatory action research (PAR; Whyte, 1991), emancipatory research (Oliver, 1992), inclusive research (Walmsley, 2001), and participatory research (Cocks \& Cockram, 1995). Scholars have struggled with the language to use when describing the approaches they have engaged in, but it has been noted that many share similarities and the lines between them are blurred (Ham et al., 2004; Stalker, 1998; Walmsley, 2001). These approaches can include quantitative, qualitative, or mixed methods and take into account social, political, and economic context (Macaulay et al., 2011). In this study, I used the terms CBPR and action research interchangeably to represent these different approaches. CBPR was decided upon to parallel the approach that members of the focal project use, and thus the theoretical and practical traditions from which they most directly pull.

In CBPR, community members are co-researchers and should be seen as equal partners throughout. All project members involved thus share the responsibility of being considered researchers (Israel et al., 2003; Christopher, Watts, McCormick, \& Young, 
2008). As such, traditional academic researchers and investigators are referred to as academics partners or academic researchers. Community members who are part of the research team are referred to as community partners or community researchers. Community partners' knowledge and expertise on important issues present in their lives and communities, on which research questions are built, is welcomed and appreciated. Since the basic needs and understandings of the community come from the community partners, the academic partners are seen more as facilitators of the project and take a less directive role than is typical of traditional research (Stringer, 1996). Academic partners are essentially assisting community members further develop or gain the education, research knowledge, and skills of creating positive social change stemming from research (Brydon-Miller, 1997). Many components of the work are out of the hands of the academics. The relinquishing of power by academics can be difficult, but it can also prove to be very rewarding (Chataway, 1997). Since everyone involved in the research process is considered an equal stakeholder, all individuals on the project have the right to be encouraged and respectfully involved in meeting project objectives (Stevens \& Folchman, 1998).

The importance of including community members in the very early stages of the project, including helping with the formulation of ethical guidelines to present to the institutional review board (IRB), is emphasized in CBPR (Bosner, 2006; Ham et al., 2004; Higgins \& Metzler, 2004). Open dialogue and communication are necessary in order to utilize CBPR theory in the way the approach calls for (Chataway, 1997; Minkler \& Wallerstein, 2008). Establishing a working model, individual roles, and project goals 
from the beginning of a project is necessary, but a balance with being flexible when working in a CBPR context is also essential. Through academics and community partners working closely together, differences will inevitably emerge. As a research team makes strides toward the best outcome for a community, being fluid in how the project should move along is important (Minkler \& Wallerstein, 2008; Stevens \& Folchman, 1998). Both academic and community partners understanding the motivation and goals of a research project can be a positive way to avoid roadblocks and promote timely progression of the research process (Balcazar et al., 2006; Israel et al., 2003).

Clarity about role responsibilities and definitions are extremely important in the progression of a CBPR project. The shared role of researcher between community and academic partners does not mean every detail needs to be done in unison together. Unnecessarily forcing every decision to be made with the whole group and a collaboration that hinders the project's progress to move forward at a reasonable pace deemphasizes the unique contributions different partners can bring to the team. The whole research project is equal and collaborative, and the singular role division from within is equal but different (Israel at al., 2003; Ward \& Trigler, 2001). Community partners' unique skills and knowledge are reasons academic partners should join partnerships. Lack of sharing power and misunderstanding of other project members' skills can lead to poorly constructed research (Walmsley, 2004b). When it comes to the topic of empowerment within the project, sharing information can set the stage for empowering actions, such as sharing opinions that contribute to decision-making and demonstrating individual autonomy (Fawcett, White, Balcazar, \& Suarez-Balcazar, 1994). See Figure 1 
for a visual representation of community and academic responsibilities in a CBPR process (Nicolaidis et al., 2011).

The relationship between community and academic partners in CBPR should demonstrate Friere's (1970) definition of dialogue, which is characterized as an epistemological relationship. Both academic and community partners are attempting to gain knowledge from one another in a way that will be beneficial to everyone, ultimately serving the needs of the community to achieve social change. The dialogue is in and of itself a means for better learning and knowing between groups. Theorizing about individual experiences inevitably exists through the sharing of ideas (Friere, 1970). Action research represents a bridge built on trust that allows for communication and knowledge to be shared between two populations (Christopher et al., 2008; DworskiRiggs \& Langhout, 2010; Minkler \& Wallerstein; 2008). In order to establish trust, Christopher and colleagues' (2008) experiences have lead them to the following five recommendations: acknowledge person and institutional histories, understand the historical context of the research, be present in the community and listen to community members, acknowledge the expertise of all partners, and be upfront about expectations and intentions. Trust built through open dialogue and communication being effective and positively directed is one of the cornerstones of action research (Nelson, Ochocka, Griffin, \& Lord, 1998). The reciprocity of the relationship between academic and community partners fosters an environment that is "simultaneously knowledge based in action and action based in knowledge" (Brydon-Miller, 1997, p. 660). 
Community partners provide academic partners with necessary information on how to accomplish practical use of research findings and the partnership is characterized by a continued effort in striving toward a desired outcome, typically some form of social change (Brydon-Miller, 1997; Stringer, 1996). In order for social change to become a reality, barriers that separate academic partners and community partners need to be broken down by sharing knowledge and respecting each project members' unique expertise (Minkler, 2004; Taylor, Braveman, \& Hammel, 2004). Adequate funding needed to pay community partners (Bigby \& Frawley, 2010), keeping community partners engaged (Bigby \& Frawley, 2010; Davidson, 2009; Jurkowski, Rivera, \& Hammel, 2009), geographical distance between academic and community partners (Christopher et al., 2008), and differences in cultural and demographic characteristics (Christopher et al., 2008; Dias et al., 2012) have been noted as some barriers experienced in CBPR.

A core part of CBPR is having mutual respect for various views and the sharing of expertise. Academic partners bring their dedication to using empirical knowledge to promote positive social change. Community partners bring their expertise of important issues within their own personal lives and the community in which they reside (Lantz, Viruell-Fuentes, Israel, Softley, \& Guzman, 2001) and their interest in positive social change for their communities (Israel et al., 2003; Minkler \& Wallerstein, 2008). This approach can be thought of as a reciprocal sharing of life experiences that can better enhance the research process and the research outcome (Sample, 1996). 
CBPR operates on several levels of interactions, including personal, societal, communal, political, and emotional. These levels create a deeper need for maintenance of its structure and evaluation of how it affects one's sense of community (Stringer, 1996). CBPR represents community psychology ideals where research should reflect the needs of the community, and the process of research projects should be able to facilitate the empowerment and allow voices of participants, academic partners, and community partners to be heard (Stagg, 2008). CBPR is a way for community psychologist to work alongside and share power with populations that are usually excluded to work toward positive social change (Goodley \& Lawthom, 2005). Monitoring power balances by making sure voices are heard and opinions are respected and valued is important to make sure the community is being represented accurately. This process of representing the community accurately can be understood at its easiest level as a cyclical model of action. It is a process of gathering significant and applicable information, thinking and expounding on that information, and finally acting and evaluating the results. The cycle is repeated until the desired outcome of both community partners and academic partners are satisfied with steps that are taken to reaching specific goals (Israel et al., 2003; Minkler \& Wallerstein, 2008; Stringer, 1996). Monitoring the balance between community and academic partners' input and control over a project adds an extra component of constant surveillance in CBPR work (Minkler \& Wallerstein, 2008; Stagg, 2008). This produces both positive and negative aspects of conducting CBPR.

Academics who have utilized CBPR as a research approach have noted several benefits to the research, the community, and the lives of community and academic 
partners. The combination of insider and outsider knowledge allows both academic and community members to experience gains (Chataway, 1997; MInkler \& Wallerstein, 2008). Community partners also bring a sense of urgency and commitment to change and closeness to the project and the community (Minkler \& Wallerstein, 2008). CBPR creates an opportunity to improve scientific data collection and implementation because it forces research to be focused on real life concerns of community members. CBPR is ecological situated which promotes accuracy of data collection. Because of the differences between populations that are the focus of various research projects, research to adjust to those differences to be efficient. For example, adaptation of measurements may be necessary to assure construct validity (Stringer, 1996).

In general, action research looks at specific situations with localized problem solving. This ecological specific generalizability creates a unique context for real problems that effect communities to be observed, solutions to be brainstormed, and realistic ideas of change to be effectively put into action (Bryon-Miller, 1997; Stringer, 1996). Being ecologically specific is about taking a preventative approach; instead of dealing with the results of a problem, an aim is to create systematic changes that promote justice and well-being (Kelly, 1971). Due to the community-specific perspective of CBPR projects, it has been argued that results are hard to generalize to other populations (Kiernan, 1999). The ecological nature of CBPR forces academic and community partners to acknowledge that data gained from research in CBPR are contextually based in time and place of the research and researchers' subjectivity (Jurkowski \& Ferguson, 2008). However, looking on a smaller scale of the benefits of research within specific 
communities, context-specific ideas allow the academic partners to realize hidden talents and unique contributions that community partners can make to improve communities. Noticing the interconnectedness of a community allows research to develop in a way that will benefit the total community rather than only certain individuals, groups, or organizations within communities (Kelly, 1971).

Action research has also been praised for its ability to more easily produce knowledge translation than traditional research (Israel et al., 1998; Minkler \& Wallerstein, 2008). Knowledge translation is a relatively new word coined by the Canadian Institute of Health Research (CIHR). Knowledge translation refers to the process of empirically collected knowledge getting to the right people in order to use it for the benefit of the community (Sudsawad, 2007). With community members being involved in all areas of a CBPR project, it is argued that the knowledge gained from studies goes through a easier transition into application and social action (Green, 2004; Higgins \& Metzler, 2001; Lantz et al., 2001). This smoother transition exists, in part, because of the research design mutually decided on by community and academic partners include context-specific models. The framework of CBPR allows for the community members to conceptualize how to effectively implement findings within their community that will be welcomed and beneficial (Stevens \& Folchman, 1998).

Another strength of CBPR, in communion with community psychology ideals, is the community-specific nature. Because academic and community partners are working toward a mutually agreed upon social issue, the increased likelihood of positive social change coming about is central (Brydon-Miller, 1997). Through detailed accounts of the 
collaboration process between community and academic partners, research projects can be replicated and the benefits of CBPR can be realized in a countless number of marginalized communities. As such, it is not only the community partners who are benefiting from action research. Academic partners are able to look at their work in a new way because of the unique ideas and important topics community members bring to research projects (Ward \& Trigler, 2001). In the literature, there is a focus on the benefits and outcomes of CBPR; however, it would be ignorant and of little help to future people who seek to utilize CBPR to not note some of the challenges that have developed in some CBPR collaborations.

\section{Challenges of Putting CBPR into Practice}

Although most of the literature discusses the benefits of CBPR and focuses on the successes of working relationships, some pressures within CBPR exist. One of the major pressures is being unable to follow as closely as the team might like to their definition of action research. Academic partners, specifically those who are novices to using a CBPR approach, tend to underestimate some of the difficulties (Chataway, 1997). For example, being in total collaboration with community members adds a time component that may not exist in most traditional research approaches (Davidson, 2009; Jurkowski \& PaulWard, 2007; Minkler \& Wallerstein, 2008; Paiewonsky, 2011). Time is important in research projects because of funding issues and a push to complete the research and share important results with the academic and local communities involved in the work (Lantz et al., 2001; Balcazar et al., 2006). Also, rarely is the research in the full control of community members and this brings about tension over whether it is worth the time and 
energy to get involved. Likewise, those who decide to become involved in the project can drastically change the dynamic and direction a project takes and commitment is neither permanent nor predictable (Cornwall \& Jewkes, 1995).

Additionally, challenges may develop at the onset of a project in respect to establishing trusting mutual relationships between community and academic partners. Balcazar and colleagues (2006) note some of the confounding factors that go into these organizing difficulties. These factors include: differences between academic and community partners, power understanding and equality, previously established negative feelings of community partners towards academics, lack of existing ties between the two groups, and an overly aggressive approach of recruitment by academics (Balcazar et al., 2006).

In a comprehensive overview of CBPR, Israel and colleagues (1998) note lack of trust and respect between community and academic partners as the most mentioned challenge in the literature. Furthermore, a history of unequal power balance between individuals involved in the collaboration maybe reflected within the work. Conflicts over funding, priorities, and process also add a unique and challenging component to doing CBPR research. Importantly, disagreements over who represents the community and how involved those individuals should be in a project have been a subject of much debate in the research. Some of the methodological challenges included questions of validity, reliability, and objectivity, proving intervention success, and keeping a balance between research and action. Structural barriers also exist. For example, competing desires 
between community organizations and academic structures and priorities, including the importance of achieving tenure (Israel et al., 1998).

It should be equally noted that, in most cases, researchers believed the challenges to using CBPR are outweighed by its benefits. Despite some of the added pressures, the results of the community being equal stakeholders in research create higher quality research and more scientifically sound data (Ward \& Trigler, 2001). As noted, both groups understanding the motivation and goals of a research project from the beginning can be a positive way to avoid roadblocks (Balcazar et al., 2006). Some other suggestions include developing group norms together, having a democratic leadership, identifying key community members as facilitators, and involving a support staff or team for the project (Israel et al., 1998).

\section{CBPR Outcomes}

CBPR as an equal partnership among community and academic partners can come to produce certain system and contextual outcomes as pointed out by Wallerstein and colleagues (2008). Some of the intended outcomes include changes in policies and practices, sustainable interventions, changes in unequal power relations, and empowerment. Empowerment is explained here as the people in the community having their voices heard and used in decision-making, the development of critical thinking, and community representation on advisory councils. See Figure 2 for Wallerstein and colleagues (2008) contextual-logic model of CBPR.

Social change has become a core characteristic and driving force in academics' decision to use CBPR (Brydon-Miller, 1997; Minkler, 2004). The information gained 
through the partnership, that will hopefully lead to change within community, is considered essential, relevant, and more sustainable (Oden et al., 2010). Along with striving for positive social change, the history of action research has developed so academic and community partners can work together to take steps to achieve empowerment (Boog, 2003). With academic partners serving mostly as facilitators but also as experts on science, CBPR enables community partners to re-claim power and control over their lives because the research being produced is relevant to the communities in which they live (Jason, Keys, Suarez-Balcazar, Taylor, \& Davis, 2004). Empowerment characteristics such as power sharing, autonomy over one's own life, and having one's voice heard can be seen in CBPR as sharing knowledge to achieve observation based outcomes and an added understanding of what sense of community encompasses and suggests (Minkler, 2004). The sense of community that is gained by being a part of a CBPR project can be noticed and appreciated by community members as they re-establish themselves as viable members of a community. Their voices are able to be heard and recognized. Therefore, they start to realize their voices are appreciated as a representation of a powerful group of individuals involved in collective communities (Jason et al., 2004).

Some academics even note that their research no longer seems like work to them. Instead their research becomes a way of life as they join with communities to bring about positive social change and empower community members (Chataway, 1997). Empowerment in CBPR can be seen where project members exhibit a respect of autonomy, meaning the chance for individuals to make their own decisions about choices 
that are going to directly influence their lives, is not just assumed but put into action. Community members are rightfully recognized as the experts of their own lives (Minkler, 2004). Specific to this project, Goodley and Lawthom (2005) argue that the qualities of action research alongside the interaction of community psychology and disability studies work because of the similar struggles both disciplines have experienced. There are not many studies that have used CBPR with persons with developmental disabilities. In the next section, I discuss similarities and differences of using CBPR with persons with disabilities. I highlight why some disability researchers emphasize the use of CBPR in all research that involves individuals with disabilities (Walmsley, 2001).

\section{CBPR and People with Developmental Disabilities}

Academic and community partners with and without developmental disabilities collaborating in a CBPR project adds unique qualities to the research (Ferguson, 2004). First, it is important to understand developmental disabilities. The Centers for Disease Control and Prevention (CDC) defines a developmental disability as impairment related to major life activities such as language, mobility, learning, self-help, and independent living that developed before the age of 22 and usually lasts a lifetime (Centers for Disease Control and Prevention, 2011).

Developmental disability encompasses an array of different disabilities. For example, autism spectrum disorders, intellectual disabilities, cerebral palsy, visual impairment, and hearing loss all fall under the umbrella of developmental disability. Autism spectrum disorders are characterized as impairments or differences in communication and social interactions. Cerebral palsy refers to a group of disorders that 
cause physical limitations, including affecting how a person moves and balances.

Intellectual disability is characterized by an individual having a significantly lower than average intelligent quotient score and limitations in activities of daily living (Center for Disease and Control Prevention, 2011). Different definitions of disability creates confusion and further alienates persons with disabilities. The implications that exist because of the diversity of the disability community reflect how disability is defined and seen by individuals in and outside the disability community. Disability affects individuals differently even when people share the same disability. In some cases, a disability can be seen and in others disabilities are hidden. While individuals with hidden disabilities may be able to pass as non-disabled in an attempt to maintain control over their identities and judgments of others, the negative effects of received skepticism by others in an attempt to receive appropriate accommodations may be limiting (Olney \& Kim, 2001).

Persons with developmental disabilities are often considered to be an underrepresented and marginalized population (Redmond, 2005). Importantly, CBPR is growing in popularity among academics studying marginalized populations (Bastida, Tseng, McKeever, \& Jack, 2010). Ecological motivations and interpretations are intrinsic in CBPR models. Different populations add unique components to how CBPR should be understood and utilized (Jurkowski \& Ferguson 2008; Stagg, 2008). Collaborating with persons with disabilities in research may look different than working with other marginalized populations.

In the past, power in disability research has been imbalanced and persons with developmental disabilities have been exploited. There has been a shift from using the 
medical model of disability to ecological and social models of disability in order to examine different aspects of disability (Ferguson, 2004; Walmsley, 2001). The medical model of disability focuses on clinical diagnosis and finding a cure for disability in an attempt to normalize individuals. This model emphasizes disability as an individual issue and limitation that one can and hopes to avoid (Brisenden, 1986). On the other hand, the social ecological models of disability rejects the ideas of the medical model and sees disability as a function of the barriers put on individuals by society. The barriers that exist for persons with disability are a result of systematic isolation and exclusion. Disability is seen as an intersection between individual qualities and environmental factors that cannot be ignored (Tate \& Pledger, 2003). Participatory approaches with people with disabilities developed out of social models of disabilities. Ultimately, when conducting research on people with disabilities rather than with them, social stereotypes will prevail instead of progression forward (Goodley, 1999). Social models of disability align with community psychology ideals. Community psychology does not see individuals as being the only and necessary component to change in order to get over limitations, but sees the need for community development that does not limit people (Goodley \& Lawthom, 2005).

Historically, the relationship between disability and research is considered a controversial one because of past maltreatment of persons with developmental disabilities in research (Freeman, 2001; McDonald \& Keys, 2008; McDonald, Keys, \& Henry, 2008). Therefore, some academics propose that collaborative approaches should always be used (Redmond, 2005). The inclusion of persons with disabilities in research allows for them to be active in necessary changes they hope to see in their communities instead 
of passive subjects as decisions are made for them (Walmsley, 2004a). In using action research, persons with disabilities are given the chance to voice their perspectives on their own lives and an opportunity to share what they feel is important to study (Oden et al., 2010).

A benefit and reason some scholars identify for using action research to collaborate with persons with developmental disabilities within the disability community is the importance of inclusion (Björnsdóttir \& Svensdóttir, 2008; Bonham et al., 2004; Davidson; 2009; Knox, Mok, \& Parmenter, 2000; Paiewonsky, 2011; Richardson, 2000). It has been suggested that psychological harm is less likely to develop when there is a balance of power between the traditionally powerful and powerless than when the powerful make decisions for the powerless (Clements, Rapley, \& Cummins, 1999). The basis of conducting this research with persons with developmental disabilities follows the core principles of CBPR; however, intrinsic to the CBPR definition is its capability to adapt within different projects. The main reason identified in using CBPR in disability research is to improve the quality of life of persons with disabilities (Balcazar et al., 2006; Björnsdóttir \& Svensdóttir, 2008; Bonham et al., 2004; Dias et al., 2012; Sample, 1996). Quality of life is an important aspect in the lives of person with developmental disabilities because it promotes positive values and respect for diverse life experiences (Schalock, Gardener, \& Bradley, 2007).

Action research used to collaborate with persons with developmental disabilities also puts individuals at the forefront of possible positive social change (Dowse, 2009; Garcia-Iriate, Kramer, Kramer, \& Hammel, 2009; Jurkowski \& Paul-Ward, 2007; 
Sample, 1996). Academic partners are resources that persons with developmental disabilities can use in order to carry forward their voices (Walmsley, 2004a; Redmond, 2005). Action research creates a context that allows for individuals with developmental disabilities, situations, and the environment to collide harmoniously and develop a status of empowerment seen through power sharing, autonomy, and voices being heard and respected (Zimmerman, 1990). In certain cases, academics that have utilized action research in their work are unable to untangle the term empowerment from the definition of action research. For example, Jason and colleagues (2004) define participatory research as a broad term enveloping many different approaches that empower community partners and increase citizen power and voice in communities.

Persons with developmental disabilities being equal partners in research allow their opinions and ideas to contribute to the discovery of a solution to many social issues in their community. In the past fifteen years, in some instances, persons with developmental disabilities have been able to take more active roles in research, which allows their abilities to be seen (Bonham et al., 2004; Davidson, 2009; Ham et al., 2004). Garcia-Iriarte \& colleagues (2009) describe how the cyclical process of CBPR between action and reflection facilitates persons with developmental disabilities' ability to participate because it allows knowledge building and understanding to develop.

CBPR also creates an opportunity for community members to develop and exercise individual autonomy and empower individuals with disabilities within the process (Atkinson, 2004; Björnsdóttir \& Svensdóttir. 2008; Conder, Milner, \& MirfinVeitch, 2011; Paiewonsky, 2011; Williams, 2005; Williams \& Simons, 2005). Persons 
with developmental disabilities often have this right taken away from them, possibly even from individuals who claim to have their best interest in mind. Past atrocities in research have led to ideas that all persons with developmental disabilities need to be protected. This mindset can lead to restricting behavior of persons with developmental disabilities that is unnecessary and harmful (Freeman, 2001; McDonald \& Keys, 2008; McDonald et al., 2008). Overprotectiveness does not allow for an individual to experience normal risk taking behavior that is needed for basic human growth and development (Perske, 1972). Even with an individual's best interests in mind, protectiveness strips individuals of a voice to share their expert opinions on their own lives with others. Persons with developmental disabilities involved in past action research projects have demonstrated an increase capacity to participate in decisions that influence their lives (Jurkowski \& Ferguson, 2008; Garcia- Iriarte et al., 2009). This opportunity to share their knowledge can lead to others understanding how valuable persons with developmental disabilities opinions are and demonstrate they are the best educators about their own life experiences (Ham et al., 2004). Additionally, Jurkowski and Ferguson (2008) emphasize the skills and confidence they believe persons with developmental disabilities gained through being researchers.

Certain accommodations are seen as a unique highlight of collaborating with persons with developmental disability in CBPR. Accommodations, such as expressing ideas plainly so that they may be understood more clearly by persons with developmental disabilities, allows persons with developmental disabilities to more readily be included as partners on projects (Richardson, 2002; Rodgers, 1999; Sample, 1996). Additionally, 
conducting pre-meetings so all project members understand materials, conducting initial and ongoing trainings (Bonham et al., 2004), using visuals (Richardson, 2002), creating a space that project members feel safe and comfortable to voice their opinions (Conder et al., 2011; Dowse, 2009; Garcia-Iriate et al., 2009; Jurkowski, 2008; Richardson, 2002), and spending informal time together to build trusting relationships (Dowse, 2009) have all been noted as effective ways to support persons with developmental disabilities that are part of research teams (Caldwell, Hauss, \& Stark, 2009).

In addition to and echoing some of the already noted challenges of conducting research using a CBPR approach, there are some unique pressures that exist in doing CBPR with persons with developmental disabilities. For example, Caldwell and colleagues (2009) in their study on persons and family members with disabilities noted academic partners expressing difficulty in recruiting and keeping advisory board members. The self-advocates active on many of the mentioned boards were active in other disability related committees, which may have added to attrition rates because of their busy schedules. In this light, the authors also focus on the need to expand recruitment of advisory board members outside of the most active self-advocates. A more diverse group of board members creates an important perspective and keeps the disability self-advocacy movement progressing (Caldwell et al., 2009). Also, Nicolaidis and colleagues (2011) note these communication accommodations may add an even greater time dimension than is seen in CBPR with different populations. Since diverse communication preference exist, not all forms of communication are best for all partners. Challenges come up, and in this particular collaboration, constantly monitoring how the 
group can improve and continue to be inclusive of all partners is highlighted (Nicolaidis et al., 2011). Other challenges mentioned by disability scholars include difficulty in leaving the project because of the relationships that developed (Atkinson, 2004), difficulty securing funds for community partners (Bigby \& Frawley, 2010), making all aspects of the project accessible to community partners (Bigby \& Frawley, 2010; Dias et al., 2012; Garcia-Iriate et al., 2009; Jurkowski, 2008; Richardson, 2002; Sample, 1996; Stalker, 1998), inherent power imbalances (Conder et al., 2011), and assumptions about the capacity for persons with developmental disabilities to be actively involved (Rogers, 1999).

CBPR with persons with developmental disabilities encompasses the social and ecological models of disability, which suggests that it is not a person's impairment that places limits on her or his life. Instead, it is social and political stigma and structures that excludes persons with disabilities. This model concentrates on ideas of inclusion as a way to eliminate these barriers (Richardson, 2000; Kiernan, 1999). In order to demonstrate the outcomes, uniqueness, and complexity of conducting CBPR with person with developmental disabilities, I developed a theoretical model of the process and its consequences of conducting CBPR with persons with developmental disabilities with the assistance of individuals on my research team. This model is based on literature about CBPR, disability, inclusion, and my understanding of the combination of the three. It was a process of collecting key themes of CBPR work with various populations and incorporating those themes within a social and ecological disability framework. The model of using CBPR with persons with developmental disabilities I created can be seen 
in Figure 3. The concepts that overlap with concepts shown in Wallenstein and colleagues (2008) conceptual logic model of CBPR described earlier are bolded. This model demonstrates how individual and group motivations for social change combined with an understanding of social and ecological models of disability create a context for a relationship to begin where common goals can be achieved. Through collaboration, inclusion, and accommodations, a community built on mutual relationships, respect, communication, and trust begins to form. Academic and community partners are equal partners with unique contributions that are brought together in shared decision making, learning, and understanding. There is an important balance of community needs, which usually center on community growth and social change, and academic needs, which include appealing to grant funders. Since persons with developmental disabilities, who have previously been less included in research, have an opportunity in CBPR to be coowners of the research, they are able to gain control over research. The combination of community and academic knowledge coming together improves data collection because research becomes more accessible for persons with developmental disabilities. Additionally, ecological relevant understanding and solutions to social issues become apparent (Nicolaidis et al., 2011). The process leads to research outcomes being more readily used practically in the community through a smoother transition. This phenomenon known as knowledge translation is defined by the National Institute on Disability and Rehabilitation Research (NIDRR) as "the multidimensional, active process of ensuring that new knowledge gained through the course of research ultimately improves the lives of people with disabilities, and furthers their participation in society" 
(NIDRR, 2005). Practical use in the community allows for positive social change that will improve the quality of life for persons with developmental disabilities. Communication about project goals and project members' unique roles from the beginning of the project is necessary to establish a working relationship that will be beneficial for both groups throughout the process (Walmsley, 2004a).

The Community-Based Participatory Research with Persons with Developmental Disabilities model I developed emphasizes that community and academic partners with and without disabilities bring unique and important aspects to research projects and the research processes. The concepts included in the model have contributed to the development of data collection questions. Specifically, I focus on empowerment in CBPR with persons with disabilities because it is highlighted in both CBPR and disability research. The model has allowed me to organize many concepts surrounding CBPR, empowerment, and disability. Through the development of this model, I began to think about how building community may be a key aspect that leads to individual's feelings of empowerment in CBPR. The building of community mentioned in the model, which includes trust, respect, mutual relationships, and communication, relates to the four components of sense of community described by McMillian \& Chavis (1986), membership, integration and fulfillment of needs, influence, and shared emotional connection. Therefore, I explore how sense of community may be related to community partners' perceived empowerment in CBPR. Again, this is represented in the interview questions I ask community partners. For example, what helps you contribute to the Partnering Project? How did these things come to be? This represents my belief that the 
accessibility and building community may allow for community partners to feel empowered within the project. Although, my data collection and analyses, in ways, have been driven by this connection, the theoretical model is primarily relied upon to organize and explain where my project fits within CBPR with persons with disabilities ideas.

In addition to the focus of my study, the model lays out how both groups of partners may gain significant qualities that can be used in other life activities they may be involved in. The model also highlights how community partners bring their lived expertise and flexibility with the research development, which allows individuals to be open and willing to grow and learn through the process. Academic partners bring their knowledge of the research process and role of facilitating research. Similar to community partners, academic partners must be flexible in their relationship with the research project to encourage contributions and gain needed input from community partners. For community partners, the collaboration with academic partners allows them to gain research expertise, autonomy, and empowerment. For academic partners, the collaboration allows them to gain community knowledge, higher quality research, greater openness to community participation, and respect from the community.

Oden and colleagues (2010) share one of the few evaluations available of an action research process with persons with disabilities. Their collaboration with minorities with disabilities is studied one year after the project ended. By using qualitative inquiry, these academics were able to identify the positive effects action research had on some of the community partners. For example, some community partners gained a deeper understanding about disabilities and disability rights, which led them to pursue their 
rights to accessible establishments. This accessibility, which was the aim of their initial collaborative research project, led to a greater feeling of independence. The community participants described themselves developing an increased understanding of power structures and a desire to work toward equal rights. In turn, this guided those of them to want to continue to advocate for the community. They described their work within the project as empowering, and they were using their gained sense of empowerment to keep working for disabilities rights outside of the project. Two participants expressed ideas of empowerment to a lesser degree than the others (Oden et al., 2010).

As mentioned, empowerment is a key theme in many CBPR projects, which collaborate with various populations (Atkinson, 2004; Conder et al., 2011; Israel et al., 2003; Minkler \& Wallerstein, 2008; Paiewonsky, 2011). Empowerment is an important aspect in the lives of persons with disability as they strive to be included and live more independent lives (Dywad \& Bersani, 1996; Miller \& Keys, 1996). The disability selfadvocacy movement has been growing rapidly over the past several decades. People First, which is a self-advocacy group started and operated by persons with disabilities, lists empowerment as the group's number one principle with equal opportunity, learning and living together, and non-labeling just after (Dybwad \& Bersani, 1996). Interestingly, I have the opportunity to look at how empowerment manifests itself in the lives of persons with disabilities and CBPR. I hope that understanding empowerment in CBPR will provide a space for persons with developmental disabilities to continue to contribute to and grow the disability movement's core concept. 


\section{Empowerment}

Autonomy and independence over choices one makes in his or her life are rights often assumed and taken for granted. For persons with disability, these rights are often taken away because of ideas of protection and concern for the risk (Redmond, 2005; McDonald \& Kidney, 2012). Persons with disabilities have been working to gain power through the development of self-advocacy networks in the United States for the past 35 years. Empowerment is seen as a goal where individuals have the opportunities and rights of all other people to live a self-determined and normal life through personal and social progress (Goodley, 2000). Self-advocacy networks are designed to create opportunities for persons with developmental disabilities to improve their life situations (Dybwad \& Bersani, 1996). Academic researcher can potentially exploit vulnerable populations by conducting research that is not representative of the target population's needs or values. This exploitation can add to those populations' disempowerment and oppression in society. Current discussions about the relationship between research and disability focus on the necessity of inclusion and empowerment of persons with developmental disabilities (Ferguson, 2004). Redmond (2005) notes that his work with persons with intellectual disability on a CBPR project allowed him to see the day-to-day struggle persons with developmental disabilities experience to gain independence and empowerment.

There exists no single definition for empowerment, but much of the literature on the subject shares common themes (Miller \& Keys, 1996). Scholars have been grappling with defining the construct and translating it within diverse cultures since it first appeared 
in the literature (Erzinger, 1994). Because of this distinction, I attempted to operationalize empowerment as I saw it unfold in the literature, but I also ask participants in this study to more fully understand how they defined empowerment. I am interested in how empowerment is experienced and develops in the lives of community partners with and without disabilities as a result of their work on a CBPR project.

Within a community setting, empowerment is defined as a group-based, participatory, developmental process through which marginalized or oppressed groups gain greater control over their lives and environments, acquire valued resources and basic rights, and achieve important life goals and reduce societal marginalization (Maton, 2008). Psychological empowerment includes a focus on the fit between contextual and individual components within an individual's life. Individually oriented components of empowerment do not take into account the setting-level affects on empowerment (Zimmerman, 1990). Empowerment theories connect individual well-being with larger scale social and political communities. The process of feeling empowered is as important as the outcome and usage of empowerment in other life activities. Individuals need to realize the opportunities present to understand the necessity, importance, and availability of feeling and becoming empowered (Zimmerman, 2000). Additionally, the principles behind the idea of empowerment include individual's participation in the decisionmaking processes that are connected to his or her life. Empowerment is not just about having a sense of control or power. It is about understanding how and why a specific decision is reached in addition to being a part of the deciding (Trickett, 1991). It is related to Freire's (1970) definition of conscientization or critical awareness leading groups to 
action. And, specific to people with developmental disabilities, Atkinson (2004) suggests empowerment develops through understanding and knowledge leading to action.

Many groups in society lack power across multiple contexts. Persons with disabilities experience social and physical barriers that make it difficult to pursue beneficial and necessary personal goals. The social and ecological models of disability consider empowerment as a core quality needed to improve quality of life for persons with disabilities (Goodley, 2000). Empowerment is an ecologically specific construct. Steps to gaining and understanding empowerment by one population may not be the same in other populations. Understanding the ecological differences in a population gaining empowerment reflects the need for the realization and connection of one's belonging in a community (Zimmerman, 2000). Through the contextual-behavioral model of empowerment, which lays out the importance of the relationships between the person or group, the environment, and the level of empowerment, the complexity of empowerment and the significance of understanding it as being context-specific are highlighted. Within this model is the idea that a person or group's past connection with power will influence the rate and effect of empowerment being incorporated in his, her, or their lives. Additionally, the environmental dimension of the model point out how the environment facilitates empowerment. An individual or group may demonstrate different levels of empowerment at different times in their lives and in different domains of interaction with their environment and society (Fawcett et al., 1994). In this light, an important approach to spreading empowerment is to help individuals learn skills that will assist in producing positive social change that is important to them (Zimmerman, 2000). 
The definitions of empowerment described above include control and independent influence over one's immediate personal choices; however, it has been argued that in a large number of situations, actual control is conflated by the sense of control (Riger, 1993). Riger (1993) claims that empowerment sometimes is mistakenly related simple participation, supporting that certain situations will automatically lend themselves to changes in communities or in resource distribution. Garcia-Iriarte and colleagues (2009) agree than mere participation does not equal control. They defined control as "members intentionally influenced the outcomes of the group or changed the structure of the group" (Garcia-Iriate et al., 2009, p. 17). Therefore, participation is seen as an aspect of control, but being an influential participating member is a key feature. Participation and inclusion are just means to provide persons with disabilities an avenue to experience equality and shared decision making. It allows for individuals to take control over their own lives (Goodley, 2000).

It has been stated that empowerment where an individual or group of individuals tries to empower others hinders the process of empowerment for those they are actually trying to empower. Furthermore, even with good intentions, in an attempt at the creation of an egalitarian structure, the structure will not always be equally distributed because, in most situations, the relationships that exist outside the structure will be unequal (Gruber \& Trickett, 1987). As a solution to this dynamic, it has been proposed that establishing interdependencies and individuals crossing boundaries between groups is important to any collaborative effort (Riger, 1993). For empowerment to be achieved many things 
need to be interacting. For example, there needs to be opportunities for shared leadership, development of individual and group skills, growth, and direct and welcomed community influence (Zimmerman, 1990). It is important to balance power and roles between community and academic partners where moving forward in the project is difficult without the consensus of all groups. This creates an interconnected group of individuals all positively moving to the set goal (Hughes \& Katz, 2011). The inclusion of persons with disabilities within these interconnected groups shows respect for the disability selfadvocacy movement, which emphasizes that persons with disabilities should have the opportunities that all others have to empower themselves (Dybwad \& Bersani, 1996).

Since CBPR has a goal of creating positive social change, empowerment of community partners is an important step. Empowerment is a specific construct needed to achieve and implement social change (Zimmerman, 2000). Dworski-Riggs and Langhout (2010) argues that the use of participatory research allows communities to notice the barriers being placed on them and give them an opportunity to gain control. Redmond (2005) claims many of the community partners with developmental disabilities he engaged in research with state they had used their involvement on the project to demonstrate their independence in order to address the lack of empowerment they experience in their daily activities. It allows community partners voices to be heard instead of the academics' translation of their voices (Redmond, 2005). Important to note, empowerment should not only be attributed to one's work on a research project. Community partners likely come into this work already empowered (Björnsdóttir \& Svensdóttir, 2008; Goodley, 1999). 
The focal CBPR project of this study is a demonstration of interconnected groups of academic and community partners with and without disabilities working toward a common goal. The inclusion of persons with developmental disabilities on this research project adds a unique voice to the progression of the project. Self-advocates on the project are representing the voices of their communities. Ideas of empowerment are spoken about in disability research often, but this study looked to empirically examine examples of where individuals becoming empowered are experienced. Their voices may be heard and recognized, but evidence of empowering events need to be noted also. This can produce a more observable sense of community within a group. The sense of community that is gained by being a part of a CBPR project can be noticed and appreciated by community members as they re-establish themselves as viable members of a community. Therefore, they start to realize their voices are appreciated as a representation of a powerful group of individuals involved in collective communities (Jason et al., 2004). As previously discussed, building community through trust, respect, communication, and mutual relationships are aspects that are part of the process of CBPR (Israel et al., 2003). These ideas closely represent the concept of psychological sense of community. Trust and respect within a group allow for community members of a CBPR project to grow together through shared decision making, equal partnerships, and colearning toward becoming empowered (Minkler \& Wallerstein, 2008).

In summary, empowerment is an ecologically situated concept and is related to different needs of communities (Zimmerman, 2000). Empowerment has historically been an important component of self-advocacy groups in the disability rights movement 
(Dywbad \& Bersani, 1996). Additionally, empowerment represents groups gaining greater control over the their lives and environments (Maton, 2008).

\section{Psychological Sense of Community}

McMillan (1976) defined psychological sense of community (PSOC) as "a feeling that members have of belonging and being important to each other, and a shared faith that members' needs will be met by their commitment to be together" (p. 11). This definition encompasses Sarason's (1974) sentiments when describing the difficulty psychologists had in studying PSOC because of its highly emotional attributes. Sarason ultimately concludes that "you know when you have it and when you don't" (p. 157).

PSOC can be experienced in two different, non-mutually exclusive ways. PSOC can be demonstrated geographically like neighborhoods, or PSOC can be seen as a common quality among individuals that brings them together regardless of location (Farrell, Aubry, \& Coulombe, 2004). McMillan \& Chavis (1986) describe PSOC as being comprised of four components: membership, influence, integration and fulfillment of needs, and shared emotional connection. Membership is a feeling of community belonging and sharing of some human quality. Influence is an examination of one's self worth within a community. Resources received by being a member of a group represent integration and fulfillment of needs. Shared emotional connection is the belief that members have certain shared characteristics (McMillan \& Chavis, 1986).

PSOC relates to the proposed project because empowerment may be a product of building a positive PSOC community through a cycle of respect, mutual relationships, communication, and trust that results from share decision making, equal partnerships, and 
co-learning illustrated in my Community-Based Participatory Research with Persons with Developmental Disabilities concept model (refer to Figure 3).

\section{The Focal CBPR Project: Partnering with People with Developmental Disabilities to}

\section{Address Violence}

Persons with developmental disabilities are among the most vulnerable individuals to experience interpersonal violence (IPV). Persons with developmental disabilities may be exposed to general forms of IPV such as verbal, emotional, physical, and sexual abuse, as well as disability-specific forms of IPV such as withholding and destroying adaptive equipment and manipulation of medication. Studies have also shown that persons with disabilities are more likely than persons without disabilities to experience physical and sexual forms of violence (Powers et al., 2008). Similar to persons without disability, in most cases of abuse, persons with disabilities have a previous relationship with the offender. Offenders include biological family members, dates, strangers, and step-family members. As an additional risk, many persons with disabilities utilize personal assistance services (PAS) (Saxton et al., 2001). IPV can have negative lasting effects on the victims. Abuse against persons with developmental disabilities limits their opportunities to live and work independently (Powers et al., 2008). Additionally, individuals who report being victims of IPV experience higher rates of depression, suicide, and substance abuse disorder (Nicolaidis et al., 2008).

The Partnering with Persons with Developmental Disabilities Project's (hereafter referred to as the Partnering Project) aim is to determine the relationship between IPV, health, and disability among adult with developmental disabilities. Specifically the 
members of the Partnering Project are interested in identifying the outcomes of IPV on the health and well-being of persons with developmental disabilities, assessing the extent to which disability places individuals at risk for IPV, and assessing the association between disability and the development of secondary conditions due to IPV.

The Partnering Project is separated into three phases. The first phase included community and academic collaboration in adapting measures, consent forms, and recruitment procedures. The second phase involved cognitive interviews in which the adapted survey was administered to persons with developmental disabilities to examine its understanding. These first two phases are complete. The current and last phase is the administering of the survey, which will include 400 participants (200 participants in Oregon and 200 participants in Montana). The survey is taken by participants by using a computer-assisted self-interviewed (CASI). If needed or preferred, participants have the option to listen to the question audibly.

The Partnering Project is a CBPR project. It is a unique example of a CBPR project because it spans across two states. The multisite nature of the project may influence some of the findings present, specifically communication based issues. CBPR is used in this project with the hopes that its rigorous methodological process will demonstrate how persons with developmental disabilities can be involved in all phases of the research process and assist in the development of valid measures, consent forms, and recruitment procedures that can be adapted to be effectively used with adults with developmental disabilities. The inclusion of persons with developmental disabilities is also important because they have been left out of other research important to the 
disability community in the past. The Partnering Project collaboration involves the six groups of the project having separate and unique tasks. The six groups are the coordinating team, two steering committees (SC), two community advisory boards (CAB), and consultants. There is an Oregon SC and a Montana SC. The SCs includes both academic and community partners. Their responsibilities include day-to-day work on the project and implementing measurement changes, and they focus on the completion of important project tasks. The SC then relays their work to the coordinating team, which consists of investigators, research assistants, and some community partners. The most important task of the coordinating team is to communicate decided upon information of the SCs and CAB committees across sites and make final approval decisions. SC members facilitate the CAB meetings. In both Montana and Oregon, there is a CAB that consists of community members who are disability self-advocates, family members of persons with developmental disabilities, allies of persons with developmental disabilities, and/or service providers to persons with disabilities. The CABs meet regularly to discuss changes that need to be made to measurements and other research materials, such as consent forms and a research summary, in order to make them more accessible to persons with disabilities, as well as keep them included and up-to-date on all decisions made within the project. Finally, consultants communicate with the coordinating team to evaluate the progress of the project. These six groups, their roles, and their processes have evolved throughout the process. After deciding on a model that works best for all involved, a community member created a model to visual depict the roles of each group in order to create consistency and responsibility (See Figure 4). The coordinating team, 
$\mathrm{SC}$ members, and $\mathrm{CAB}$ members will be referred to collectively as project members throughout this paper.

The Partnering Project has investigators, academic partners, and community partners in Montana and Oregon. Additionally, one of the consultants on the project is in Texas. The Partnering Project is funded by the Association of University Centers on Disabilities (AUCD) and the Center for Disease Control and Prevention (CDC). Rosemary Hughes, $\mathrm{PhD}$, is the principal investigator of the project. She is affiliated with the University of Montana Rural Institute: Center for Excellence in Disability Education, Research, and Service. There are three co-investigators. Christina Nicolaidis, MD, MPH, serves as the Oregon Health and Science (OHSU) site investigator. Laurie Powers, $\mathrm{PhD}$, is the Portland State University (PSU) site investigator. Mary Oschwald, PhD, is the project director in Portland and the CASI study manager and works for PSU. Additionally, Marsha Katz, MSEd, is the project director in Montana and contributes from the University of Montana site (Hughes, McDonald, Goe, Stack, \&, Lund, 2010).

The CBPR process allows persons with developmental disabilities with an opportunity to demonstrate their capabilities, and it goes with an important saying in the disability community, "Nothing about us without us" (Charlton, 1998). Academic partners involved in the Partnering Project sought to eliminate assumptions that would be made without persons with disabilities present in all areas of the project development, most notably the adaptation of the project's surveys. The benefits of using CBPR have been written about in some detail but rarely empirically studied. Notably, the academic partners on this project challenged themselves to make sure they were conducting their 
research in the most beneficial way for the disability community and to document the challenges they faced to aid others interested in conducting similar projects by pursuing an ongoing external project evaluation. This evaluation is being conducted by Katherine McDonald, Ph.D.

\section{The Present Study}

This study examined the use of CBPR research approach that can be used as a way to capture community members' voices in decisions that affect their lives and research. The aim of the overall evaluation is to empirically study the theories underlying CBPR as they relate to adults with developmental disabilities. Academics conducting research talk about the benefits and challenges of using CBPR in their work, but few studies could be located that examine self-report ideas and feelings of community members throughout their work on the project.

Among the overall goals of the evaluation are to examine individual's feeling about CBPR, the things that are working well on the project, where things could be working better, and ideas from project members about how to make things on the project run smoother. Additionally, since CBPR is a new process for many project members, including some academic partners, what project members have been learning as a result of being on the project is assessed. Also, questions about what, if anything, project members have been learning has changed how they work on the project is asked. Finally, individual contributions to and challenges within the overall project are assessed. Project members are always given an opportunity at the end of their group or individuals 
interviews to add anything about the project they think is important or would like to add about their work.

Project members work under the belief that persons with disabilities are marginalized and many decisions, including important life choices, are made for them not by or with them. These values likely will drive their responses to several questions studied herein. Most importantly, they will affect ideas surrounding CBPR, inclusion, and empowerment. The belief that persons with disability still need to be protected still exists. The lack of participants with this belief will most likely paint a picture of CBPR that is more positive than may be the case. However, I will pay close attention to evidence of disablism and ableism within the Portland and Montana CABs. Disablism is the unequal treatment of individuals based on their actual or perceived disability and ableism is the practice of expressing sympathy towards a group while still keeping them in an inferior societal and economical position (Campbell, 2008). Disablism and ableism are important aspects that may not reflect project members' noted beliefs but could possibly be evident in their reflections. The subset of questions that are the focus of this study relate to empowerment and how CBPR can be a mechanism through which community partners with and without developmental disabilities gain empowerment. Participants had the opportunity to describe and explore empowerment within the project as a result of their work on the project. Specifically, this project examined two research questions.

\section{Research Question One}

The first research question addresses in what ways, if any, working on a CBPR project has affected the way community partners define empowerment. Specifically, what 
does empowerment mean to community partners and have those definitions evolved overtime? For any community member whose perception of empowerment has changed, what has the change been? Because of the differing views of what empowerment is and the complexity of empowerment as a phenomenon (Miller \& Keys, 1996), I anticipated the community partners to have different definitions of empowerment. This complexity has shaped how I asked about empowerment because I was more open and anticipate diverse and numerous responses. Additionally, it is a main reason why understanding what empowerment means to community members with and without disabilities was an important component of my work. I asked this question at only one time point, so participants were asked to retrospectively reflect on what empowerment meant to them before the project and at the time of their interview. I expected that through their work on a CBPR project perceptions of empowerment would have changed and developed into something that could be defined positively in relation to their lives because of a increased understanding of capabilities and confidence. Specifically, I expected project members to describe empowerment as their voices being heard and respected. Additionally, I anticipated ideas of power sharing to be an important aspect to community partners' definitions of empowerment.

\section{Research Question Two}

The second research question examined whether working on a research project that utilizes CBPR allows for community partners to gain empowerment within the context of the research project. Specifically, how has working on a CBPR project allowed community partners to demonstrate empowerment within the context of the research 
project? I examined community partners' responses from individual interviews about which parts of the project helped and hindered individuals' ability to become empowered. I was interested in whether a community partner's involvement on a CBPR project allowed for persons with and without developmental disabilities to express and develop empowerment within the research project. I expected that being involved in a CBPR project allowed a space for community partners with and without developmental disabilities to increase their sense of empowerment, including a sense of power over research and trust over decision-making ability. Within the context of this research process, I predicted that to include individuals making key decisions within the project and speaking up when they did not understand or like a decision that has been made. Both research questions are explored primarily from the individual interviews with community partners on the Partnering Project, but academic partners' individual interview transcripts are used as a secondary data source to supplement the findings. 


\section{Method}

\section{Study Context}

This evaluation is part of an ongoing external project evaluation being conducted by Dr. McDonald. I am a graduate research assistant on the project. The overall evaluation is being done to study the use of CBPR with persons with developmental disabilities. Specifically, the multi-method, multi-source evaluation is looking to answer how CBPR can be done effectively with adults with developmental disabilities and how academic and community partners experience the collaboration. In an effort to answer these questions, investigators, research assistants, consultants, and steering committee members complete ongoing reflections about their work on the project, which accounted for one data source. Dr. McDonald created the reflection questions with the help of an academic partner with a disability, Emily Lund, and community partner with a disability, Dora Raymaker. Initially reflections were filled out at main junctures in the project (i.e., the grant writing phase, the $\mathrm{CAB}$ assembly, and the $\mathrm{CAB}$ start-up process). Then project members were asked to fill out reflections monthly. To reduce response burden, reflections are now collected bimonthly from investigators, research assistants, and steering committee members and quarterly from consultants. Reflections are collected in a manner that is accessible for all project members. Some project members prefer filling the reflections out in written form and others prefer discussing their reflections over the telephone with me. As a second source of data, annual focus groups are conducted in Oregon and Montana with $\mathrm{CAB}$ members to evaluate their thoughts and feeling about the project and their position within it. Listserv communications, CAB participant 
observations, and coordinating team minutes have also been data sources that may be used as part of the overall evaluation.

The current study examines what empowerment means to community partners on the Partnering Project and how working on a CBPR project has affected community partners with respect to empowerment within the project. For this project, I conducted follow-up individual interviews with community and academic partners to gain an understanding of important aspects of empowerment. The individual interviews were the only time project members were asked directly about empowerment and they are the main data source used for this study. The $\mathrm{CAB}$ focus group guide and $\mathrm{SC}$ reflection questions both asked questions related to empowerment, such as things about the project that help project members contribute, what it means to individuals to be included in research, things project members are learning and how it is affecting their work, and relationships between project members. However, those data are not included in this study.

My role on the overall evaluation includes data collection by conducting bimonthly phone interview reflections with SC members. I transcribe the CAB focus groups and assist with identifying core themes in the $\mathrm{CAB}$ focus group transcripts and the SC reflections. Additionally, I help write and present preliminary findings from the data collection to project members. My position as a research assistant on this evaluation is unique because of the relationships my advisor has established with many of the participants. The trust Dr. McDonald has built with self-advocates and their allies through her work in the Oregon disability community has provided me with an opportunity to 
build relationships quickly. As a non-disabled, female, academic researcher new to the Oregon disability community, it was very helpful to have a mentor who has established such positive relationships because I believe it allowed for participants to feel more comfortable sharing their honest reflections about their work on the project with me.

The Partnering Project began in October of 2009, and the evaluation of the project started in May 2010. I have been active in the project since June 2010. In August 2010, a preliminary report of the findings from the CAB focus groups was presented to the SC members (McDonald \& Stack, 2010a). In December 2010, a report of the initial findings from the SC reflections was shared with the SC and coordinating team (McDonald \& Stack, 2010b). Both reports were disseminated after project members Dora Raymaker and Emily Lund had the opportunity to check that the language used was accessible. The project team has continued discussions about the project and has made changes to improve the quality of their work. Some of these changes are a result of findings from the evaluation.

\section{Participants}

The primary participants for the study include community partners involved in the Partnering Project. Data has been collected from fifteen community partners across both sites as part of the ongoing evaluation. Eleven community advisory board members and four steering committee community members have contributed to the evaluation. The same participants contributed to this study. There are seven community partners who contribute in Montana, and eight community partners who contribute from Portland. Overall, ages range from 22 to 64 . Ten (67\%) of the community partners identify as 
females and five (33\%) identify as males. Thirteen community partners $(87 \%)$ identify as Caucasian, one (7) identifies as multiracial, and one (7\%) identifies as Native American/American Indian. The highest education obtained ranges from some grade school to a Juris doctorate degree. Participants were asked to report their relationship to disability, and most identified several relationships. Fourteen (93\%) identify as a person with a disability, six (40\%) identify as a family member of a person(s) with a disability, five $(33 \%)$ identify as an ally to a person(s) with a disability, two (13\%) identify as support providers to a person(s) with a disability, and one (7\%) person identifies as a domestic violence support provider.

Secondary participants included academic partners involved in the Partnering Project. As part of the ongoing evaluation, data were collected from eight academic partners to date. Only six of those eight partners are still active members of the project. Therefore, only those six academic partners contributed to individual interview data. The academic partners ages range from $27-68$, all identify as female and Caucasian, three $(50 \%)$ have a Doctoral degree, two (33\%) have a Master's degree, and one has a Medical degree $(17 \%)$. Three identify as a person with a disability $(50 \%)$, four $(67 \%)$, identify as a family member of a person(s) with a disability, and all identify as an ally to a person(s) with a disability. See Table.1 for a complete list of demographic information. The data collected from academic partners was coded to provide additional identify similarities and differences in what community partners have reported. 


\section{Measures}

This study focuses on the follow-up individual interviews that were conducted in the Fall of 2011 and Winter of 2012. I created the individual interview guide with the help of Dr. McDonald. The guide includes questions important to this study as well as questions for the overall evaluation. I used data collected from the individual interviews with community partners as my main data source, but several other instruments have been used as part of the overall evaluation. Those instruments include regular SC reflections, $\mathrm{CAB}$ focus group guides, listserv communications, $\mathrm{CAB}$ observations, and coordinating team minutes. The following measures were part of this study.

Individual Interview Guides. Again, the individual interviews with community partners are the focus of this study, and the individual interviews with academic partners were used as secondary support. I conducted individual interviews with community and academic partners in order to more fully understand previous responses and to focus on more detailed elements of project members' work. Specifically, the interviews asked project members about their roles within the project, how the project has affected their lives, how the CBPR structure has developed, and how empowerment can and cannot be seen within and outside of the project. The interview guides used with the community partners had additional questions addressing other areas of their lives in which they engage in disability advocacy (See Appendix B: Individual Interview Guide Community Research Partners). The interview guide used with the academic partners has questions addressing how the CBPR process has changed other areas of their work (See Appendix C: Individual Interview Guide - Academic Research Partners). The questions 
for both the community and academic partners interview guide developed from responses from project members from the $\mathrm{SC}$ reflections and $\mathrm{CAB}$ focus groups. Many project members spoke directly or indirectly to ideas of empowerment developing as a result of their work on this project. Additionally, my interest in empowerment also contributed to the development of many of the questions. I also asked participants to complete a demographic questionnaire following all interviews in order for us to be able to describe accurately the characteristics of those working on the Partnering Project.

Field notes. I have kept field notes about what I have observed and felt through my involvement on the project. I used these notes to supplement participants' responses to reflections and interview questions, which allowed me to more fully reflect on my role within the interviews and data and how this can be reflected in participant responses.

\section{Procedure}

In order to learn about the use of CBPR with persons with developmental disabilities and to examine whether CBPR is being utilized in a way that is beneficial, academics on the project desired for their work to be evaluated. Project members' willingness to give their time and effort to make sure their project is working well should be commended. The evaluation was put into place at the request of project members and was a part of the initial grant application.

$\mathrm{SC}$ reflections, $\mathrm{CAB}$ focus groups, and $\mathrm{CAB}$ observations have given us an understanding some of the dynamics within the Partnering Project. In order to more completely understand some of the experiences the community and academic partners on the Partnering Project have shared with Dr. McDonald and me, follow up interviews 
were conducted with SC and CAB members in Fall 2011 and Winter 2012, with the majority being completed in the Fall. In Portland, I conducted interviews at the convenience of project members and in places where they expressed feeling comfortable, such as their offices, their homes, or my office. In November, I traveled to Montana and collected interviews from almost all project members there. Again, I collected interviews at their convenience and in areas where they felt comfortable, such as their offices and homes. Two project members were not available to be interviewed because of illness or location change. In order to include these individuals, we set up times to communicate over Skype when I returned back to Portland.

Initially, I planned on data collection taking no more than ten weeks and completing all interviews during the Fall 2011 term. Unfortunately, I was not able to complete all interviews in this time. Instead, two interviews we conducted in January 2012, the final interview taking place 17 weeks after data collection began. Beginning in the Fall of 2011, the members on the project have not been meeting as regularly as they had over the past couple of years. Because of this, I feel like the added time it took for me to finish conducting interviews was not reflected in the interviews. Project members were all reflecting on the project when it was currently in the same stage. It is possible that if interviews were conducted across different stages of the project than different feelings toward the project and project members' role within the project may have affected the results. All interviews were conducted during the time that the Partnering Project members were collecting data for their study. Only a few members of the project engaged in the data collection part of the project, so other project members were just waiting for 
the dissemination stage. However, it is possible that the time project members were removed from the project may have impacted their memories and/or feelings toward the project.

I went over the consent form with all project members to ensure understanding of the project, the benefits, and the risks. I met with project members in a space they felt comfortable at a time of their choosing. This included meeting three participants in their homes, five participants in the space they meet for Partnering Project meetings, two in academic partners' office, and one individual each in my office, his office, on Skype, and on the phone. One project member filled out her responses and emailed them to me. At the end of each interview, a \$25 gift card was offered to Safeway, Albertson's, or Amazon.com, which all community partners accepted.

I began transcribing interviews immediately after conducting the first interview. Initially, I completed transcripts corresponding with the order of the interviews. However, because interviews were collected very close together in most cases, I made community partner transcripts my priority, and transcribed academic partner transcripts after all community partner transcripts were completed. Since I conducted and transcribed all interviews, there were few instances when I was unable to understand and transcribe what was being said in an interview. The transcriptions consists of verbatim speech said by all project members and me. I completed all transcriptions by March 2012 . Only one project member requested a copy of her transcript. Upon completion of transcription, I created a case analysis for each interview, so I could reflect on the interview in a more cohesive way (Miles \& Hubberman, 1994). Finally, I created a 
comprehensive summary of my project, the results, and my interpretation of the results and presented it to all participants. I asked all project members to approve the summary in order to feel confident that I am presenting their collective voice in a way that represents their feelings toward the Partnering Project and my focal constructs.

\section{Ethical Considerations}

Ethical considerations align with Syracuse University's and Portland State University’s Human Subject Review Committee. Syracuse University’s Institutional Review Board (IRB) oversees the overall evaluation, and Portland State University's IRB has approved this current study. In order to protect participant confidentiality, all participants were assigned identification numbers upon the first time they contributed to the project. Identification numbers are placed on all reflections and transcripts connected to a specific individual. Furthermore, if any project members mentions anyone by name, the name is substituted with the corresponding identification number of the individual mentioned. The identification numbers and the individuals they are connected to are located in an excel file that cannot be opened without a password. Dr. McDonald and I are the only people who know the password.

The Partnering Project members have chosen to allow their names to be connected with this evaluation because of the sense of pride they have over the work they are doing; however, no participant identifying information will be connected to any particular responses in publication, reports, or presentations. In this study, I have used pseudonyms when sharing participants' responses. All information from the project is secured in a locked office. Participants are encouraged to ask questions and share 
concerns they have at any time. Finally, I informed all participants that at any point during the interviews they could choose to not participate. All project members completed the full interview.

Dr. McDonald created consent forms that use plain language and graphics to promote accessibility (See Appendix D). I reviewed the consent forms with each participant to ensure all participants understood the purpose, benefits, and risks of the interview. I did not engage in capacity to consent procedures with participants out of respect for participants' abilities. Participants have been actively engaged in a research process for the past two years, so it was my belief that they demonstrated the skills and understanding needed to discuss this process. Additionally, due to the low risks of this study, the ideas of shared decision making in relation to consent are the qualities I emphasized (Dye, Hendry, \& Hare, 2004). Capacity to consent procedures can result in whole communities being excluded. These procedures serve only to harm and further marginalize certain populations (Juritzen, Grimen, \& Heggen, 2011).

In addition to being involved on a research project team and adapting consent forms for the Partnering Project, all community partners had already engaged in consent procedures prior to engagement in $\mathrm{SC}$ reflections or the $\mathrm{CAB}$ focus groups. I did use the Partnering Project as an example and offered to conduct pre-interview meetings with individuals who may have needed more time to understand the interview materials; however, no project members decided to have a formal pre-interview meeting. I wanted participants to feel comfortable contributing to this study, so all participants chose where 
the interviews would be conducted (i.e., in person, in live time through text, or on the telephone).

One benefit to participants may be the positive feelings about the benefits that may come out of this research for their communities, such as the identification of individual and setting level aspects of a CBPR that may empower persons with developmental disabilities. Additionally, allowing participants to have a space to share positive and negative aspects of their work may have added to relationship building amongst project members. One community partner actually discussed feeling a lot better about a misunderstanding he had with another community partner after talking with me about the project. Overall, community partners expressed gratitude for the work I had been doing within the evaluation and were excited to share their insights on a project they feel is novel, important, and beneficial.

The principles inherent to community psychology, such as working for social change and taking an ecological perspective, bring about a unique and separate set of ethical guidelines. This study focused on collaboration that is educational, task-oriented, and focused on human-rights protection which has been recommended as a way to alleviate mentioned ethical concerns (Snow, Grady, \& Goyette-Ewing, 2000).

\section{Qualitative Methods}

The aim of this project was to qualitatively study whether being a partner on a CBPR project provides a space for community partners to gain empowerment within the project. Similar to the overall evaluation, I made the choice to continue using qualitative methods because of the exploratory nature of my research questions. Also, the use of 
qualitative methods has been acknowledged as an approach that is beneficial to use with marginalized populations, such as persons with disabilities (Aldridge, 2007). Aldridge emphasizes the danger in excluding people with disabilities in research when the methods do not match the population or the research questions. The use of appropriate qualitative methods allows for building and fostering rapport between researcher and participant, which enhances quality of the data.

While I believe that the use of qualitative methods was the correct decision because it highlights the perceptions of persons with disabilities as valuable and credible (Mactavish, Mahon, \& Lutfiyya, 2000), I also know it is important to maintain scientific rigor while addressing the best approach for the participants in a study (Aldridge, 2007). I believe rich descriptions that attempt to capture participants' point of view are necessary in relation to my constructs. I identify as a critical theorist where I believe CBPR with persons with disabilities will never be fully understood because the context and lens through which I look at this work is always important and always changing. There are social, political, and individual beliefs and experiences in which this work is situated in my life as well as in the lives of my participants. This project is unique and all of those implications need to be at the forefront in order for individuals to realize and utilize the benefits of this work. I believe a detailed approximation, which I identify as the aspects of a CBPR that help and hinder empowerment can be beneficial for individuals who would like to use a CBPR in the future (Denzin \& Lincoln, 2005).

Importantly, Denzin and Lincoln (2005) describe the use of qualitative methods as a critical conversation the social sciences are attempting to have about community. 
Community psychologists work toward goals of improving community well-being and understanding the development and benefits of PSOC. This collective effort is an attempt to establish community empowerment (Rapley \& Pretty, 1999). In order to capture the diversity of the definition and benefits of complex concepts, it has been suggested that research utilize diverse methods (Hill, 1996; Rapley \& Pretty, 1999). Rapley and Pretty (1999) argue "the exact placement of an utterance, as well as its phrasing, affects meaning" (p. 700). The meaning and importance of speech, therefore, is lost when content analyses are the means by which words are understood (Rapley \& Pretty, 1999). This call to understanding the cultural connection of communities through qualitative methods emphasized by Hines (1993) and Maton (1993) in community psychology is similar to the recent focus on qualitative methods by the vocational rehabilitation researchers in order to develop a more full understanding of the experiences of persons with disabilities. Qualitative research is described as a way to culturally situate a person's life experiences as well as an "empowerment mechanism" (Niesz, Koch, \& Rumrill, 2008, p. 113). Community and academic partners use narratives, the community, and their collective community identity to promote positive membership and positive social change (Goodley \& Lawthom, 2005). I believe the use of qualitative methods to address my research questions was necessary to allow a full story to be uncovered, but it would be interesting to see how a mixed methods design may have told a similar or different story. 


\section{Self-Reflection}

I cannot untangle myself from the context in which I study my phenomena of interest. Qualitative research locates the observer within in the world of the participants (Denzin \& Lincoln, 2005). But where do I draw the line on how much to tell you about myself? I engaged in the same struggle as Merrick (1999), a white, middle class, woman, did with her study of young, black, pregnant women. I describe my involvement and status in the project, but it remains "unclear how much and how to share" with readers (Merrick, 1999, p. 54). How far back do I reflect on what brought me to this spot to engage in this research? What do the participants in my study think about my status? I cannot be sure about the affect that my status as a non-disabled, female, graduate student has on the responses community partners provide without asking them. I have tried to understand myself within the framework of my project fully in order to acknowledge some of my biases, but they will never cease to exist. Being aware of my biases forces me to regularly check my work to make sure it is the participants' voices being highlighted and not my biases. Past scholars have noted that adequate qualitative research can be conducted when researchers' life narratives do not match up with those of their participants; however, researchers should be aware of the various challenges and continuously work to monitor them (Merrick, 1999).

I have developed relationships with project members that go beyond being solely an interviewer/interviewee dynamic. I have engaged in what Goodley (1999) describes as a "getting to know" process or a gradual process of learning through immersion and prolonged engagement with the participants. This has allowed me to build relationships, 
as well as become more sensitive to subtle qualities and identities within the group. I engaged in two participant observations with the Portland $\mathrm{CAB}$ and one participant observation with the Montana CAB. Additionally, I have been present for a focus group in both locations, and I have been a part of listserv communication. This immersion over time still labels me as an outsider, but has allowed me to become more culturally sensitive (Goodley, 1999).

Griffin (1996) discloses her concerns about the "dangers involved when researchers were engaged in 'representing the Other' in more marginal groups" (Griffin, 1996, p. 186). There will always be an object of study in research. It is the researchers responsibility to step back from their study to develop detachment and understanding of the data. Additionally, there needs to be a moment in every study that the researcher steps back and fully understands the purpose of engaging in a certain project. Specifically, “"How does (or might) this project contribute to radical social change?"” (Griffin, 1996, p. 188).

Again, I work from a feminist and critical theorist perspective. I believe in new and different ways of presenting and disseminating findings. It is the belief that there are no absolute truths only approximations of truth (Denzin \& Lincoln, 2005; Merrick, 1999). I believe this identification with my subjective self is a strength of my work which develops through my illustration of how I come to know and understand this project (Goodley, 1999). As I began to reflect, certain life experiences stood out more than others. The most salient experience that has contributed to my journey to becoming a graduate student at Portland State University and a research assistant on this project 
comes to mind. Before graduate school, I worked in a residential facility that was home to persons with developmental disabilities. The residents were excluded and hidden from their surrounding community and rarely was their opinion solicited or listened to. This experience allowed me to see first hand how exclusion and power imbalances can affect community and individual well-being. My belief that decisions that affect a community should be made with members of that community is driven by this experience.

I want all of my work to have the potential to be disseminated and used in a way that can enact positive social change for persons with developmental disability. I believe research needs to be conducted in a way that radically alters how marginalized communities are viewed through the eyes of the majority. In order to do this, I believe research needs to always embody the needs and issues relevant to those populations. I am passionate about and determined to only engage in a research design that adequately outlines how the information gained from a study will be used to positively benefit individuals. I hope this project will demonstrate how a construct important to the disability community, empowerment, can be brought about in research, which has not always been welcoming or respectful to persons with developmental disabilities (Freeman, 2001; McDonald \& Keys, 2008; McDonald et al., 2008). Additionally, I think of CBPR as an ongoing process that continues even after a partnership has completed. Community and academic partners will forever be colleagues as they continue to work towards the important issues that need to be addressed for the well-being of the specific communities, as well as the societies in which those communities are situated. 


\section{Data Analysis}

I adhered to Rapley and Pretty's (1999) call for the adoption of qualitative methods in community psychology that are more rigorous and empowering. I analyzed the data through a process of content and thematic analysis that was driven by participants' voices. Ritchie and Lewis (2003) describe this process where "both the content and context of documents are analyzed: themes are identified, with the researcher focusing on the way the theme is treated or presented and the frequency of its occurrence" (Ritchie \& Lewis, 2003, p. 200).

Individual interview transcripts were organized using ATLAS.ti, a computer software program designed specifically to help manage qualitative data (Murh, 2004). Conducting and transcribing the individual interviews provided me with an opportunity to be repeatedly exposed to the data. This procedure of repeated exposure has been praised in qualitative inquiry as a way to discover patterns because the researcher is able to become deeply familiar with the data and possibly see it in a different way (Lincoln \& Guba, 1985).

I used participants' responses about empowerment definitions within their own lives and within the Partnering Project to create codes of empowerment. In most cases, respondents were able to provide a definition of empowerment; however, there were a couple of times where I shared a definition of empowerment or we worked a definition out together before moving on to the questions about empowerment. In both cases where this was necessary, I felt confident participants understood the construct. When initially creating codes, I was conservative about collapsing empowerment definitions to ensure 
all participants' voices were included. I quickly realized in order to identify similarities and differences in the definitions and space to examine empowerment within the Partnering Project I was going to have to collapse more definitions that appeared to have the same meaning. I realized this would not diminish anyone's voice. Instead, it allowed me to more concretely identify empowerment definitions. I also struggled with how I would be able to identify empowerment beliefs, such as self-esteem and self-efficacy, in a systematic way in the interviews. I was able to accomplish this with the help of theoretical sensitivity and participants' reflections on how the project has helped or hindered individual empowerment, specifically participants responding about the importance of them being on the project as well as their role within the project.

My initial codebook contained five broad domains with eighteen subdomains, including various additional branched codes for the subdomains. After discussion with Dr. McDonald and going through the transcripts with the created codes, I started my initial coding with three broad domains, individual-level empowerment, setting-level empowerment, and changes to empowerment definitions. These branched off into several codes that were again streamlined after my first round of coding where overlap and inconsistency was noticed. I was open to changing my codebook where it seemed necessary throughout the coding process in order to ensure the participants' voices were being heard. See Appendix E for an outline of my completed codebook. See Appendix F for my codes and definitions.

Flexibility in my analysis provided a way to make sure I was telling the theoretical narrative Partnering Project community and academics members were hoping 
to share about their work on a CBPR project; however, I understand this work ultimately is their narrative told through my own analytic lens and theory. I conducted member checks in two ways. After individual interview transcripts were completed, I checked in with community partners who were interested and shared their corresponding transcript to ensure I got all the ideas talked about down correctly. Second, upon completion of my interpretation of findings, I presented a summary to all community and academic partners in order to make sure I am interpreted our discussions in a way that reflects community members' intentions. Again, I understand I can never take myself out of the research. I built a story through their narratives (Griffin, 1996). The summary of my findings and interpretations (See Appendix G) was made available to community and academic partners in several ways. I emailed the summary to all project members with email access and asked them to reply with changes or questions. For those who did make a timely reply and for those that do not have email, I called and went through my summary with them over the phone. Additionally, for those that do not have email, I offered to send a copy of the summary to them through the mail. At the time this was submitted to my thesis committee prior to my thesis defense presentation, I had heard responses back or talked with 15 project members. At the time of my thesis defense presentation, I had heard responses back or talked to 18 of the 21 community and academic partners. Most project members were OK with my initial summary. Some project members provided suggestions on how to make the summary clearer, but overall, project members appreciated the graphics and layout. I also offered to share my entire document with anyone who is interested, and, so far, five project members would like a copy. One 
community partner felt the summary was too simplified, and suggested that I redo it in a way that includes more of my interpretations and provides quotes. I appreciated the concern expressed by this community partner about the oversimplification of my initial member check document. With her and Dr. McDonald assistance, I created a more comprehensive member check summary, including an explanation of member check and an interpretation of my findings (See Appendix H). I will be mailing, emailing, and meeting with community and academic partners to go over the member check again before further dissemination.

I expanded on ideas of Lincoln and Guba (1985) that it is impossible for a researcher to exist without biases. I entered into data collection and analyses knowing my relationship with project members may cause me to overlook some aspects of this work. For example, this bias might be evident through an overemphasis on the positive aspects of using CBPR with persons with developmental disabilities and the Partnering Project's process. To counter this possibility, I spent a great deal of energy to focus on ideas of disempowerment, disablism, and ableism. It is my responsibility to adequately interpret what community partners are discussing about their work. It would be a disservice to all project members involved if I did not discuss negative cases that exist within the project. It is suggest by Merrick (1999) that working in a team allows one to notice some conclusions being drawn may be a result of personal biases and misunderstandings of context. I checked in with my advisor about conclusions I drew from the data during and after my interpretation. Additionally, the use of multiple methods, sources, and researchers gave me an opportunity to observe where triangulation of data is present. The 
observation of convergence of data implies accuracy of conclusions drawn (Madill, Jordan, \& Shirley, 2000).

Finally, I only looked at data from one time point. I asked participants to express how they have seen their definition of empowerment evolve over the time they have worked on this project. It is possible participants may not recall accurately what their definition of empowerment was before working on the project. However, I still believe it was an important question that, upon reflection, revealed interesting aspects of the relationships between CBPR and empowerment. 


\section{Results}

This study examines the impact being involved in CBPR project may have on community partners with and without a developmental disability working on disability research. Specifically, I sought to identify the definition of and the evolution of the definition of empowerment and individual characteristics and elements of a CBPR setting that can facilitate or hinder empowerment. I have situated empowerment under 1) individual-level characteristics, 2) setting-level characteristics and 3) changes to empowerment definitions in order to organize the overall findings.

Individual-level empowerment referred to community members' understanding of what empowerment means to them generally. Specifically, what aspects of an individual relate to and/or affected by being empowered. The individual-level empowerment tree includes 1) empowered beliefs and 2) empowered behaviors. Empowered beliefs, or an individual being comfortable with him or herself, accepting faults, and utilizing strengths, includes 1) self-esteem and 2) self-efficacy. Empowered behaviors, or actions that are engaged in when a person is empowered, includes 1) control over decision-making, 2) disability rights advocacy, and 3) seeking involvement.

Setting-level codes refer to the qualities of the CBPR environment and how they may affect an individual's empowerment. The CBPR environment tree includes 1) inclusion, 2) accessibility, 3) partnership, 4) power-sharing, and 5) barriers. Inclusion refers to the group valuing inclusion, which includes the opportunity for project members to be involved. Accessibility includes 1) accessibility within the meetings and 2) accessibility between the meetings. Partnership, or outcomes that can be gained by the 
two groups working together, includes 1) co-learning/learning, 2) strength-based focus, 3) trust, and 4) self-proclaimed empowerment. Power sharing, or sharing ownership of the process and outcomes of the project, includes 1) shared decision-making and 2) influence. Barriers to empowerment, or qualities of the project that disempower or block an individual from being empowered, includes 1) inaccessible communication, 2) inaccessible language, and 3) lack of project ownership.

Changes to empowerment definitions relate to how one's empowerment definition changed or remain the same over the course of their work on the Partnering Project. This tree includes 1) no change, 2) negative change, and 3) positive change. Again, refer to Appendix E for an outline of my completed codebook. See Appendix F for my codes and definitions.

\section{Community members' definitions of empowerment}

Participants define empowerment in various ways when asked what empowerment meant to them. Some participants provide clearly formed definitions while most provide examples of what it hypothetically or actually looks like when they feel they are empowered or when they believe someone around them is empowered. My codebook was in some ways defined by these definitions, but I also added important ideas that manifested through the interviews overall and from the literature. The following are definitions or examples given by the participants when asked what empowerment means to them. The quotes in this section do not necessarily represent empowerment in the Partnering Project. Instead, they are examples given to me by the participants to clarify definitions as they saw them. 
Many community members define empowerment as being comfortable with one's self, accepting one's faults, and focusing on their strengths. Community partners use terms such as self-efficacy and self-esteem to describe these empowered beliefs. I coded self-efficacy as confidence in one's ability in a particular area or individual skill and selfesteem related to confidence in one's self overall:

Renee: The feeling of empowerment is self-efficacy.

Brian: It just is kind of... being confident in ... yourself.

Lily: As far as how empowerment relates to my life... it has to do with self-esteem, self-consciousness, self-exploration.

There were several behaviors that community partners identify as conditions of an individual being empowered. Many community members note control over decisionmaking, as an important component of empowerment:

Betty: I feel empowered that I can control what my own thoughts are, my own feelings, what I want to do with my life. I feel empowered... that I can make my own choices.

Jean: [If I did not have] the empowerment to get going and to take charge of my life, I would be stuck. And so I find it very important for people to have that or they are going to be stuck in the same place or job that they might not like. And they have to take change of their life. And say, 'I want to change things.'

Other empowered behaviors community partners mention to define empowerment include aspects of disability rights advocacy or being involved in and working toward achieving disability rights, which also includes disability pride: 
Lily: Self-advocacy, obviously, has a lot to do with empowerment and people speaking up for themselves and people being a part of things and being taken seriously.

Brian: Just that there is kind of a united element of trying to make life better for people with disabilities.

Additionally, the importance of inclusion in general became important when defining empowerment. This includes the opportunity to be involved as well as others valuing inclusion:

Sarah: Empowerment comes from inclusion. If we are given the chance at equal participation and assumed to be as valuable to the discussion as nondisabled people are.

Timothy: When self-advocates are empowered, I think, you know, again, people are giving them the floor, taking their opinions and thoughts seriously, stopping all other conversation to listen really good.

Furthermore, several community partners identify gaining and sharing knowledge as being the basis of defining and ultimately developing empowerment:

Betty: Knowledge to me too is empowerment... The more knowledge I have about something, the more comfortable I am with it... which allows me to be more comfortable and in all different surroundings so to me that has made me, empowered me more. 
Amanda: And in order for people to be empowered, any people, they have to feel like they made the best choice with the information they had available to them. You know, that is empowering, giving people that information.

One participant emphasizes that she believes the general popularity and political implication behind the word causes her to avoid using it:

Renee: Empowerment is an odd word and I usually try to avoid it because disempowered people often feel it is applied in ways that further marginalize, that people wave the word around to make it seem like power is present but it is really not.

\section{Empowerment and CBPR}

Using their own definitions of empowerment, community partners identify aspects of a CBPR project that may facilitate or hinder empowerment. Overall, community partners identify more aspects of CBPR facilitating empowerment rather than hindering it. Many community partners share positive things about how they feel they have been empowered through being a part of a CBPR project. When directly asked, community partners do not note anything about the project hindered them being empowered. When project members were asked if they feel empowered within the project, most members respond positively. Community members identify ways in which they feel empowered as well as observing others they feel are empowered:

Joseph: It has helped me in a long ways to become empowered.

Renee: I have seen all people in the Partnering Project make successful changes during the course of our work together, and do feel we have an empowered group. 
Some community partners noted they were already empowered before engaging in the CBPR partnership, so they did not feel the project assisted in further empowering them. For example,

Renee: I was already empowered in the ways that are relevant for the Partnering Project when I started, so it hasn't really helped me to be empowered.

In some cases, community partners express feeling empowered by being inspired by or watching other people on the project demonstrate what they believed to be empowering behaviors:

Betty: Everybody has limitations somewhere in their life and something going on. And it is just so rewarding to be with a group that with everything going on, everybody is growing themselves.

Amanda: To see people try to do something on a personal level and to see them succeed and sometimes fall down, but pick themselves up. I mean, so it is not always about success, but it is about being able to get back up and carry on. That just has been really awesome. And I don't want to sound like a movie of the week here, but it has really been beneficial to me because, you know, there are a lot of things that I have in my own life.

I identify several facilitators to empowerment related to the context of the CBPR project. Contextual factors to promote empowerment include themes related to inclusion, accessibility, partner relationships, and power sharing. Inclusion included community partners being given the opportunity to participate, which was reflected on as the overall value the group places on making sure several perspectives are heard: 
Brian: They asked if, you know, I would be willing to... lend my experience to the project.

Amanda: I can't speak for other people and I wouldn't want for other people to speak for me.

Jean: I think it is really great that people take interest in us and want to know about us and everything because we need more of that.

Some community partners mention accessibility of the materials, language, processes, and physical environment as an aspect of the CBPR partnership that provides a space for them to contribute to the project in the ways they want, which possibly lead to empowering behaviors:

Timothy: Often we stop things and go back and make sure that, you know, one or more people who have expressed confusion about what we are talking about, we can address that.

Jean: I am very lucky that [academic partner] can help me go over there and stuff.

Meghan: They accommodate really good. Like even with the files when they send an attachment. They send it in a file that works for my computer.

Several community partners mention trust, or project members feeling comfortable working with, sharing ideas, and asking questions within the group, as important quality of the partnership. Trust was identified as a facilitator to empowerment because it produces a work environment where community partners feel welcomed, 
respected, and willing to keep contributing because their ideas and experiences were taken seriously:

Brian: I think that is a strong point of what we are as a group, you know, the freedom to share our experience. It is, I know at least for me, it has made me feel... important or that the contribution and efforts I bring to this are looked at positively.

Meghan: It is a good and friendly environment to work in.

Lily: I am not going to deny that there are just things that people in public think about people with disabilities. That is just the way it is. Well, everybody walks in to this room, into the Partnering Project, regardless of what people have thought of them, you know, on their way here or whatever, well, they walk in that room and they are an equal person. And they know that they will be respected there. Some community partners also note shared leadership of the project being notable aspect of CBPR, which may also be a component leading to empowerment. I identify shared leadership as including feelings of ownership of the project, rotating leadership responsibilities, and identification as a researcher:

Lily: It is different from other self-advocacy groups. It might be hard for someone to know who is in charge right away when they first walk in the room versus in other self-advocacy groups. You walk in right away and you might know who is in charge.

Joseph: We are both in charge, the academics and self-advocates.

Michael: We are finding it together. So, that makes us researchers. 
Several community partners discuss examples of when they have directly influenced the project. Community partners engaging in a project that provides them with an opportunity to experience genuine influence over the process and its outcomes was seen as empowering. Similar to trust, community partners seeing how they have influenced the project provides a space for community partners to feel their continued contributions to the project are worth the effort. The following are some examples of community partners influencing the project:

Sarah: Seeing my suggestions considered and implemented without giving me the ninth degree was also quite lovely.

Jean: We had pieces of paper and there were words that we had to change. And some words, the meaning did not fit it or something and we had to work with it and change it or keep it the same.

Regarding influence, one community partner discusses how her leadership role within another group allowed her to influence data collection through her ability to recruit hardto- reach participants:

Mindy: I got some people to do the survey from my group.

Along these same lines, some community partners acknowledge and appreciate the focus on unique skills as empowering and a way to share power and develop a strong team:

Renee: Something I have always appreciated about the power landscape in Partnering is that people are very good about holding power when the work is 
within their expertise and releasing it when it's not. There is always a very appropriate transitioning of power in the group.

Michael: In the project, you have people who are strong at some things and weak at other things... You need people to step up and fill in the gaps and really help people

Community partners also discuss being able to advocate for disability rights within the project, which is a behavior several individuals note as empowering:

Brian: There is kind of a united element of trying to make life better for people with disabilities... We are not going to probably solve any huge things, but I think it is important to start looking at why some things are the way they are. It goes back to making things better.

Some community partners see the Partnering Project as a way to be active within the community, seek involvement, and contribute:

Janet: It has also enabled me to get around the city and become more involved in the community.

Thomas: It has given me an opportunity to stay active, do something positive. Self-efficacy, self-esteem, and learning/co-learning are seen as outcomes of these contextual CBPR factors. Again, I define self-esteem as individuals demonstrating confidence in the importance of being members of the group unrelated to specific and unique skills:

Timothy: What [self-advocates] have to say is just as valuable, if not more valuable, in some ways than what the rest of [the group has] to say. 
Joseph: I feel like my voice is important on a CBPR [project].

I define self-efficacy as an individual demonstrating confidence in her or his unique skills being an important part of the group:

Renee: I think of my role to myself in the way I think of my role on pretty much any project, human Swiss-army knife and fill-in-the-gaps-person. I feel like where I am of most value to the project is in providing structure, monitoring/adjusting power balances, translating scientific information for lay people.

Sarah: I knew that sometimes questions on the survey could be worded in awkward and confusing ways for autistics to understand and wanted to see if I could change that a bit.

As mentioned, many community partners reflect on how knowledge and learning is empowering. Several community partners discuss an outcome of the CBPR process being an opportunity to learn from academic partners, other community partners, and the research material:

Michael: We are all learning.

Amanda: I experience it as a really empowering way of learning how to work with a certain population. So I feel really good about it.

Timothy: I have knowledge of the CBPR process, which I didn't have before, so I would say that is empowering.

\section{Barriers to empowerment}

Some community partners note aspects of the project environment that could be seen as disempowering. These include inaccessible communication, inaccessible 
language, and lack of project ownership. Some community partners mention inaccessible communication, or individuals saying they feel they are not being listened to, respected or project members lacking understanding of what is happening within or the purpose of the project. Some community partners have a hard time discussing the purpose of the CBPR project:

Jean: I am not exactly sure why we have the CAB.

Additionally, one community partner feels there are times during meetings when she is ignored:

Mindy: Sometimes they don't listen to [me] when I am talking.

I also identify inaccessible language as possibly disempowering for some community partners. Inaccessible language includes not understanding what people are saying or why decisions are being made. One community partner in particular feels this was a frustrating aspect of the partnership:

Jean: I find it real hard sometimes when like [group members] are talking and they have real hard words... That is real frustrating to me. And I think with anyone, when you don't understand something it is pretty hard. Inaccessible language forces this community partner to question her contributions within the project:

Jean: When it gets to complicated, then I feel like, "Why am I here?"

Finally, I identify lack of project ownership as possibly being a barrier to empowerment for some community partners. This could be seen as community partners not feeling ownership of the project or not identifying as a researcher: 
Michael: I think the ones in power being [academic partner], [academic partner], and [academic partner]... They run it.

Thomas: No because I know what being a researcher is and I am not doing that.

\section{Empowerment redefined}

Finally, I examine whether or not community partners' engagement on a CBPR project changes their definitions of empowerment. In most cases, community partners do not see any changes in their definition of empowerment. Instead, many note how the importance of empowerment was reinforced through their involvement on a CBPR project:

Brenda: I don't know if I think of it differently, but... it has been good to be around people who are empowered. People that are, that are committed to making things better, but I don't think it has really changed... my thoughts about it greatly.

Amanda: No, I think it just reinforced what I believe as far as how to empower and being empowered.

No community partners identify any negative changes in their definition of empowerment from being involved in the Partnering Project, but some did note they noticed some positive changes. Only one participant provides an example of how it has changed:

Sarah: I think that it's attainable now. Which is something I was pessimistic about before to be honest. That's a lovely change. 


\section{Secondary data: Academic partners and empowerment}

In most instances, academic partners define empowerment and describe similar empowering characteristics of a CBPR project as the community partners. One academic partner relates self-esteem, which I coded as an empowerment belief, to empowerment:

Cindy: Empowerment means... understanding your worth as a person and... that you are valued and that you have something to contribute.

All academic partners mention independence and control over decisions and selfdetermination as an important quality of empowerment:

Dolores: Empowerment is... one's sense that they can or they have the power to do things.

Elizabeth: Empowerment is a chance to have some self-agency in a process, in a day, in a course of action.

However, like the community partner who does not like the use of the word empowerment because of the implication it holds, an academic partner mentions a similar sentiment:

Dana: I tend to use the word self-determination instead of empowerment because... I think there is a lot of political confusion around what empowerment, about empowerment theory and all that kind of stuff.

Like community partners, some academic partners note some community partners exhibiting what they believe to be empowering behaviors: 
Cindy: Just watching people who often haven't been asked for their opinions or for their input begin to realize how important they are and how critical their input is and that they have the right to not have anything, you know, people studying them or doing things on them or on their behalf, but should always be with their participation... It has been the joy of watching people, you know, kind of coming to terms with that.

Several academic partners want to emphasize how they feel empowerment developes within an individual's life. It is important for them to point out that empowerment comes from within a person. It cannot be given to them by anyone else. All other people can do is provide a space where individual's have the opportunity to be empowered:

Cindy: There is absolutely nothing in the world that we in the academic community do to empower anybody else. People can only empower themselves. We can help create a climate where people can empower themselves, but... there is no elitist bestowing of empowerment on somebody.

Dana: It is something that a person owns, you know, we can't empower somebody. You can get out of the way so they can express self-determination, and you can perhaps provide some tools for how they might be able to do that, but they are the ones that own it. They are the ones that do it. Zoey: It is like giving, helping people, or giving people the resources they need to make their own decision in whatever area. That may be in their lives or in their workplace, in their relationships. 
Academic partners focus on providing a space where there was an opportunity to be empowered. Academic partners describe similar qualities of the CBPR setting relating to empowerment as the community partners. One of the main aspects of the partnership academic partners mention is their belief in the value of inclusion, which may promote empowerment:

Brenda: I think because having people that are being studied being part of every phase of the project is personal, it is very respectful, and it is very inclusive... It makes for a better project.

Cindy: I think [CBPR] is the only permissible way to conduct research around people with disabilities... It is critical. It is essential, and I question the results in research that doesn't include people frankly.

Elizabeth: I think that... is the ultimate goal of CBPR, whether it is delivering an intervention, a survey, some sort of evaluation of a program, is you have got to include everybody in the process.

Academic partners also discuss making an effort to ensure that the CBPR process are accessible and understandable for all group members:

Brenda: Making sure that our meetings are accessible, making sure that people who are presenting at our meetings use accessible language, you know, not only just don't use acronyms... really use plain language... To accommodate people's learning styles and their cognitive styles and abilities.

Zoey: [Project members] make sure they are understanding each other correctly. 
Specifically, one academic partner provides an example from the beginning of the partnership that reflected the belief that the group was willing to accommodate for individuals to ensure inclusion:

Cindy: We met in a little room down the hall here, and we were asking people how things went or if there was anything we could do to make things better. And that room happened to have a chalkboard and there had been writing on it because people meet in there... That is something she has a... very difficult time with. And she said something, and we just like immediately just, of course we are going to find a different room then, you know. I mean it wasn't like we even had to think twice about it.

Academic partners also discuss the importance of trust within the group, which includes providing an environment where people felt comfortable to engage:

Cindy: Having and creating a climate, hopefully, where people don't hesitate to say something. I mean some people are more quiet than other people are. We don't necessarily have to drag it out of people because if some of those people have something to say they definitely will say it. So some of it is just allowing people to be who they are and to contribute in ways that are comfortable to them. But, also creating a climate where people know that they can say things and... they are not going to be judged. They don't have to be afraid of saying what they think about something... Dolores: They are just a great group... just the level of how comfortable it is to work with them. 
Zoey: Everybody's opinion is valued equally, especially in our CAB meetings. And what people have to say, people really take the time to listen to each other... You don't say, "If you don't have you PhD your opinion is not valued." In addition, some academic partners describe the development of trust within the group in more detail than community partners. Specifically, they note the importance of setting an example from the beginning of a project and checking in throughout the project:

Cindy: Our actions and words creating that sort of a climate... [but] it is not something that everybody can just often trust right from the beginning simply because that has not been their experience before. And some of them have had experiences much to the contrary. So, I think that we have been consistent about that and then people relax into it... That is where is really counts. So, I think that not only do we help set that tone, I hope, from the beginning by how we interact with each other, as well as how we interact with the people we invited to join us at the table, but then they also continue to do that.

Dana: Just like any marriage we had a period, I think, in the first few months where we were kind of feeling each other out, kind of getting to know each other... "Well, could we challenge each other?... Could we disagree and still respect and like one another? And could we be respected, probably more, would we be resected?" You know? And, I think we kind of got through that period and we bonded pretty well. I mean I think we are pretty tightly connected at this point. At least, I feel that way. 
Academic partners also emphasize the importance of providing a space for power sharing. Specifically, sharing decision- making and the project being influenced by both academic and community partners is seen as power sharing. The following are examples of shared decision-making:

Brenda: I have had to be so aware of including everybody in every decision. Dana: It is about saying that my vote means no more or less than your vote. And you make your case and I make my case.

Academic partners provide some additional examples of how community partners have been influencing this project:

Brenda: We wouldn't have been able to use accessible language and measures [in the survey] if we didn't work very closely, very intensely with our community partners.

Dolores: I do think that their input very much influenced pretty much every part of the project.

Elizabeth: The participation from community members, both for how the questions were asked [and] how the users' interface of the survey actually looked and responded physically using that laptop computer.

Despite an effort to produce an equal partnership, one academic partner notes she does not feel the partnership is not totally equal. However, this is not necessarily a negative thing:

Dolores: There is something really valuable going on in that it doesn't have to be completely equal sharing of power or for everything... That is OK because ... even 
if it is not equally shared I do think that the perspective and... just the voices of our community partner's get heard quite loudly.

Finally, academic partners do not speak directly to what community partners may be learning, but several academic partners discuss learning throughout the process as well, which supports community partners' sentiments about the CBPR process producing and opportunity to learn and be empowered through that knowledge:

Brenda: It has been a very interesting and precious learning curve for me.

Dolores: I have gotten a lot of experience from the project. I have gotten stronger working relationships... I have really learned a lot about working with people with intellectual disabilities because I think I came into the project feeling much more comfortable working with folks on the spectrum. And, it has been interesting to kind of see the overlaps as well as some of the competing accommodations.

Unique to the academic partners, a couple individuals mention the group engaging in a cyclical process of checking in with all project members to ensure positive reflection on the process and continually providing a setting where an opportunity for empowerment can exist:

Brenda: Meeting with the local team here in just a few minutes to... get an update and problem solve barriers and ways that we can do things a little bit better and continue doing things well that we are doing well.

Cindy: We were asking people how things went or if there was anything that we could do to make things better. 
One academic partner provides an example of how the team has struggled in some ways to make things accessible to all partners. Again, I relate an inaccessible partnership to disempowerment because it limits individual's ability to participate effectively: Jane: Transportation has been difficult for him for steering committee meeting, and so we had him on the phone more and I think... we haven't done as well in that respect. It is just tough with that. To have one person on the phone, particularly when the person on the phone is the member of the team that really brings an expertise in cognitive disability.

\section{Multisite project: Montana and Portland}

For the most part, the differences that may exist between the Montana and Portland sites do not relate to my research questions. There are not notable differences between community partners' empowerment definitions across the two sites. Though most community and academic partners in Portland state they enjoy the process, it appears to be a more professional setting. Whereas in Montana both academic and community partners refer to the partnership as family-like or developing friendships and that it does not feel like work:

Michael: We are like family. We are friends. People bring home baked food. You know, it doesn't seem like work... The CAB meeting is like a room of friends having a good conversation and it doesn't seem like work. So, I think that makes it easy... on me.

Zoey: I have made some really good friends that I will hopefully keep being friends with when this all ends. 


\section{Discussion}

This study examined theorized benefits of using CBPR to partner with persons with developmental disabilities. Community partners being empowered as a result of their engagement on a CBPR project has been a noted by many scholars (Balcazar et al., 2006; Brydon-Miller, 1997; Chappell, 2001; Cocks \& Cockram, 1995; Israel et al., 2003; Minkler \& Wallerstein, 2008), but rarely has this valued outcome been studied, specifically, with persons with developmental disabilities (Atkinson, 2004; March et al., 1997). Additionally, it has been proposed that collaborative approaches should always be used in partnerships with persons with developmental disabilities (Redmond, 2005). With this belief adding to the growing use of CBPR with persons with developmental disabilities over the past decade, the characteristics of CBPR need to be studied and better understood (Cook, 2008; Stack \& McDonald, in preparation). This study aimed to continue exploring some noted CBPR characteristics by examining individual empowerment definitions, evolution of empowerment definitions, and CBPR factors that may affect an individual being empowered. Community partners were asked to reflect on their work on a CBPR project and discuss how it has affected them vis-à-vis empowerment. Overall, individual empowerment beliefs and behaviors and setting qualities were identified as affecting how an individual defined empowerment and felt empowered through their work on a CBPR project. 
I utilized qualitative methods because of the exploratory nature of my research questions and to amplify the voices of the community partners (Aldridge, 2007; Niesz et al., 2008). I engaged in grounded theory approach because I believe the phenomenon of interest to be ever changing and also my data collection and analysis process was interrelated. My analysis emerged out of community partners' responses during the interview process (Corbin \& Strauss, 1990). Community partners' definitions assisted in the development of my coding process and guided my analysis. The CBPR with persons with developmental disabilities concept model I developed from the literature has driven my interpretation of the findings. This has allowed me to organize my thoughts in a way that connects scholarship and the view of those involved on the Partnering Project. I developed an ecological model of empowerment as a result of the findings (See Figure 5). This model places the individual, including her or his empowerment beliefs and behaviors, within the CBPR setting, which include barriers and facilitators to empowerment. The individual and CBPR setting characteristics are situated in broader societal ideas, including the value of inclusion, seen as identifying experts through scholarly knowledge versus experts through related lived experiences. This ecological model demonstrates the belief that it is impossible to study an individual phenomenon without understanding the contextual, societal, and historical factors that may have an impact on it.

In order to organize the barriers and facilitators present, I developed a figure to demonstrate some of the findings contributing to individual empowerment (See Figure 6). This figure shows empowerment, defined as self-efficacy, self-esteem, control over 
decision-making, and disability rights advocacy. Setting barriers include inaccessible language, inaccessible communication, and lack of project ownership. Some examples of inaccessible language provided were the use of complicated words and involvement in complicated discussions. Inaccessible communication was seen through poorly specified project goals, not listening or talking over one another, misunderstanding suggestions, and lack of conflict resolution. Lack of project ownerships was observed through mention of unshared leadership and lacking researcher identity. Setting facilitators include inclusion, co-learning/learning, accessible partnerships, and power sharing. Examples of inclusion provided were being asked to be involved, being involved in meetings, and valuing diverse perspectives. Accessible partnerships include providing needed accommodations, accessible meeting locations and rooms, avoiding jargon and acronyms, and speaking and presenting in plain language. Power sharing examples include shared decision-making and influence.

The contextual-behavioral model of empowerment defines empowerment as the intersection of the relationships between the person or group, the environment, and an individual's past or current level of empowerment across time and contexts (Fawcett et al., 1994). This model has fit the findings of this study, which can be seen in how empowerment has emerged through both individual and setting-level codes. Level of empowerment, including past and current empowerment across contexts, was also noticed as an important factor within this study. Empowerment was not always a necessary outcome for individuals because project members already felt empowered before their engagement on a CBPR project, paralleling some scholars sentiments that the 
CBPR process is given too much credit for empowering community member (Björnsdóttir \& Svensdóttir, 2008; Goodley, 1999), and, in many cases, an individual will realize her or his marginalization in a community and begin to engage in necessary behaviors promoting empowerment (Zimmerman, 2000), which may explain why some community members decided to work on this current project.

\section{Empowerment defined}

Community partners were asked to identify what empowerment meant to them in order to evaluate how empowerment is experienced in their lives and how it has developed through their work on a CBPR project. Most community partners used examples of what empowerment looked like in their own lives rather than give specific definitions and two community partners struggled to even provide a definition of empowerment, which supports the complexity of the term (Fawcett et al., 1994; Miller \& Keys, 1996). Additionally, the wide range of responses provided by community partners reflected the various definitions observed to exist in the literature (Miller \& Keys, 1996; Perkins \& Zimmerman, 1995). Both of these conclusions support my decision to ask community partners to define empowerment and to use their definitions in the formulation of my analysis in order to determine if community partners obtained empowerment within the CBPR process.

The definitions and examples of empowerment described by community partners demonstrated antecedents to empowerment, such as inclusion, knowledge, and influence. They also shared behaviors exhibited by an individual when she or he is empowered, such as independence over decisions and engagement in disability rights advocacy. 
Overall, community partners' definitions matched empowerment definitions and relationships of their definitions to empowerment in the literature.

For example, community partners' definitions resembled empowerment definitions in the literature relating empowerment to an individual gaining mastery and control in their lives and settings (Maton, 2008; Rappaport, 1987; Zimmerman, 1990; Zimmerman, Israel, Shulz, \& Checkoway, 1992). Additionally, community partners mentioned several antecedents of empowerment shown in the literature within their empowerment definitions, such as inclusion and participation (Zimmerman, Israel, Shulz, \& Checkoway, 1992; Maton, 2008), knowledge and understanding (Atkinson, 2004; Minkler \& Wallerstein, 2008), and enhanced self-efficacy (Maton, 2008).

Community partners also noted self-advocacy as an important component of empowerment. Self-advocacy may be seen as an outcome of empowerment. This parallels scholars who have noted that when people are empowered and realize their expertise and importance, they will begin to work toward positive social change for their communities (Lantz et al., 2001; Minkler, 2004; Taylor et al., 2004). Along those lines, in order to increase the number of empowered individuals it is necessary to look at what community-level components promote empowerment (Maton; 2008; Rappaport, 1987) within an individual's life. Related to this work, identifying whether or not an individual has been empowered through their work on a CBPR project had many inherent settinglevel components that have manifested through my interviews with project members.

Some project members dislike of the term empowerment. Similar to scholars who want the focus to be on true empowerment rather than mere participation which can 
further marginalize (Garcia-Iriate et al., 2009; Riger, 1993), some project members discussed the political connotations associated with empowerment which limited their use of the term. A couple academic partners described their view that no one can empower anyone else. Like Trickett (1991), they believe individuals need to engage in an empowerment process on their own. This reflects the idea that the process of trying to empower others actually hinders individuals from becoming empowered (Gruber \& Trickett, 1987; Riger, 1993). Academic partners' goal of creating a space that provides an opportunity for community partners to realize their marginalization and the importance of their voice (Dworski-Riggs, 2010) through respect, shared leadership, development of skills and knowledge, and direct and welcomed influence parallels empowerment theory (Fawcett et al., 1994; Maton, 2008; Zimmerman, 1990).

\section{Empowerment and CBPR}

Settings that create an opportunity for individuals to be engaged and provide an opportunity for individuals to establish or re-establish the importance of their voice have shown to promote empowerment (Atkinson, 2004; Ham et al., 2004; Oden et al., 2010). Again reflecting on Maton's (2008) definition of inclusion allowing for individuals to gain control, inclusion is a component to gaining empowerment noted by many community partners. Through inclusion, individuals are able to see the barriers placed on them and gain control back (Dworski-Riggs, 2010). Both community and academic partners emphasizing the value of inclusion and gaining the perspective of all project members, allows for a space where individuals can realize their importance and begin to gain mastery and control of a setting. Community partners identified accommodations, 
including providing American-sign language interpreters and sending files in an appropriate format. Academic partners discussed avoiding jargon and acronyms, speaking and presenting materials in plain language, and meeting in a space that was acceptable to all group members. These accommodations allowed community partners the opportunity to contribute and have a meaningful role within the project.

Providing the space for individuals to be meaningfully engaged may have promoted feelings of belonging and membership allowing them to go beyond basic inclusion. This reflects the idea that while inclusion is an important aspect to empowerment, it is also important that individuals realize their value within a group. As an individual begins to realize her or his value, they begin to or continue to influence a project. In $\mathrm{CBPR}$, this bridge can be built through respect, trust, and knowledge gaining and sharing (Christopher et al., 2008; Dworski-Riggs \& Langhout, 2010; Minkler \& Wallerstein; 2008). Community partners overwhelmingly discussed how they felt confident providing their opinions because of the trust and respect that was either present from the beginning or grew over time. Additionally, co-learning, which is a core principle of CBPR (Israel et al., 2003), was seen through both community and academic partners acknowledging the affect the process has within their lives. In many ways, it seems apparent that these characteristics of the partnership played a part in community partners becoming empowered. Again, however, simply providing an opportunity for people to participate does not lead to empowerment (Riger, 1993).

Importantly, many community partners expressed that they were able to affect change within the project. Additionally, several community partners provided examples 
of ways in which they felt they had directly influenced the project and shared a leadership role with academic partners. For example, community partners talked about their suggestions being considered and implemented without scrutiny, creating the project logo, and influencing the research process, which included changing the meetings processes, modifying the measures, implementing their work into the community, and helping with recruitment. Since having influence and power is considered an empowering mechanism (Fawcett et al., 1994; Maton, 2008), this may have contributed to community partners feeling empowered within the project. Academic partners also noted examples of community partners' input making the project better and being directly implemented, which included adaptation of measures, accessibility of the survey technology, and assisting with recruitment materials. Because of the community and academic partners' reflections on the impacts community partners had on the project, I have concluded that community partners were not simply token members of the project.

Despite project members feeling their involvement on a CBPR project did not hinder them becoming empowered, I did identify some components that may, in some ways, disempowered community partners. These included some instances of inaccessible communication or language and lack of project ownership, which was identified through lack of researcher identity and acknowledging academic partners as the leaders of the project. These components represented a contrast to what is proposed by authors as a context conducive to empowerment (Gruber \& Trickett, 1987; Maton, 2008; Zimmerman, 1990). However, with the few mentioned incidents of possibly disempowering components of the partnership, overall, the collaboration seemed to 
promote empowerment based on accessibility of the project, inclusion, co-learning, and power sharing.

Empowerment within CBPR may be related to the cyclical nature of the CBPR process (Israel et al., 2003; Minkler \& Wallerstein, 2008; Stringer, 1996) because it provides a space for project members to reflect on things that are and are not working well for all project members. The overall evaluation provided Partnering Project members with the opportunity to reflect. Additionally, Portland project members have the opportunity at the end of each $\mathrm{CAB}$ meeting to reflect on things they would like to keep and things they would like to change. This provides an ongoing opportunity for change to be made at the research process and group evolves. The cyclical process builds on the trust and respect that has developed. It allows for individuals to feel comfortable expressing opinions, which may result in disempowering situations being ameliorated.

Overall, setting-level components of the partnership and many individuals identifying being empowered through the CBPR process supports that a CBPR process can be an empowering process for individuals with developmental disabilities. The findings relate to the model I created. Specifically, meaningful collaboration, providing accommodations, and valuing inclusion leads to a sense of community built through respect, communication, mutual relationships, and trust. This relates to an equal partnership based on shared decision-making, shared leadership, and co-learning. These components of the CBPR process have ultimately led to community partners becoming empowered. But, again, it is possible that too much credit is given to characteristics of a 
CBPR process that may be empowering (Björnsdóttir \& Svensdóttir, 2008; Goodley, 1999).

\section{Empowerment redefined}

When asked about the evolution of what empowerment means, a couple community partners mentioned that it had changed how they think of empowerment. However, only one project member was able to directly identify how her definition of empowerment evolved over time. This probably closely relates to the stability of empowerment as a concept even though it has several interpretable meanings amongst project members. Community partners, in most cases, identified their view of empowerment remaining stable overtime.

\section{Multisite project: Montana and Portland}

There were few noticeable differences between ideas shared by community partners on the Portland team and Montana team that related to the research questions within this project. This may have been a result of the timing of the individual interviews. Through other communications with project members, it is clear that some changes were made in the CBPR process along the course of the project in both locations. For example, because of communication difficulties across sites for some steering committee members, project communication was restructured. Some partners were unable to participate in phone conversations, while others were unable to participate in text communications. It is possible that the communication barriers that existed in some meetings may have been 
disempowering for some community partners. In a sense, those involved in meetings that had the communication mechanisms of choice were the ones with the most power because they were able to contribute. It would be interesting to have assessed empowerment during this stage of the process and after to identify how empowerment may have been affected. Again, the cyclical reflection process that has been implemented within the group seems to provide a space where changes can be made to ensure all project remain comfortable in the process.

Unique to the Montana team, several community partners talked about the group dynamic representing a family. They mentioned how they worked well together, but they felt the project seemed more like a gathering of friends than work. This may reflect unique personalities in both groups. In CBPR, it is necessary to work in a way that is most beneficial for all project members. Project members need to continuously be flexible throughout the process and the project should reflect the uniqueness and needs of the project members in order to be successful (Minkler \& Wallerstein, 2008). Additionally, in Montana, the principal investigator did not initially attend CAB meetings. Therefore, the Montana CAB may have developed into a more discussionbased group, which was able to bond over shared ideas, rather work progress. In Portland, the group has work as a decision-making body focused on the progression and implementation of decisions being made, which may have resulted in less informal, nonwork rapport development.

Important to note is that no community partners on the Montana team had engaged in a CBPR project prior to the Partnering Project. Academic partners in 
Montana have engaged in collaborative work in the past with a community-based focus. However, the concepts embedded in CBPR were new in practice to the academic partners. In Portland, several project members have engaged in CBPR, including two community partners. Both of these community partners noted differences between their other CBPR projects and the Partnering Project. Again, this represents how even with several of the same individuals on multiple projects that the uniqueness of the research question, goals, and the group make-up can alter the way a team effectively utilizes CBPR ideas in a way that works for any particular group (Minkler \& Wallerstein, 2008).

\section{Strengths}

There are several strengths of this current study. First, relying on project members' responses to empowerment definitions to guide my analysis allowed me to feel more confident attributing certain CBPR characteristics as empowering for community partners within the process because it served as a reliability check to ensure community partners and I were discussing the same concept. Their voices contributed to my overall understanding of what empowerment can look like to people with developmental disabilities within a CBPR project.

I have also followed the guidelines discussed by Guba (1981) to establish trustworthiness of my findings and interpretations. Guba (1981) contends there are four criteria for establishing trustworthiness: 1) credibility, 2) transferability, 3) dependability, and 4) confirmability.

I established credibility, or representing the multiple realities revealed by project members, through my prolonged engagement with project members and data, engaging in 
peer debriefing, establishing triangulation, and conducting member checks. This was a way to check that I was making accurate descriptions and interpretations of the experience of project members on a CBPR project (Guba, 1981). I became a part of the project about mid-way through the first year, and I have been involved in the overall evaluation of this project in many ways. This has allowed me to meet and build rapport with many of the project members before conducting the individual interview with them. Building rapport along with the use of qualitative methods to allow participants voices to be heard, specifically for persons with developmental disabilities, is believed to enhance the quality of data (Aldridge, 2007). I think the relationships I have built with project members over the course of our work together has provided the opportunity for them to feel comfortable sharing their true feelings about their work on a CBPR project with me. It also helped me feel more comfortable during the individual interviews, including a space to make mistakes and grow as a novice researcher. Additionally, I have been involved in all data collection and analysis for this study. I conducted, transcribed, and analyzed all the interviews that took place with the community and academic partners. This repeated contact with the data, including looking at the data from a different lens, has allowed me to become deeply familiar with the words of the project members and discover the emergence of various patterns (Lincoln \& Guba, 1985). In terms of peer debriefing, Dr. McDonald assisted with my understanding of this work as it developed. This was particularly important during data analyses when I could feel myself losing sight of the particular research questions I was trying to answer. I changed my codebook through this process, which is suggested by Guba (1981) as a way to check in throughout 
the debriefing process. Dr. McDonald and I engaged in an iterative process as I developed my codes and presented my findings. This provided a reliability check of the developed codes. The last process I engaged in to establish credibility was complete member checks with all 21 project members who engaged in individual interviews. This allowed me to make sure I was interpreting the statements made by individuals in the way that they had hope.

Next, to establish transferability, I attempted to provide highly descriptive explanations of my results and interpretations in order for the lessons learned through this process to be effectively transferred to other CBPR contexts (Guba, 1981).

Empowerment in CBPR with persons with developmental disabilities is an underexplored topic. Rich descriptions make it possible for other parties interested in conducting CBPR, specifically with persons with developmental disabilities, the opportunity to engage in a process that can be empowering for community partners.

To establish dependability, or "trackable variability" (Guba, 1981, p. 81), of results includes identifying and examining possibilities of inconsistency (Guba, 1981). I engaged in a process of triangulation to establish dependability in this study. I looked at community and academic partners data from individual interviews to establish consistencies and inconsistencies across groups. Triangulation is also a process of establishing the forth standard of merit, confirmability. To further represent confirmability within my project, I engaged in a self-reflexive process where I have revealed my epistemological assumptions where so my biases are known.

\section{Limitations}


Some limitations exist in this current study. In terms of transferability, I did not engage in purposive sampling or sampling that attempts to engage various viewpoints on the same subject. In a way, I was able to get all the opinions of the project members on the Partnering Project, but this does not representing all CBPR teams in partnerships with persons with developmental disabilities. This was a part of the project that was out of the scope of this work. Furthermore, a suggestion to establishing transferability is to collect descriptively rich data (Guba, 1981). This was the first time in my work that I had conducted interviews of this intensity. I have taken a qualitative methods class where we read about, discussed, and engaged in the interview process. Despite this, the most important lessons I learned developed out of experience. I implemented what I could and learned from my mistakes and successes with some interviews being more successful than others. A lot of what I learned is discussed in the literature. Actually conducting the interviews allowed me to find ways some of these things would work for me. I learned that being more prepared and comfortable asking following up questions is necessary. I also learned to feel more comfortable with taking time to make sure I am asking all questions. This includes realizing that participants have agreed to be a part of the study, they have the option to opt out or discontinue participation at any time during the process, and, for the most part, I believe project members wanted to be as informative as possible. Furthermore, building rapport is as important for the participant as it is for the interviewer. I found myself feeling more comfortable talking with some project members than others, and the length and depth of those conversations reflected that. It is possible that I did not capture all aspects of the individual and CBPR setting that may have 
affected empowerment because I did not ask follow-up questions when they were warranted. Additionally, it is possible that my uneasiness in some interviews made the project members uncomfortable, which limited their responses. Upon reflection with my advisor, I still have many things to learn, but I feel this opportunity has been successful overall for my development and in providing support for my questions of inquiry.

In terms of relationships with project members, being in Portland and having the opportunity to engage with the Portland $\mathrm{CAB}$ more often that with the Montana $\mathrm{CAB}$ has given me the chance to know Portland project members in a different way than Montana project members. This became most noticeable when conducting the individual interview with two community partners in Montana. The individual interview was the first time I had met them in person. One of these individuals is on the $\mathrm{SC}$, so we talk regularly over the phone and through email. In this case, I felt comfortable about the rapport that had been built between us. With the other individual, I had engaged in many email exchanges prior to meeting and upon meeting it appeared he was comfortable because we discussed a broad range of topics before getting into the interview. But, it is possible the lack of rapport that is suggested in qualitative research (Lincoln \& Guba, 1985) may have effective the interview.

Along those same lines, because I collect reflections from SC members, I have engaged with community partners on the SCs on a more regular basis than community partners on the CABs. Additionally, community partners on the SCs have seen and heard questions that are similar to the interview questions more times than community partners on the CABs. These individuals therefore have had more time to reflect on the questions I 
asked, and this could have possibly affected their responses. It is also possible they could have held back some information that they have or felt they have already expressed in their monthly reflections.

Furthermore, it took me four and a half months to conduct all the interviews. I had initially hoped all interviews would be collected within two months in order to ensure all project members were reflected on the same time point of the project. Due to conflicting schedules and the multisite nature of the project, this was not possible. Though I was able to collect all interviews during the data collection phase of the project, it is possible experience outside the project may have affected responses. Additionally, some community partners throughout and after their interviews commented on the difficulty and length of the interviews. I was able to talk through most of the difficulties with individuals involved, but it still is possible that I was disempowering community members through the interview process possibly causing them not to share as much as they would have if they felt more comfortable with the questions being asked. It is also possible that I did not get full answers to some questions due to lack of understanding. Empowerment and disempowerment ideas are complex. I coded lack of researcher identity, examples of lack of power sharing, and example of unequal influence as disempowerment in order to examine the full range of work within the project. It is possible these things do not necessarily always equate to an individual being or feeling disempowered. I feel I would need to analyze what individuals hoped to get out of their engagement on the project separate from what is discussed by the group in order to identify individual empowerment. 
Community partners' and scholarly definitions of empowerment emphasize knowledge as a mode to empowerment (Minkler \& Wallerstein, 2008; Zimmerman, 2000). Additionally, CBPR scholars discuss the co-learning process (Israel et al., 2003; Minkler \& Wallerstein, 2008). In all the interviews, community partners discussed learning a variety of things from their involvement on the project. Additionally, several mentioned their contributions to the project I assume led to learning by other project members, but it was difficult in most cases to make a confident connection. Therefore, I coded examples of learning and co-learning together. It is possible that this caused me to identify more examples of co-learning than may have been present in the group. It is possible that I also missed many examples of knowledge being gained. However, many academic partners also mentioned learning things from the project, partnership, and the community members, which illustrate a co-learning atmosphere.

Finally, it has been noted that the responses provided by the community partners on the project express overwhelming gratitude toward academic partners for providing a space where community partners feel empowered. While this represents a positive outcome of the developed relationships, there is potential risk of these positive feelings of empowerment developing within the project and little good being done to change the community as a whole. Relatedly, empowerment was only examined within the CBPR context. It is anticipated that empowerment behaviors and feelings will translate to other areas of community partners' lives, but that was outside the scope of this current project. However, it should be noted that translation of empowerment outside of the CBPR context might be limited. 


\section{Implications and Conclusions}

CBPR has rarely been studied empirically though it is often celebrated. The knowledge gained from this study about promoting empowerment in CBPR can serve to inform others conducting CBPR projects collaborating with persons with developmental disabilities and others who experience similar marginalization. Persons with developmental disabilities have often been excluded from research (Juritzen et al., 2011; McDonald \& Keys, 2008). CBPR provides an opportunity for persons with developmental disabilities to be included in the research processes as well as possibly gain important qualities throughout, such as empowerment. Inclusion of persons with disabilities in research gives them a space for their voice to be heard and to create the positive social change they hope to see in their communities. It also helps academic partners establish research questions that can be answered by and implemented into the community more readily. Academic partners also benefit from community members urgency community members bring to a project, which can also be reflected in community members commitment to successful project outcomes (Israel et al., 1998; Minkler \& Wallerstein, 2008).

In disability research, there have been increasingly more attempts made to include persons with developmental disabilities in the research process (Walmsley, 2001). Including persons with developmental disabilities in the research process can serve to benefit both persons with developmental disabilities, as well as the research process (Bigby \& Frawley, 2010; Conder et al., 2011). Despite the noted positive outcome of empowerment because of the utilization of CBPR with persons with developmental 
disabilities (Atkinson, 2004; Björnsdóttir \& Svensdóttir. 2008; Conder et al., 2011;

Paiewonsky, 2011; Williams, 2005; Williams \& Simons, 2005), it is important to provide empirical evidence to support and inform the benefits of utilizing a CBPR approach, specifically empowerment of community partners. This study provides support that a CBPR process can be empowering for community partners. It also provides contextual components that can be emulated by other project in order to promoted community partner empowerment. Most importantly inclusion, accessibility, co-learning between project members, and power sharing are noted as empowering CBPR components.

It is important to empirically study what aspect of a CBPR project promote empowerment in the lives of persons with and without developmental disabilities on a CBPR project in order to ensure empowerment is an outcome of the process. Empowerment is beneficial to communities looking to promote positive social change because it can create communities that are more fully inclusive and continuously working toward community betterment for all community members (Maton, 2008). Providing a built in structure to reflect, like the current overall evaluation, has provided a concrete way for Partnering Project members to reflect on their work. I think both these aspects of this current project can help others looking to engage in this work in a positive way. Community and academic partners have repeatedly thanked me for the work Dr. McDonald and I have been doing and for giving them to opportunity to reflect on their partnership and understand how they as a group feel about the partnership through the evaluation reports provided to the team. The cyclical nature and reflection process is a core principle of CBPR (Israel et al., 2003), but I think more focus should be placed on a 
formalized reflection process where project members share their thoughts about the partnership and these findings are reported more often in the literature.

It has been noted that community members who are involved on CBPR project are already empowered and therefore understand the importance of having their voices heard (Minkler \& Wallerstein, 2008). It is possible that this may have been the case in this study, as several community partners are engaged in other CBPR projects or are active members in disability advocacy groups. Disability self-advocacy groups provide a space for persons with developmental disabilities to acquire leadership skills as other means such as school and employment activities are sometimes limited (Caldwell, 2010). Most project members have worked with others on the team in other self-advocacy work. While established relationships have been a way to avoid time to build trust (Minkler \& Wallerstein, 2008) and access to a leader to represent communities has been a strategy in CBPR work (Minkler \& Wallerstein, 2008), I think individuals looking to engage in CBPR work need to make sure there is diversity within the individuals representing the community, and to avoid only the most powerful within the community being involved. This creates a tension between building trust and relationships to promote a continued and long-term collaboration and making sure the same people are not being called on to represent a large community. I believe the established relationships could led to connecting with more marginalized individuals within the community and promoting a more diverse inclusion. Caldwell (2010), in his study of disability self-advocacy group leaders, makes a call for more leadership opportunities for persons with developmental disabilities. I think participation in CBPR can be an opportunity for persons with 
developmental disabilities to be involved and promote positive social change for the disability community.

Additionally, CBPR projects are generally conducted at the local level (Minkler \& Wallerstein, 2008). The multisite aspect of the Partnering Project was unique for a CBPR project. In addition to the above mentioned communication issues that existed before the enactment of the separate site steering committees, some community members on the CABs mentioned being disappointed they have never had communication with the project members at the other site. In most cases, keeping a CBPR collaboration at a local level may be the best option. However, when partnerships do span across sites, I think it would be beneficial and empowering for all group members to understand the scope of the project as a whole, which includes meeting all project members involved.

Finally, this study adds to the literature because it attempts to identify which aspects of a CBPR project can be empowering and disempowering. It also provides more evidence that the CBPR process in itself can be empowering for community partners with and without developmental disabilities. Future research should continue to evaluate and document the process of CBPR partnerships, as well as reflections by community members in order to continue to enhance collaborations in order to produce positive outcomes for all project members. 
Table 1. The Partnering Project Demographic Information

\begin{tabular}{|c|c|c|c|c|c|}
\hline \multicolumn{6}{|c|}{ Location } \\
\hline $\begin{array}{l}\text { Demographic } \\
\text { Information }\end{array}$ & $\begin{array}{c}\text { Montana } \\
\text { Academic } \\
\text { Partners } \\
\mathrm{N}(\%) \\
\end{array}$ & $\begin{array}{c}\text { Montana } \\
\text { Community } \\
\text { Partners } \\
\mathrm{N}(\%) \\
\end{array}$ & $\begin{array}{c}\text { Portland } \\
\text { Academic } \\
\text { Partners } \\
\text { N (\%) } \\
\end{array}$ & $\begin{array}{c}\text { Portland } \\
\text { Community } \\
\text { Partners } \\
\mathrm{N}(\%) \\
\end{array}$ & $\begin{array}{r}\text { Total } \\
\text { N (\%) }\end{array}$ \\
\hline $\begin{array}{l}\text { Age } \\
\qquad \begin{array}{l}18-30 \\
31-40 \\
41-50 \\
51-60 \\
61 \text { and older }\end{array}\end{array}$ & $\begin{array}{c}1 \\
-- \\
-- \\
-- \\
2\end{array}$ & $\begin{array}{l}2 \\
2 \\
2 \\
-- \\
1\end{array}$ & $\begin{array}{c}-- \\
-- \\
2 \\
1 \\
--\end{array}$ & $\begin{array}{l}1 \\
2 \\
2 \\
1 \\
2\end{array}$ & $\begin{array}{l}4(19) \\
4(19) \\
6(29) \\
2(10) \\
5(24) \\
\end{array}$ \\
\hline $\begin{array}{l}\text { Gender } \\
\text { Female } \\
\text { Male }\end{array}$ & $\begin{array}{l}3 \\
-- \\
\end{array}$ & $\begin{array}{l}5 \\
2 \\
\end{array}$ & $\begin{array}{c}3 \\
--\end{array}$ & $\begin{array}{l}5 \\
3 \\
\end{array}$ & $\begin{array}{c}16(76) \\
5(24) \\
\end{array}$ \\
\hline $\begin{array}{l}\text { Race } \\
\text { Caucasian/White } \\
\text { Multiracial } \\
\text { Native American }\end{array}$ & $\begin{array}{l}3 \\
-- \\
-- \\
\end{array}$ & $\begin{array}{l}6 \\
-- \\
1 \\
\end{array}$ & $\begin{array}{c}3 \\
-- \\
-- \\
\end{array}$ & $\begin{array}{r}7 \\
1 \\
-- \\
\end{array}$ & $\begin{array}{c}19(90) \\
1(5) \\
1(5) \\
\end{array}$ \\
\hline $\begin{array}{l}\text { Education } \\
\text { Some grade school } \\
\text { High school diploma } \\
\text { Some college } \\
\text { Bachelor's degree } \\
\text { Master's degree } \\
\text { Juris doctorate } \\
\text { Doctoral degree } \\
\text { Medical degree } \\
\end{array}$ & $\begin{array}{l}-- \\
-- \\
-- \\
-- \\
-- \\
1 \\
-- \\
2 \\
--\end{array}$ & $\begin{array}{l}1 \\
1 \\
3 \\
1 \\
1 \\
-- \\
-- \\
--\end{array}$ & $\begin{array}{l}-- \\
-- \\
-- \\
-- \\
-- \\
-- \\
2 \\
1\end{array}$ & $\begin{array}{l}-- \\
3 \\
1 \\
2 \\
2 \\
1 \\
-- \\
--\end{array}$ & $\begin{array}{l}1(5) \\
4(19) \\
4(19) \\
3(14) \\
4(19) \\
3(14) \\
4(19) \\
1(5) \\
\end{array}$ \\
\hline $\begin{array}{l}\text { Identity } \\
\text { Person with } \\
\text { disability } \\
\text { Family member } \\
\text { Ally } \\
\text { Support provider } \\
\text { Domestic violence } \\
\text { service provider }\end{array}$ & $\begin{array}{l}2 \\
2 \\
3 \\
-- \\
--\end{array}$ & $\begin{array}{l}6 \\
4 \\
3 \\
1 \\
1\end{array}$ & $\begin{array}{c}1 \\
2 \\
3 \\
-- \\
--\end{array}$ & $\begin{array}{l}8 \\
2 \\
2 \\
1 \\
--\end{array}$ & $\begin{array}{l}17(81) \\
10(48) \\
11(52) \\
2(10) \\
1(5)\end{array}$ \\
\hline $\begin{array}{l}\text { Employment } \\
\text { Full-time } \\
\text { Part-time } \\
\text { Volunteer } \\
\text { Self-advocacy } \\
\text { Student } \\
\text { Retired } \\
\text { Unemployed } \\
\end{array}$ & $\begin{array}{l}3 \\
-- \\
-- \\
-- \\
-- \\
-- \\
--\end{array}$ & $\begin{array}{l}1 \\
1 \\
3 \\
3 \\
2 \\
-- \\
--\end{array}$ & $\begin{array}{l}3 \\
-- \\
-- \\
-- \\
-- \\
-- \\
--\end{array}$ & $\begin{array}{l}2 \\
-- \\
-- \\
2 \\
-- \\
1 \\
2 \\
\end{array}$ & $\begin{array}{c}9(43) \\
1(5) \\
3(14) \\
5(24) \\
2(10) \\
1(5) \\
2(10) \\
\end{array}$ \\
\hline Total & $3(14)$ & $7(33)$ & $3(14)$ & $8(38)$ & 21 \\
\hline
\end{tabular}

Note: "—_ indicates zero (0) projects reporting a category. 
Figure 1: The Partnering CBPR process model (adapted from AASPIRE)

\section{Community}

\section{KEEPS RESEARCH ETHICALLY SOUND AND SOCIALLY RELEVANT}

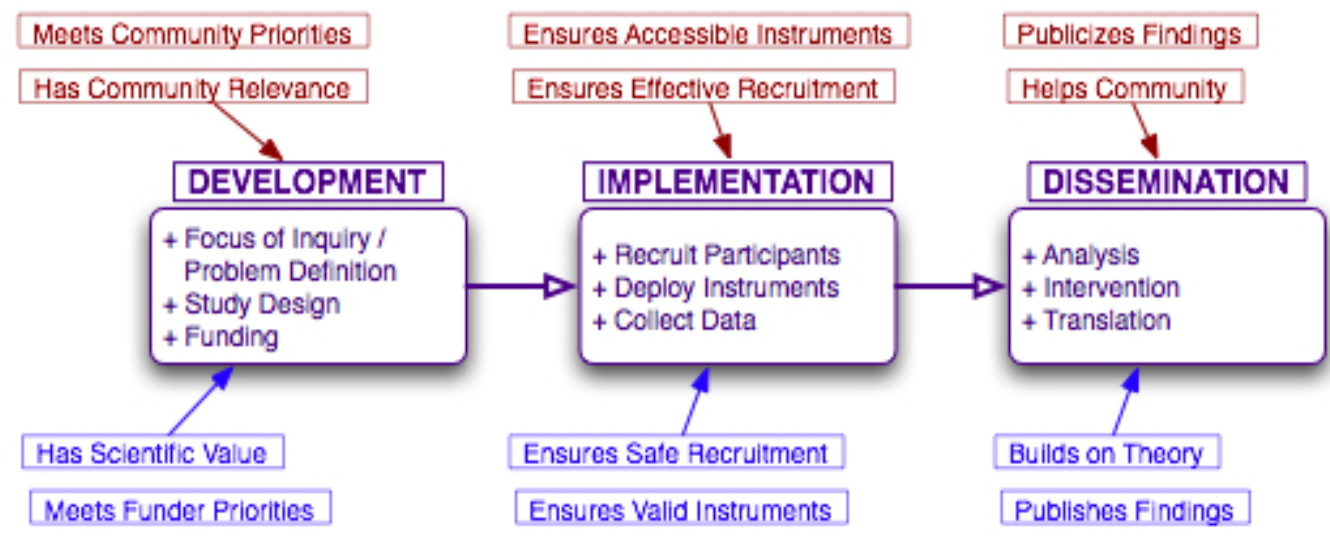

CBPR

Process

KEEPS RESEARCH SCIENTIFICALLY SOUND AND ACADEMICALLY RELEVANT

\section{Researchers}

(Nicolaidis et al., 2011) 
Figure 2: CBPR Conceptual Logic Model

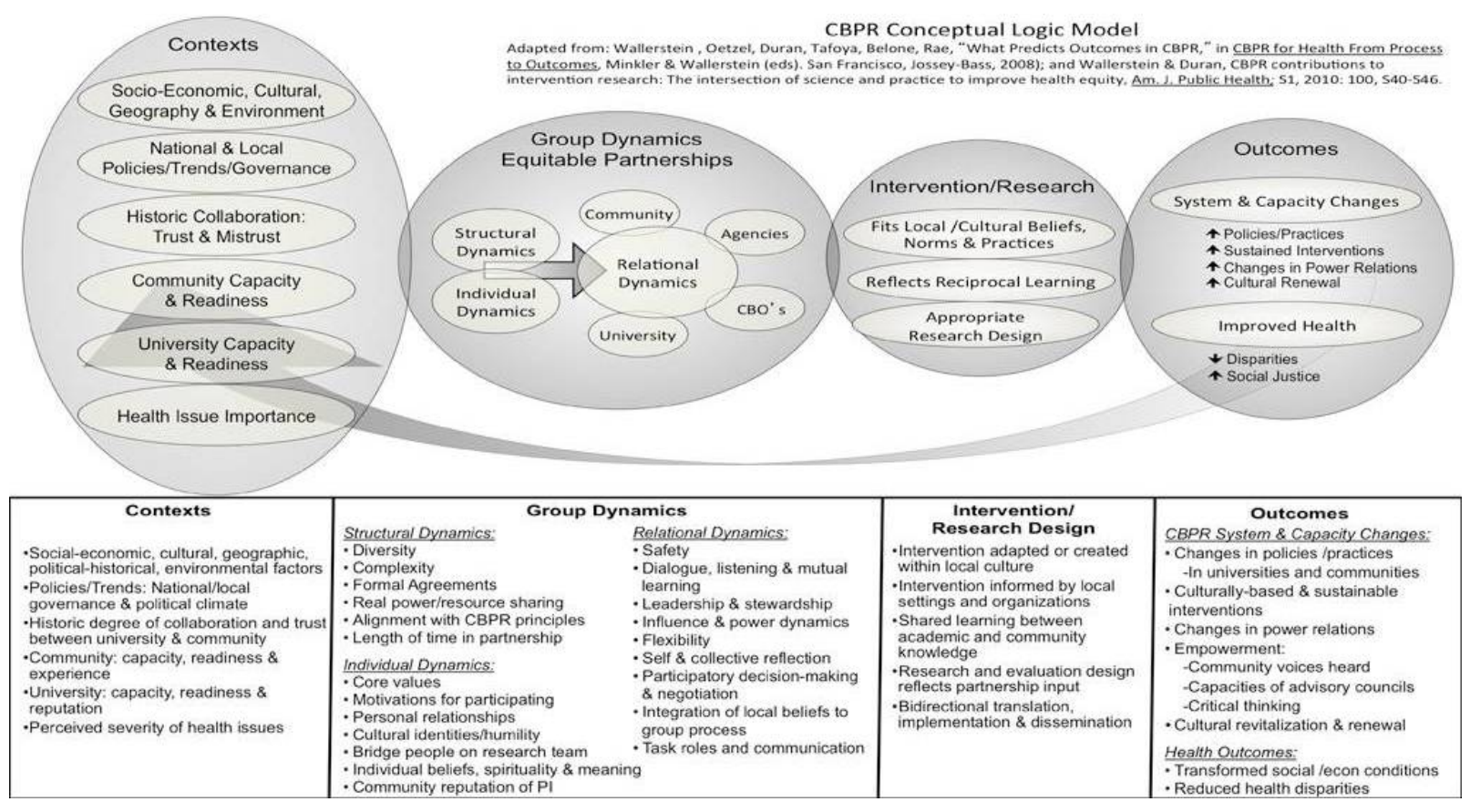

(Wallerstein et al., 2008). 
Figure 3: Community-Based Participatory Research with Persons with Developmental Disabilities Concept Model

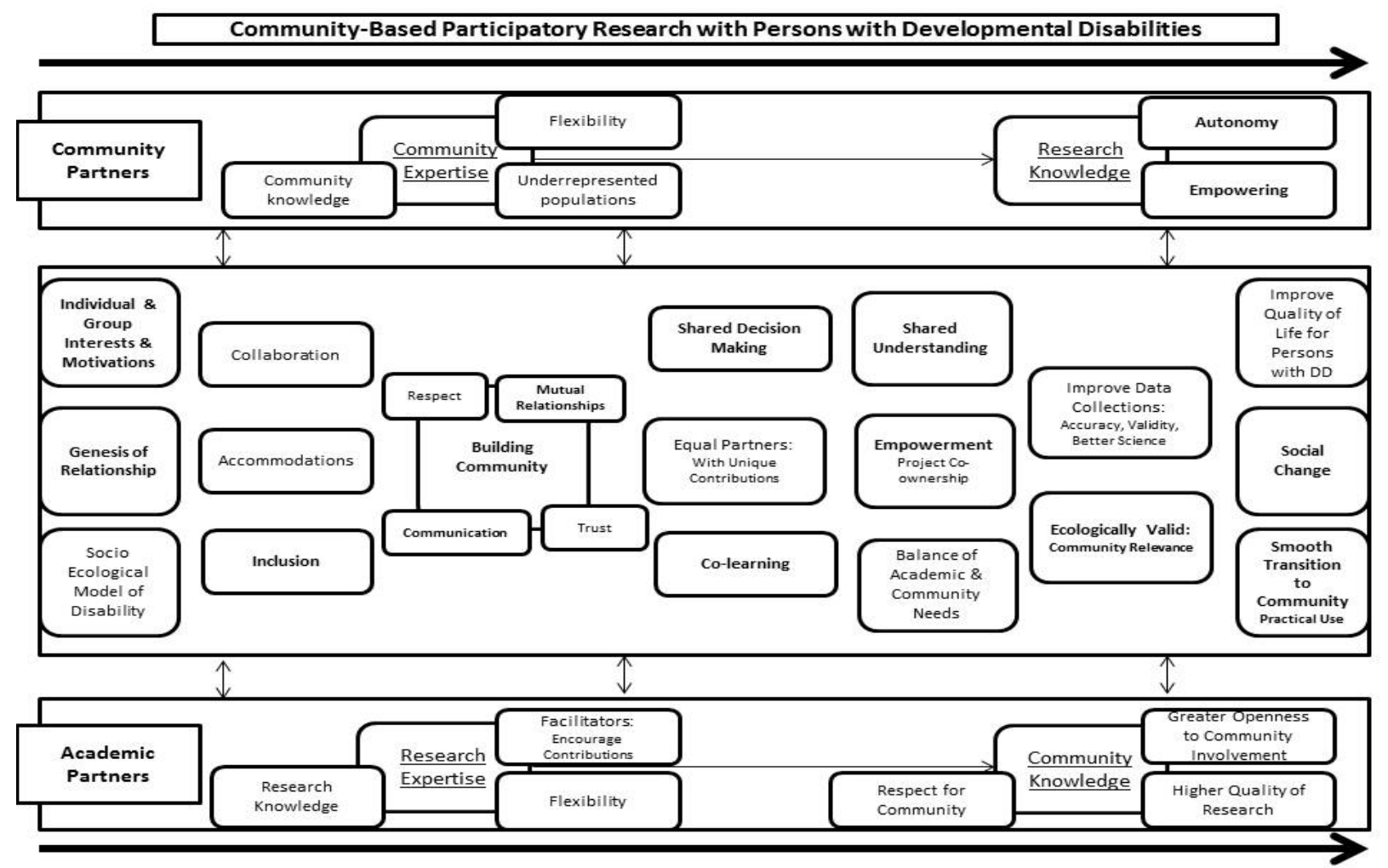

* Bolded items indicate concepts that overlap with Wallerstein and colleagues's conceptual logical model of CBPR. 
Figure 4: Partnering Project Infrastructure Model

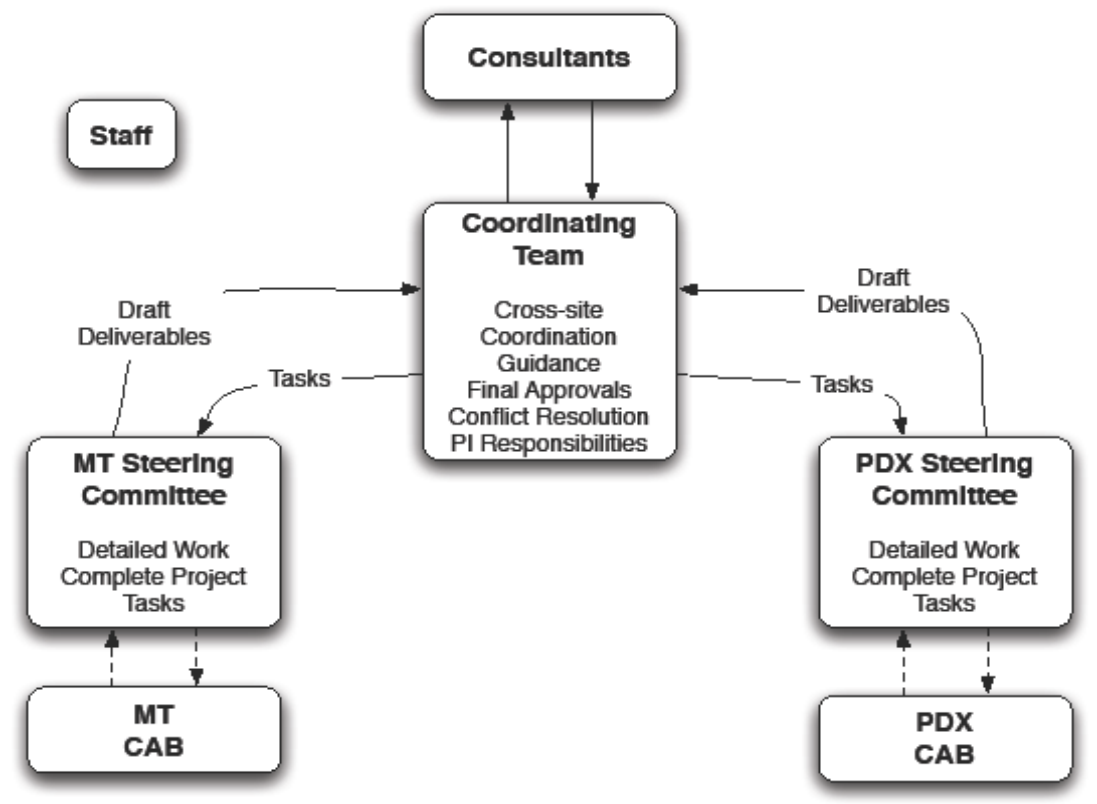

Partnering Project Infrastructure Model 2011/02/02 
Figure 5: Ecological model of Empowerment in CBPR: Expressions of and Influences on Empowerment within CBPR

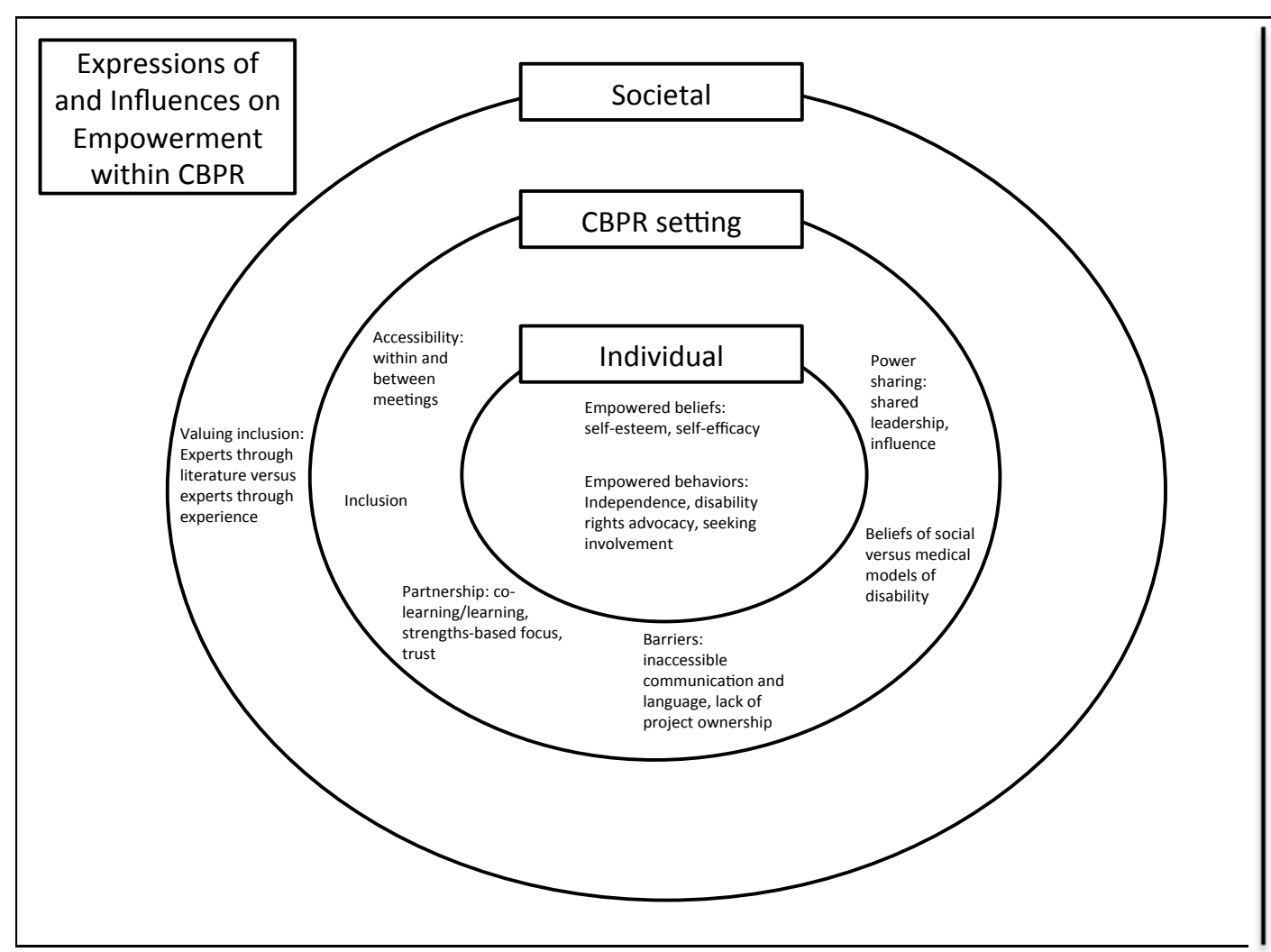


Figure 6: Setting Barriers and Facilitators in Individual Empowerment

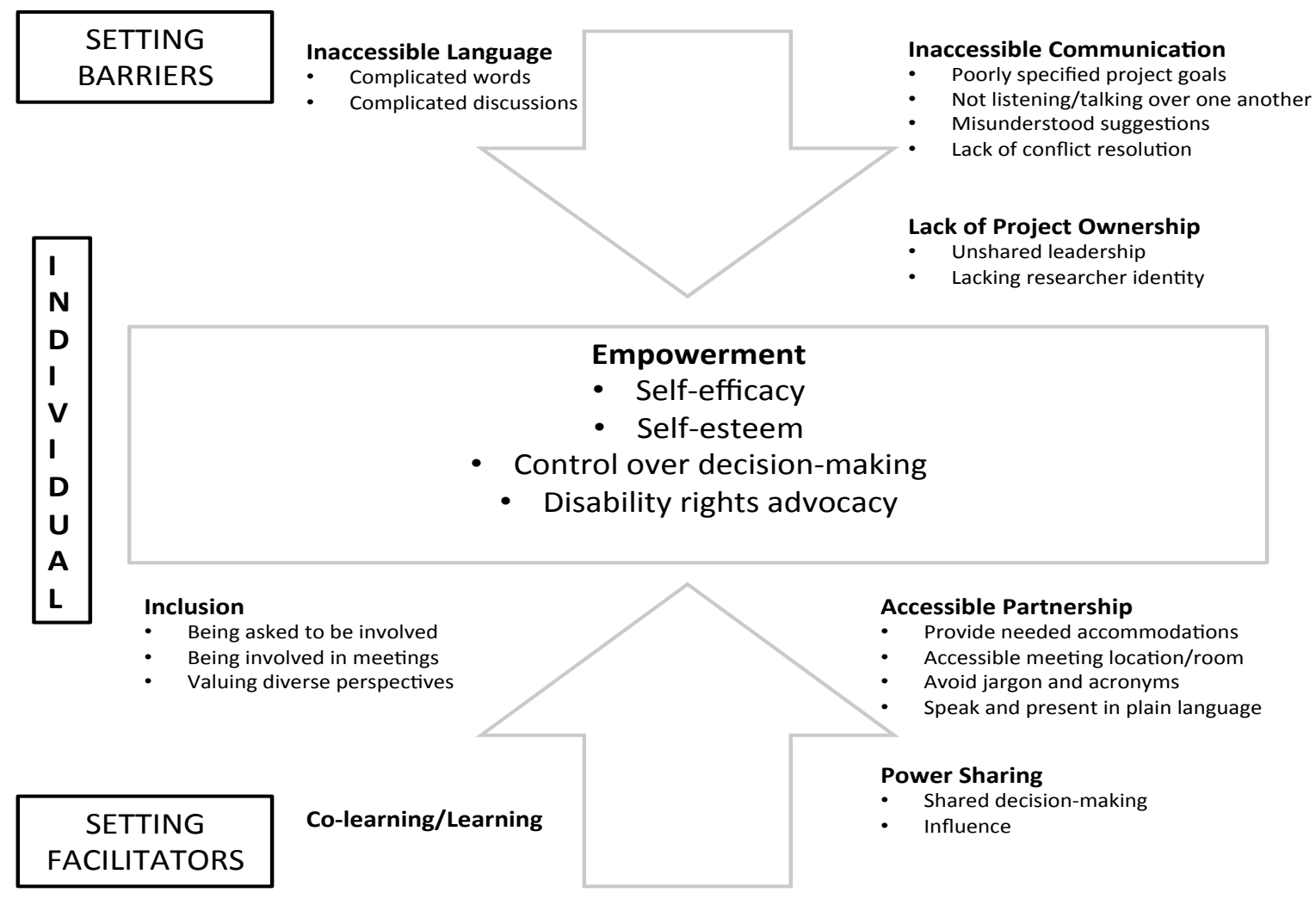




\section{References}

Aldridge, J. (2007). Picture this: The use of participatory photographic research methods with people with learning disabilities. Disability \& Society, 22(1), 1 - 17.

Atkinson, D. (2004). Research and empowerment: involving people with learning difficulties in oral and life history research. Disability \& Society, 19(7), 691 702.

Balcazar, F.E., Keys, C.B., Kaplan, D.L., \& Suarez-Balcazar, Y. (2006). Participatory action research and people with disabilities: Principles and challenges. Canadian Journal of Rehabilitation, 12(2), 105-112.

Bastida, E. M., Tseng, T.S., McKeever, C., \& Jack, L., Jr. (2010). Ethics and communitybased participatory research: Perspectives from the field. Health Promotion Practice, 11 (1), 16-20.

Bigby, C. \& Frawley, P. (2010). Reflections on doing inclusive research in the "Making Life Good in the Community" study. Journal of Intellectual \& Developmental Disability, 35 (2), $53-61$.

Björnsdóttir, K. \& Svensdóttir, A.S. (2008). Stuck in the land of disability? The intersection of learning difficulties, class, gender, and religion. Disability \& Society, 25(1), $49-62$.

Bonham, G.S., Basehart, S., Schalock, R.L., Marchand, C.B., Kirchner, N., \& Rumenap, J.M. (2004). Consumer-based quality of life assessment: The Maryland Ask Me! project. Mental Retardation, 42 (5), 338 - 355. 
Boog, B.W.M. (2003). The emancipatory character of action research, its history and the present state of the art. Journal of Community and Applied Social Psychology, $13(6), 426-438$.

Bosner, S. (2006). Ethics and power in community-campus partnerships for research. Action Research, 4 (1), 9-21.

Brisenden, S. (1986). Independent living and the medical model of disability. Disability, Handicap, and Society, 1 (2), 173-178.

Brydon-Miller, M. (1997). Participatory action research: Psychology and social change. Journal of Social Issues, 53 (4), 657 - 666.

Caldwell, J., Hauss,S., \& Stark, B. (2009). Participation of individuals with developmental disabilities and families on advisory boards and committees. Journal of Disability Policy Study, 20 (2), 101 - 109.

Caldwell, J. (2010). Leadership development of individuals with developmental disabilities in the self-advocacy movement. Journal of Intellectual Disability Research, 54 (11), $1004-1014$.

Campbell, F. (2008). Exploring internalized ableism using critical race theory. Disability \& Society, $23(2), 151-162$.

Centers for Disease Control and Prevention (2011). Developmental Disabilities: Topic Home. Retrieved April 16, 2011 from http://www.cdc.gov/ncbddd/dd/default.htm. 
Chappell, A.L. (2001). Emergence of participatory methodology in learning difficulty research: Understanding the context. British Journal of Learning Disabilities, 28 (1), $38-43$.

Charlton, J.I. (1998). Nothing about us without us: Disability oppression and empowerment. Berkeley, CA: University of California Press.

Chataway, C.J., (1997). An examination of the constraints on mutual inquiry in a participatory action research project. Journal of Social Issues, 53 (4), 747 - 765.

Christopher, S., Watts, V., McCormick, A., \& Young, S. (2008). Building and maintaining trust in a community-based participatory research partnership. American Journal of Public Health, 98 (8), 1398 - 1406.

Clements, J., Rapley, M., \& Cummins, R. A. (1999). On, to, for, with- vulnerable people and the practices of the research community. Behavioural and Cognitive Psychotherapy, 27 (2), 103-115.

Cocks, E. \& Cockram, J. (1995). The participatory research paradigm and intellectual disability. Journal of Applied Research in Intellectual Disability, 8 (1), 25 - 37.

Conder, J., Miller, P., \& Mirfin-Veitch, B. (2011). Reflections on a participatory project: The rewards and challenges for the lead researchers. Journal of Intellectual and Developmental Disability, $36(1), 39$ - 48.

Cook, W.K. (2008). Integrating research and action: A systematic review of communitybased participatory research to address health disparities in environmental and occupational health in the USA. Journal of Epidemiol Community Health, 62 (8), $668-676$. 
Corbin, J. \& Strauss, A. (1990). Grounded theory research: Procedures, canons, and evaluative criteria. Qualitative Sociology, 13 (1), 3 - 21.

Cornwall, A. \& Jewkes, R. (1995). What is participatory research? Social Science Medical, 41 (12), $1167-1176$.

Davidson, A. (2009). Producing self-advocacy videos through a process of collaborative research with adults living with intellectual disabilities. International Journal of Learning, $16(9), 687-698$.

Denzin, N.K. \& Lincoln, Y.S. (2005). The SAGE handbook of qualitative research. Thousand Oaks, CA: Sage Publications, Inc.

Dias, J., Eardley, M., Harkness, E., Townson, L., Brownlee-Chapman, C., \& Chapman, R. (2011). Keeping wartime memory alive: An oral history project about the wartime memories of people with learning difficulties in Cumbria. Disability \& Society, 27 (1), $31-49$.

Dowse, L. (2009). It's like being in a zoo.' Researching with people with intellectual disability. Journal of Research in Special Educational Needs, 9 (3), 141 - 153.

Dworski-Riggs, D. \& Langhout, R.D. (2010). Elucidating the power in empowerment and the participation in participatory action research: A story about research team and elementary school change. American Journal of Community Psychology, 45, 215-230.

Dybwad, G. \& Bersani, H. (1996). New voices: Self-advocacy by people with disabilities. Cambridge, MA: Brookline Books, Inc. 
Dye, L., Hendy, S., Hare, D. J., \& Burton, M. (2004). Capacity to consent to participate in research: A recontextualization. British Journal of Learning Disabilities, 32 (3), 144-150.

Erzinger, S. (1994). Empowerment in Spanish: Words can get in the way. Health Education Behavior, 21(3), 417 - 419.

Farrell, S., Aubry, T., \& Coulombe, D. (2004). Neighborhoods and neighbors: Do they contribute to personal well-being? Journal of Community Psychology, 32 (1), 925.

Fawcett, S.R., White, G.W., Balcazar, F.E., \& Suarez-Balcazar, Y. (1994). A contextualbehavioral model of empowerment: Case studies involving people with physical disabilities. American Journal of Community Psychology, 22 (4), 471-496.

Ferguson, D. (2004). Learning disability research: A discussion paper. Learning Disability Practice, 7 (6), 17-19.

Freedman, R. (2001) Ethical challenges in the conduct of research involving persons with mental retardation. Mental Retardation, 39(2), 130-141.

Freire, P., (1970). Pedagogy of the oppressed. New York, NY: Herder \& Herder.

Garcia-Iriarte, E., Kramer, J.C.,Kramer, J.M., \& Hammel, J. (2009). 'Who did what?': A participatory action research project to increase group capacity for advocacy. Journal of Applied Research in Intellectual Disabilities, 22(1), 10-22.

Goodley, D. (1999). Disability research and the "Researcher Template": Reflection on grounded subjectiveity in ethnographic research. Qualitative Inquiry, 5(1), 24 46. 
Goodley, D. (2000). Self-advocacy in the lives of people with learning difficulties. Buckingham, UK: Open University Press.

Goodley, D. \& Lawthom, R. (2005). Epistemological journeys in participatory action research: Alliances between community psychology and disability studies. Disability and Society, 20(2), $135-151$.

Green, L. W. (2004). Ethics and community-based participatory research: Commentary on Minkler. Health Education \& Behavior, 31 (6), 698-701.

Griffin, C. (1996). 'See whose face it wears': Difference, otherness, and power. Feminism \& Psychology, 6 (2), 185 - 191.

Gruber, J., \& Trickett, E.J., (1987). Can we empower others? The paradox of empowerment in the governing of an alternative public school. American Journal of Community Psychology, 15 (2), 253- 371.

Guba, E. (1981). Criteria for Assessing the Trustworthiness of Naturalistic Inquries. Education Communication and Technology, 29(2), 75 - 91.

Ham, M., Jones, N., Mansell, I., Northway, R., Price, L., \& Walker, G. (2004). 'I'm a researcher!' Working together to gain ethical approval for a participatory research study. Journal of Learning Disabilities, 8 (4), 397-407.

Higgins, D. L. \& Metzler, M. M. (2001). Implementing community-based participatory research centers in diverse urban settings. Journal of Urban Health, 78 (3), 488494.

Hill, J.L. (1996). Psychological sense of community: Suggestions for future research. Journal of Community Psychology, 24 (4), 431 - 438. 
Hines, A.M. (1993). Linking qualitative and quantitative methods in cross-cultural survey research: Techniques from cognitive science. American Journal of Community Psychology, 21 (6), 729-746.

Hughes, R. \& Katz, M. (April 27, 2011). A participatory approach to adapting measures of health and violence for use with people with developmental disabilities. Retrieved June 13, 2011 from http://www.aucd.org/resources/webinar_detail.cfm?event=2600\&parent=740.

Hughes, R.B., McDonald, K., Goe, R., Stack, E., \& Lund, E. (2010, November) Perspectives from the trenches: Using CBPR to study violence in adults with developmental disabilities. Symposium presented at Association of University Centers on Disability Conference, Washington D.C.

Israel, B.A., Schulz, A. J., Parker, E. A., \& Becker, A. B. (1998). Review of communitybased research: Assessing partnership approaches to improve public health. Annual Review Public Health, 19 (1), 173 - 202.

Israel, B. A., Schulz, A. J., Parker, E. A., Becker, A. B., Allen III, A. J., \& Guzman, J. R. (2003). Critical issues in developing and following community-based participatory research principles. In M. Minkler \& N. Wallerstein (Eds.), Community-based participatory research for health (pp. 53-76). San Francisco, CA: Jossey-Bass.

Jason, L., Keys, C., Suarez-Balcazar, Y., Taylor, R., \& Davis, M. (Eds.) (2004). Participatory community research: Theories and methods in action. Washington D.C.: American Psychological Association. 
Juritzen, T.I., Grimen, H., \& Heggen, K. (2011). Protecting Vulnerable Research Participants: A Foucault-inspired analysis of ethics committees. Nursing Ethics, $18(5), 640-650$.

Jurkowski, J.M. \& Paul-Ward, A. (2007). Photovoice with vulnerable populations: Addressing disparities in health promotion among people with intellectual disabilities. Health Promotion Practice, 8 (4), 358 - 365.

Jurkowski, J.M. \& Ferguson, P. (2008). Photovoice as participatory action research tool for engaging people with intellectual disabilities in research and program development. Intellectual and Developmental Disabilities. 46 (1), 1-11.

Jurkowski, J.M., Rivera, Y., \& Hammel, J. (2009). Health perceptions of latinos with intellectual disabilities: The results of a qualitative pilot study. Health Promotions Practice, 10 (1), $144-155$.

Kelly, J.G., (1971). Qualities for the community psychologist. American Psychologist, 26 (10), $897-903$.

Kiernan, C. (1999). Participation in research by people with learning disability: Origins and issues. British Journal of Learning Disabilities 27 (2), 43 - 47.

Knox M., Mok, M., \& Parmenter, T.R. (2000). Working with experts: Collaborative research with people with intellectual disability. Disability \& Society, 15 (1), 49 61.

Lantz, P. M., Viruell-Fuentes, E. A., Israel, B. A., Softley, D., \& Guzman, R. (2001). Can communities and academia work together on public health research? Evaluation results from a community-based participatory research partnership in Detroit. 
Journal of Urban Heath: Bulletin of the New York Academy of Medicine, 78 (3), 495-507.

Lewin, K. (1946). Action research and minority problems. Journal of Social Issues, 2, 34 $-46$.

Lincoln, Y.S. \& Guba, E.G. (1985). Naturalistic inquiry. Newbury Park, CA: Sage. Macaulay, A.C., Jagosh, J., Seller, R., Henderson, J., Cargo, M., Greenhalgh, T., . . Pluye, P. (2011). Assessing the benefits of participatory research: a rationale for a realist review. Global Health Promotion, 18 (2), 45-48.

Mactavish, J.B., Mahon, M.J., \& Lutfiyya, Z.M. (2000). "I can speak for myself”: Involving individuals with intellectual disabilities As research participants. Mental Retardation, 38 (3), 216 - 227.

Madill, A., Jordan, A., \& Shirley, C. (2000). Objectivity and reliability in qualitative analysis: Realist, contextualist and radical constructionist epistemologies. British Journal of Psychology, 91 (1), $1-20$.

Maton, K.I. (1993). A bridge between cultures: Linked ethnographic-empirical methodology for culture-anchored research. American Journal of Community Psychology, 21 (6), 745-773.

Maton, K.I., (2008). Empowering community settings: Agents of individual development, community betterment, and positive social change. American Journal of Community Psychology, 41 (1), 4-21. 
McDonald, K. \& Keys, C. (2008). How the powerful decide: Access to research participation for those at the margins. American Journal of Community Psychology, 42 (1), 79-93.

McDonald, K., Keys, C. \& Henry, D. (2008). The gatekeepers of science: Attitudes toward the research participation of adults with intellectual disabilities. The American Journal on Mental Retardation, 113 (6), 466-478.

McDonald, K. \& Stack, E. (2010a). Partnering with people with developmental disabilities to address violence evaluating the use of community-based participatory research: Preliminary report. Portland, OR.

McDonald, K. \& Stack, E. (2010b). Partnering with people with developmental disabilities to address violence evaluating the use of community-based participatory research: Preliminary report: Monthly Reflections. Portland, OR.

McDonald, K. \& Kidney, C. (2012). What's right? Ethics in intellectual disability research. Research Ethics, 19(1), 27 - 39.

McMillan, D. W. \& Chavis, D.M. (1986). Sense of community: A definition and theory. Journal of Community Psychology, 14 (1), 6-23.

McMillan, D. (1976). Sense of community: An attempt at definition. Unpublished manuscript, George Peabody College for Teachers, Nashville, TN.

Merrick, E. (1999). “Like chewing gravel”: On the experience of analyzing qualitative research finding using a feminist epistemology. Psychology of Women Quarterly, $23(12), 47-57$. 
Miles, M. \& Huberman, M. (1994). Qualitative Data Analysis: An expanded sourcebook. Thousand Oaks, CA: Sage Publications.

Miller, A. \& Keys, C. (1996). Awareness, action, and collaboration: How the selfadvocacy movement is empowering for persons with developmental disabilities. Mental Retardation, 34 (5), 312-319.

Minkler, M. (2004). Ethical challenges for the "outside" researcher in community-based participatory research. Health Education \& Behavior, 31 (6), 684-697.

Minkler, M. \& Wallerstein, N. (Eds.) (2008). Community-based participatory research for health: From processes to outcomes. San Francisco, CA: Jossey-Bass.

Muhr, T. (2004). User's manual for ATLAS.ti 5.0, ATLAS.ti scientific software development. GmbH, Berlin.

National Institute on Disability and Rehabilitation Research (2005). Long-range plan for fiscal years 2005-2009. Retrieved April 21, 2011, from http://www.ed.gov/legislation/FedRegister/other/2006-1/021506d.pdf

Nelson, G., Ochocka, J., Griffein, K., Lord, J. (1998). "Nothing about me, without me": Participatory action research with self-help/mutual aid organizations for psychiatric consumer/survivors. American Journal of Community Psychology, 26 (6), 881-912.

Nicolaidis, C., Gregg, J., Galian, H., Curry, MA, McFarland, B., \& Gerrity, M. (2008). "You always end up feeling like you're some hypochondriac": Intimate partner violence survivors' experiences addressing depression and pain. Journal of General Internal Medicine, 23 (8), 1157 - 1163. 
Nicolaidis, C., Raymaker, D.M., McDonald, K., Dern, S., Ashkenazy, E., Boisclair, C., . . . Baggs, A. (2011). Collaboration strategies in non-traditional CBPR partnerships: lessons learned from an academic-community partnership with autistic selfadvocates Progress in Community Healh Partnerships: Research Education and Action, 5 (2), $143-150$.

Niesz, T., Koch, L., \& Rumrill, P.D. (2008) The empowerment of people with disabilities through qualitative research. Work, 31 (1), 113 - 125.

Oden, K., Hernandez, B., \& Hidalgo, M. (2010). Payoffs of participatory action research: Racial and ethnic minorities with disabilities reflect on their research experiences. Community Development, 41 (1), 21 - 31.

Oliver M. (1992). Changing the social relations of research production? Disability, Handicap Society, 7 (2), 101-14.

Olney, M.F. \& Kim, A. (2001). Beyond adjustment: Integration of cognitive disability into identity. Disability \& Society, 16 (4), 563-583.

Paiewonsky, M. (2011). Hitting the reset button on education: Student reports on going to college. Career Development for Exceptional Individuals, 34 (1), 31 - 44.

Perkins, D. \& Zimmerman, M. (1995). Empowerment theory, research, and application. American Journal of Community Psychology, 23(5), 569 - 579.

Perske, R. (1972). The dignity of risk. In W. Wolfensberger (Ed.), Normalization: The principle of normalization in human services (pp. 194-200). Toronto: National Institute on Mental Retardation. 
Powers, L.E., Renker, P., Robinson-Welen, S., Oschwald, M., Hughes, R., Swank, P., Curry, MA. (2009). Interpersonal violence and women with disabilities : Analysis of safety promoting behaviors. Violence Against Women, 15 (9), 1040 - 1049.

Rappaport, J. (1987). Terms of empowerment/exemplars of prevention: Toward a theory for community psychology. American Journal of Community Psychology, 15(1), $121-148$.

Redmond, M. (2005). Co-researching with adults with learning disabilities: Roles, responsibilities, and boundaries. Qualitative Social Work, 4 (1), 75-86.

Richardson, M., (2000). How we live: participatory research with six people with learning difficulties. Journal of Advanced Nursing, 32 (6), 1383 - 1395.

Richardson, M. (2002). Involving people in the analysis. Journal of Learning Disabilities, 6 (1), $47-60$.

Rapley, M. \& Pretty, G. (1999). Play Procrustes: The interactional production of a “psychological sense of community”. Journal of Community Psychology, 27 (6), $695-713$.

Riger, S., (1993). What's wrong with empowerment. American Journal of Community Psychology, 21 (3), 279- 292.

Ritchie, J. \& Lewis, J. (Eds.) (2003). Qualitative research practice: A guide for social science students and researchers. Thousand Oaks, CA: Sage Publications.

Rodgers, J. (1999). Trying to get it right: Undertaking research involving people with learning difficulties. Disability and Society, 14 (4), 421-33. 
Sample, P.L. (1996). Beginnings: Participatory action research and adults with developmental disabilities. Disability \& Society, 11 (16), 317-332.

Sarason, S.B. (1974). The psychological sense of community: Prospects for community psychology. San Fransisco, CA: Jossey Bass.

Saxton, M., Curry MA., Powers, L.E., Maley, S., Eckels, K., Gross, J. (2001). “Bring my scooter so I can leave you": A study of disabled women handling abuse by personal assistance providers. Violence Against Women, 7 (4), 393 - 417.

Schalcok, R.L., Gardener, J.F., \& Bradley, V.J., (2007). Quality of life for people with intellectual and other developmental disabilities. Washington, D.C.: American Association on Intellectual and Developmental Disabilities.

Snow, D.L., Grady, K., \& Goyette-Ewing, M. (2000). A perspective on ethical issues on community psychology. In J. Rappaport \& E. Seidman (Eds.) Handbook of community psychology. New York, NY: Kluwer Academic/ Plenum Publishers.

Stack, E. \& McDonald, K. (in preparation). Nothing about us without us: Does action research in developmental disabilities research measure up? Journal of Policy and Practice in Intellectual Disabilities. **Winner of the 2012 IASSID Tosinver-San Raffaele Group Journal of Policy and Practice in Intellectual Disabilities Scholar's Award**

Staggs, S. L. (2008). Intergroup relations in participatory research. Unpublished doctoral dissertation, University of Illinois at Chicago. 
Stevens, A., \& Folchman, R. (1998). Using participatory action research to evaluate programs serving people with severe disabilities: Reflections from the field. Journal of the Association for Persons with Severe Handicaps, 23 (3), 203-210.

Stringer, E. (1996). Action research: A handbook for practitioners. Thousand Oaks, CA: Sage.

Sudsawad, P. (2007). Knowledge translation: Introduction to models, strategies, and measures. Austin, TX: Southwest Educational Development Laboratory, National Center for the Dissemination of Disability Research. Retrieved April 21, 2011, from "http://www.ncddr.org/kt/products/ktintro/ktintro.pdf"

Tate, D. \& Pledger, C. (2003). An integrative conceptual framework of disability: New directions for research. American Psychologist, 58 (4), 289-295.

Taylor, R. R., Braveman, B., \& Hammel, J. (2004). Developing and evaluating community-based services through participatory action research: Two case examples. American Journal of Occupational Therapy, 58 (1), 73-82.

Trickett, E.J. (1991). Living an idea: Empowerment and the evolution of an alternative high school. New Haven, CT: Brookline Books.

Wallerstein N., Oetzel, J., Duran, B., Tafoya, G., Belone, L., \& Rae, R. (2008). What predicts outcomes in CBPR? In M. Minkler \& N. Wallerstein, (Eds.), Communitybased participatory research for health: From process to outcomes (pp. 371 392). San Francisco, CA: Jossey-Bass.

Walmsley, J. (2001). Normalisation, emancipatory research and inclusive research in learning disability. Disability \& Society, 16 (2), 187 - 205. 
Walmsley, J. (2004a). Inclusive learning disability research: The (nondisabled) researcher's role. The British Journal of Learning Difficulties, 32 (2), 65 - 71.

Walmsley, J. (2004b). Involving users with learning difficulties in health improvement: Lessons from inclusive learning disability research. Nursing Inquiry, 11 (1), 54 64.

Ward, K. \& Trigler, J.S., (2001) Reflections on participatory action research with people who have developmental disabilities. Mental Retardation, 30 (1), 57-59.

Whyte, W. F. (Ed). (1991). Participatory action research. Newbury Park, CA: Sage Publishers.

Williams, V. (2005). Did you solve it yourself?' Evaluation of self narratives of discrimination by people with 'learning difficulties'. Communication \& Medicine, $2(1), 77-89$.

Willaims, V. \& Simons, K. (2005). More researching together: The role of nondisabled researcher in working with people first members. British Journal of Learning Disabilities, 33 (1), $6-14$.

Zimmerman, M.A., Israel, B.A., Schulz, A., \& Checkoway, B. (1992). Further Explorations in Empowerment Theory: An empirical analysis of psychological empowerment. American Journal of Community Psychology, 20(6), 707 - 727.

Zimmerman, M.A., (1990). Taking aim on empowerment research: On the distinction between individual and psychological conceptions. American Journal of Community Psychology, 18 (1), 169-177. 
Zimmerman, M.A. (2000) Empowerment theory: psychological, organizational and community levels of analysis. In Rappaport, J. and Seidman, E. (Eds), Handbook of community psychology (pp. 43 - 63. New York, NY: Plenum Press. 


\section{Appendix A: Israel et al. nine principles of Community-Based Participatory}

\section{Research}

Nine Principles of Community-Based Participatory Research

1. A community is a unit of identity that is reinforced through social interactions and characterized by shared values and norms and mutual influences.

2. Activities should build on community resources and relationships.

3. Programs should establish equal partnerships in all phases of research.

4. Programs should promote co-learning that facilitates reciprocal transfer of knowledge, skills, and capacity.

5. Activities should achieve balance between research and action.

6. Research programs should address locally relevant health problems and consider the multiple determinants of health and disease.

7. Program development should occur through a cyclical and iterative process that includes ongoing assessments of successes and obstacles.

8. Knowledge gained from community research should be actively disseminated to all partners in language that is understandable and respectful.

9. Community-based research involves a long-term commitment.

(Israel, Schultz, Parker, Becker, Allen, \& Guzman, 2003) 


\title{
Appendix B: Individual Interview Guide - Community Research Partners
}

\author{
Partnering with People with Developmental Disabilities to Address Violence: \\ Evaluating the Use of Community-Based Participatory Research (CBPR) \\ Individual Interview Guide \\ Community Research Partners
}

Objectives:

- To explore how empowerment is defined by persons with and without developmental disabilities (DD) in relation to their lives

- To understand some of the challenges and benefits community and academic partners share about community-based participatory research (CBPR)

- To explore if persons with and without DD experience perceptions of empowerment through their work as a community and academic partners on a CBPR project

- To explore if persons with and without DD think their experiences of empowerment transfers to other areas/other projects they are involved with

$\underline{\text { Introduction }}$

Thank you for agreeing to be interviewed about your involvement on a community-based participatory research (CBPR) project. I value what you have to share and want to learn from you. As a reminder, there are no right or wrong answers. I simply would like to hear about your opinions and experiences. We will be talking about your work as a community partner on a community-based participatory research project. Specifically, we will be discussing what you have learned, how you have felt, and what you have done as part of this project.

If you do not have an answer for a question that is OK. You can also ask me to repeat the question or to ask the question in a different way. Or you can ask to move on to the next question. If you skip a question, we can go back to it later. If at any time you need a break, just ask.

Do you have any questions?

At times, I will be taking notes. That does not mean you did or said anything wrong. I just need to remember some things for later. If you would like to see my notes at any time during or after the interview, just ask. Does this sound OK?

The interview will last about [add after piloting] minutes.

Recording and Confidentiality

I would like to audio-record the interview. Later, I will play the recording back and type all the words that we said. The typed words are called a transcript This will allow me to read over what we talked about today at a later time. Would it be OK with you to audio-record this session? [Turn on audio recorder]

The things you tell me today will be kept confidential. This means that I will not share them with people other than my advisor. Only my advisor, Katie McDonald, and I will have access to the things you share with me here today. On all materials I have about this interview I will use an ID number instead of your

Individual Interview - Community Partners August, 2011 Page 1 of 7 
name to protect your privacy. I will also delete the audio-recording. Do you have any questions about confidentiality?

At any time during or after you finish the interview, you can ask me to not put something you said in the transcript. When I am finished with the transcription, we can go over it together if you would like, or I can provide you with a summary of what we discussed here today.

Do you have any questions?

Are you ready to begin the interview?

Time interview started:

Please think about these questions in relation to your work as a community partner on the Partnering Project.

1. Opening:

a. Tell me about the Partnering Project?

1. What is the purpose of the Partnering Project?

b. Tell me about your decision to become involved in the Partnering Project?

1. Who invited you to join the Partnering Project?

2. How were you invited?

3. Who helped you decided to become involved?

4. What helped you decided to become involved?

c. What helps you contribute to the Partnering Project?

1. How did these things come to be?

2. Is trust and respect important to your work?

3. What does trust and respect mean to you?

4. How do you know trust and respect is present?

1. How did the trust and respect develop?

2. How does a group change or stay the same because trust and respect are there?

d. How has involvement in the Partnering Project affected you?

e. How has involvement in the Partnering Project affected your life (e.g., your work, your advocacy efforts, your relationships, your community, your living, etc.)?

1. How has your decision to become involved in the Partnering Project affected your life positively?

1. Ask for stories or examples.

Individual Interview - Community Partners

August, 2011

Page $\mathbf{2}$ of 7 
2. How has involvement in the Partnering Project affected your life negatively?

1. Ask for stories or examples.

f. The Partnering Project is a CBPR project. How do you feel about community-based participatory research (CBPR)?

1. What do you think is good (or valuable) about CBPR?

1. Ask for stories or examples.

2. What do you think is bad about CBPR?

1. Ask for stories or examples.

3. What do you think is hard or challenging about CBPR?

1. Ask for stories or examples.

2. If so, how were you and the team able to get through these challenges?

4. How is the CBPR process making the research better?

5. What is your role in the Partnering Project?

1. How would others, including the academic partners, describe your role?

6. Do you consider yourself a researcher?

1. If yes, how does CBPR make you a better researcher?

7. How does "Nothing about us without us" relate to CBPR? What does nothing about us without us mean to you when doing CBPR?

2. Empowerment

A lot of people talk about CBPR and power. I am interested in how empowerment might relate to a person's work on a CBPR project. The following questions are about empowerment and CBPR. Again, there are no right answers. I would just like to hear your opinion. (Interviewer note: Focus on getting at each of the following: feelings, knowledge, and behaviors)

a. What does empowerment mean to you?

1. How does someone feel when they are empowered?

2. How does someone think when they are empowered?

3. How does someone act when they are empowered?

4. What does power in the Partnering Project look like?

1. Ask to describe or provide examples.

5. In your opinion, who has power in the Partnering Project?

b. What does empowerment look like in CBPR?

1. Ask for stories or examples. 
c. What does empowerment look like in the Partnering Project?

1. In the Partnering Project, how does someone feel when they are empowered?

2. In the Partnering Project, how does someone think when they are empowered?

3. In the Partnering Project, how does someone act when they are empowered?

4. Ask for stories or examples.

5. In what ways has your work on the Partnering Project helped you be empowered?

1. Ask for stories or examples.

6. In what ways has your work on the Partnering Project gotten in the way of you being empowered?

1. Ask for stories or examples.

d. Do you think of empowerment differently now than when you started working on the Partnering Project?

1. Can you describe how or how not?

2. How is it different?

3. How is it the same?

e. How do you think power-sharing is part of empowerment?

f. How do you think making decisions about one's own life is part of empowerment?

g. How do you think independence (control, influence) is part of empowerment?

h. How do you think the disability slogan "Nothing about us without us" relates to empowerment?

1. Do you feel this through your work on the Partnering Project?

3. Future Direction:

a. Do you feel differently as a result of your work on the Partnering Project? 1. Other research project, work, home, school, or other activities.

b. Do you think differently as a result of your work on the Partnering Project? 1. Other research project, work, home, school, or other activities

c. Do you act (behave) differently as a result of your work on the Partnering Project? 1. Other research project, work, home, school, or other activities What would you say if someone asked you to be involved in a project that uses CBPR in the future?

d. Why or why not would you like to be in another project that uses CBPR?

Individual Interview - Community Partners August, 2011 
4. Other involvement:

a. Self-advocates: Have you or are you involved in any self-organized advocacy groups?

1. IF YES:

1. What about the group(s) and the CAB are similar?

2. What about the group(s) and the CAB are different?

b. Have you been involved in a research project other than the Partnering Project?

1. IF YES: What was that project about?

1. What are the similarities between that project's research process and the Partnering Project's research process?

2. What are the differences between that project's research process and the Partnering Project's research process?

5. Closing:

a. Is there anything else about your work on this project that you would like to share with me?

\section{Background Questions}

Before we finish up our interview, I'd like to ask you a few more questions about your background. We ask these questions to be able to describe the people in our study.

1. What is your date of birth?

$\square$ Do not wish to say

2. What gender are you?

$\square$ Do not wish to say

3. What is your race?

$\square$ African-American/Black

$\square$ Caucasian/White

$\square$ Asian or Pacific Islander

$\square$ Native American/American Indian, Indian/Alaskan Native

$\square$ Biracial or multiracial

$\square$ Other (specify)

$\square$ Do not wish to say

Individual Interview - Community Partners

August, 2011

Page 5 of 7 
4. Are you of Latino origin? yes no

$\square$ Do not wish to say

5. Education:

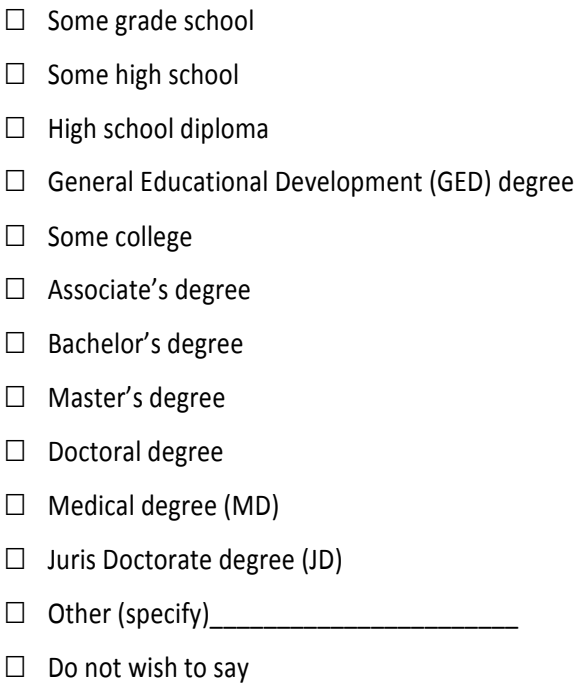

6. Do you identify as:

$\square$ A person(s) with a disability.

$\square$ A family member of a person(s) with a disability.

$\square$ An ally to a person(s) with a disability.

$\square$ A support provider to a person(s) with a disability.

$\square$ A domestic violence service provider.

$\square$ Other (specify)

$\square$ Do not wish to say

7. How do you spend most of your day right now?

$\square$ Do not wish to say

Thank you for taking the time to talk to me about your experience being involved in a community-based participatory research project. I really appreciate you taking the time to share your opinions with me.

As a reminder, everything you shared with me here today will be kept confidential. If after you leave here today you would like to add anything else to your responses, here is my contact information. Additionally, if there is anything you would like me to not include in the transcript feel free to contact me and let me know. Would you like me to contact you and provide you with a summary or copy of the transcript that I can review with you when the work is completed? YES or NO.

Individual Interview - Community Partners

August, 2011

Page 6 of 7 


\title{
Appendix C: Individual Interview Guide - Academic Research Partners
}

\author{
Partnering with People with Developmental Disabilities to Address Violence: \\ Evaluating the Use of Community-Based Participatory Research (CBPR) \\ Individual Interview Guide \\ Academic Research Partners
}

Objectives:

- To explore how empowerment is defined by persons with and without developmental disabilities (DD) in relation to their lives

- To understand some of the challenges and benefits community and academic partners share about community-based participatory research (CBPR)

- To explore if persons with and without DD experience perceptions of empowerment through their work as a community and academic partners on a CBPR project

- To explore if persons with and without DD think their experiences of empowerment transfers to other areas/other projects they are involved with

\section{$\underline{\text { Introduction }}$}

Thank you for agreeing to be interviewed about your involvement on a community-based participatory research (CBPR) project. I value what you have to share and want to learn from you. As a reminder, there are no right or wrong answers. I simply would like to hear about your opinions and experiences. We will be talking about your work as an academic partner on a community-based participatory research project. Specifically, we will be discussing what you have learned, how you have felt, and what you have done as part of this project.

If you do not have an answer for a question that is OK. You can also ask me to repeat the question or to ask the question in a different way. Or you can ask to move on to the next question. If you skip a question, we can go back to it later. If at any time you need a break, just ask.

Do you have any questions?

At times, I will be taking notes. That does not mean you did or said anything wrong. I just need to remember some things for later. If you would like to see my notes at any time during or after the interview, just ask. Does this sound OK?

The interview will last about (add after piloting) minutes.

\section{Recording and Confidentiality}

I would like to audio-record the interview. Later, I will play the recording back and type all the words that we said. These typed words are called a transcript. This will allow me to read over what we talked about today at a later time. Would it be OK with you to audio-record this session? [Turn on audio recorder]

Individual Interview - Academic Partners 
The things you tell me today will be kept confidential. Only my advisor, Katie McDonald, and I will have access to the things you share with me here today. This means that I will not share them with people other than my advisor. On all materials I have about this interview I will use an ID number instead of your name to protect your privacy. I will also delete the audio-recording. Do you have any questions about confidentiality?

At any time during or after you finish the interview, you can ask me to not put something you said in the transcript. When I am finished with the transcription, we can go over it together if you would like or I can provide you with a summary of what we discussed here today.

Do you have any questions?

Are you ready to begin the interview?

Time interview started:

Please think about these questions in relation to your work as an academic partner on the Partnering Project.

1. Opening:

a. Tell me about the Partnering Project?

1. What is the purpose of the Partnering Project?

b. Tell me about your decision to become involved in the Partnering Project?

1. How did you become part of the Partnering Project?

2. Who helped you decided to become involved?

3. Why did you become involved?

c. What is your role in the Partnering Project?

d. How has involvement in the Partnering Project affected you?

e. How has involvement in the Partnering Project affected your life?

1. How has your decision to become involved in the Partnering Project affected your life positively?

1. Ask for stories or examples. 
2. How has your decision to become involved in the Partnering Project affected your life negatively?

1. Ask for stories or examples.

f. How has involvement in the Partnering Project affected your research?

1. How has involvement in the Partnering Project affected your research positively?

1. Ask for stories or examples.

2. How has involvement in the Partnering Project affected your research negatively?

1. Ask for stories or examples.

g. What helps you contribute to the Partnering Project?

1. How did these things come to be?

2. Is trust and respect important to your work?

3. What does trust and respect mean to you?

4. How do you know trust and respect is present?

1. How did the trust and respect develop?

2. How does a group change or stay the same because trust and respect are there?

h. How would you describe how Partnering Project works? What is the structure of the Partnering Project?

1. What was it like to select the $C A B$ and get it started?

1. In the beginning of the project, what was important for the $C A B$ ?

2. How did you make the CAB work?

2. What would you do differently next time?

i. How do you feel about community-based participatory research (CBPR)?

1. What do you think is good (or valuable) about CBPR?

1. Ask for stories or examples.

2. What do you think is bad about CBPR?

1. Ask for stories or examples.

3. Have there been any challenges that have come up along the way?

1. Ask for stories or examples.

2. If so, how were you and the team able to get through these challenges?

Individual Interview - Academic Partners 
4. How is the CBPR process benefitting research?

5. How does engaging in CBPR impact your research?

6. How does "Nothing about us without us" relate to CBPR? What does nothing about us without us mean to you when doing CBPR?

7. How would you describe inclusion in the Partnering Project?

1. What helps promote inclusion?

2. What gets in the way of being fully inclusive?

j. What do you think is unique or different about doing CBPR with persons with developmental disabilities?

1. What processes or practices are necessary for CBPR with persons with developmental disabilities?

\section{Empowerment}

A lot of people talk about CBPR and power. I am interested in how empowerment might relate to a person's work on a CBPR project. The following questions are about empowerment and CBPR. Again, there are no right answers. I would just like to hear your opinion. (Focus on getting at each of the following: feelings, knowledge, and behaviors)

a. What does empowerment mean to you?

1. How does someone feel when they are empowered?

2. How does someone think when they are empowered?

3. How does someone act when they are empowered?

4. What does power in the Partnering Project look like?

1. Ask to describe or provide examples.

5. In your opinion, who has power in the Partnering Project?

6. How do you think power-sharing is part of empowerment?

7. How do you think making decisions about one's own life is part of empowerment?

8. How do you think independence (control, influence) is part of empowerment?

9. How do you think the disability slogan "Nothing about us without us" relates to empowerment?

1. Do you feel this through your work on the Partnering Project?

Individual Interview - Academic Partners

August, 2011

Page 4 of 7 
b. What does empowerment look like in CBPR?

1. Ask for stories or examples.

c. What does empowerment look like in the Partnering Project?

1. In the Partnering Project, how does someone feel when they are empowered?

2. In the Partnering Project, how does someone think when they are empowered?

3. In the Partnering Project, how does someone act when they are empowered?

4. Ask for stories or examples.

5. In what ways has your work on the Partnering Project helped you be empowered?

1. Ask for stories or examples.

6. In what ways has your work on the Partnering Project gotten in the way of you being empowered?

1. Ask for stories or examples.

d. Do you think of empowerment differently now than when you started working on the Partnering Project?

1. Can you describe how or how not?

2. How is it different?

3. How is it the same?

3. Future Direction:

a. Do you feel differently as a result of your work on the Partnering Project?

1. Other research project, work, home, school, or other activities.

b. Do you think differently as a result of your work on the Partnering Project?

1. Other research project, work, home, school, or other activities

c. Do you act (behave) differently because of your work on the Partnering Project?

1. Other research project, work, home, school, or other activities What would you say if someone asked you to be involved in a project that uses CBPR in the future?

d. What would you say if someone asked you to be involved in a project that uses CBPR in the future?

1. Why or why not would you like to be in another project that uses CBPR?

4. Closing:

Individual Interview - Academic Partners

August, 2011

Page 5 of 7 
a. Is there anything else about your work on this project that you would like to share with me?

\section{Background Questions}

Before we finish up our interview, I'd like to ask you a few more questions about your background. We ask these questions to be able to describe the people in our study.

1. What is your date of birth?

$\square$ Do not wish to say

2. What gender are you?

$\square$ Do not wish to say

3. What is your race?

$\square$ African-American/Black

$\square$ Caucasian/White

$\square$ Asian or Pacific Islander

$\square$ Native American/American Indian, Indian/Alaskan Native

$\square$ Biracial or multiracial

$\square$ Other (specify)

$\square$ Do not wish to say

4. Are you of Latino origin? yes no

$\square$ Do not wish to say

5. Education:
$\square$ Some grade school
$\square$ Some high school
$\square$ High school diploma
$\square$ General Educational Development (GED) degree
$\square$ Some college
$\square$ Associate's degree
$\square$ Bachelor's degree
$\square$ Master's degree
$\square$ Doctoral degree
$\square$ Medical degree (MD) 
$\square$ Juris Doctorate degree (JD)

$\square$ Other (specify)

$\square$ Do not wish to say

6. Do you identify as:

$\square$ A person(s) with a disability.

$\square$ A family member of a person(s) with a disability.

$\square$ An ally to a person(s) with a disability.

$\square$ A support provider to a person(s) with a disability.

$\square$ A domestic violence service provider.

$\square$ Other (specify)

$\square$ Do not wish to say

7. How do you spend most of your day right now?

$\square$ Do not wish to say

Thank you for taking the time to talk to me about your experience being involved in a community-based participatory research project. I really appreciate you taking the time to share your opinions with me.

As a reminder, everything you shared with me here today will be kept confidential. If after you leave here today you would like to add anything else to your responses, here is my contact information. Additionally, if there is anything you would like me to not include in the transcript feel free to contact me and let me know. Would you like me to contact you and provide you with a summary or copy of the transcript that I can review with you when the work is completed? YES or NO.

Thanks again for your participation. 


\section{Appendix D: Individual Interview Consent Forms}

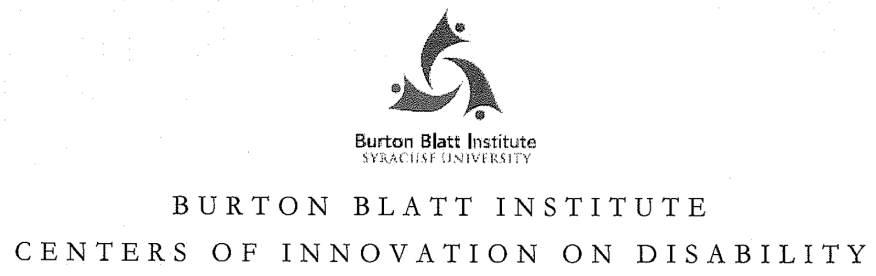

Partnering with People with Developmental Disabilities to Address Violence:

Evaluating the Use of Community-Based Participatory Research (CBPR)

\section{Individual Interview Consent Form}

- You are a part of a research evaluation (checking on how the project is going) of the project you are working on, Partnering with People with Developmental Disabilities to Address Violence.

- You have been participating in this evaluation because you are a member of the project's Community Advisory Board (CAB), Steering Committee, or Investigator Team.

- This form has information about participating in this evaluation.

- If you understand everything on this form and would like to continue to participate, you need to sign this form.

- You can choose to continue to participate or not.

$\begin{gathered}\text { Syracuse University } \\ \text { IRB Approved }\end{gathered}$
EXPIRES SEP 1920 月2 Evaluating CBPR: Individual Interview
Consent Form 4
September, 2011
Page 1 of 8


Who is in charge of this research evaluation?

Katherine (Katie) McDonald, Ph.D. Assistant Professor

Department of Public Health, Food

Studies \& Nutrition

Syracuse University

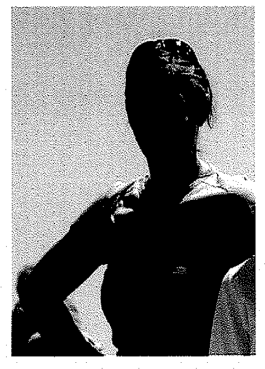

What is the evaluation for?

To learn your opinion or what you think about:

o How researchers and adults with developmental disabilities can work together on research

o. How researchers and adults with developmental disabilities are changed by working together on research 


\section{What will happen if you decide to continue to participate in the research?}

You may have been a part of group interviews and/or you may have provided reflections about your experience on the project. In order to make sure your opinions about this work are understood, Katie and her research assistant, Erin Stack, would like to ask you more questions.

Some of these questions will be similar to questions Katie or Erin have asked you before. For example:

1. How do you feel about Community-Based Participatory Research (CBPR)?

2. How do you feel about this research project?

Some of these questions will be new to you. For example:

1. How has your involvement on the Partnering Project affected your life positively?

2. What does empowerment mean to you?

You can skip questions or stop whenever you want.

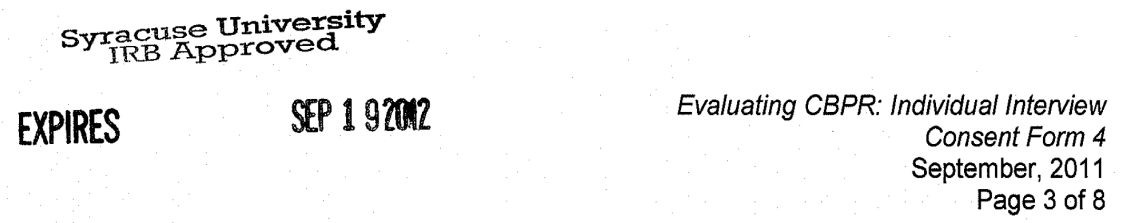


The Interview

May last up to two hours

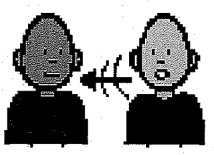

No right or wrong answers

Interested in your opinion

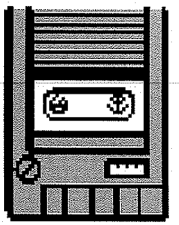

Audio-recorded
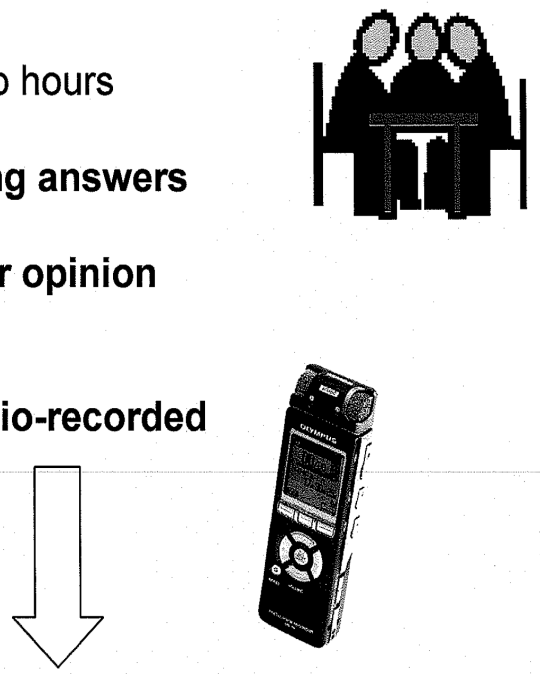

Then...

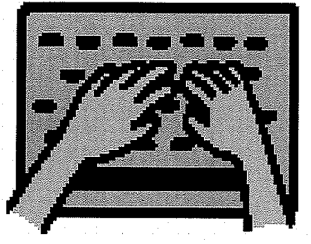

A research assistant will type

everything you said onto a

page
Syracuse University
IRB Approved

EXPIRES SEP 19202
Evaluating CBPR: Individual Interview Consent Form 4 September, 2011 


\section{Can anything bad happen to you from participating in the evaluation?}

Katie does not expect anything bad to happen to you from participating in the evaluation. You might be concerned about or uncomfortable with sharing negative experiences with Katie. However, you can always tell Katie to remove something you say from the data. Also, Katie will not keep your name next to what you say and will not report your name when she shares summaries of findings with others.

Everything you say in the monthly interview will be confidential

Confidential means Katie and Erin will keep what you say private or secret.

Katie and Erin will:

- Not tell anyone you were the person who said something

- Use a code number on all the information we collect from you instead of your name

- Keep a list on the computer that connects each code to each person. The list can only be accessed by those who have the password.

- Lock the office where we keep your information

- Erase audio recording and list on the computer that connects codes to names after 5 years
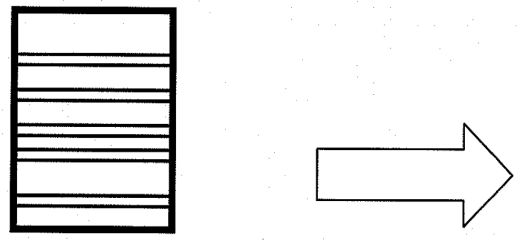

syracuse University
IRB Approved

EXPIRES

SEP 19202
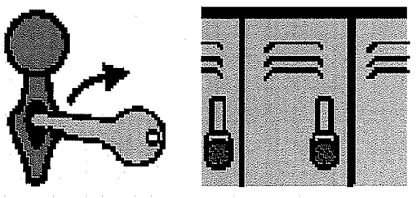

Evaluating CBPR: Individual Interview

Consent Form 4

September, 2011

Page 5 of 8 
What will you get from participating in the evaluation?

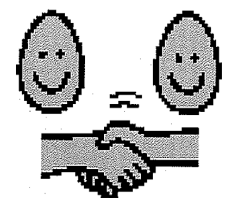

You might like sharing your experiences

You may feel good about helping us learn more about how researchers and adults with

developmental disabilities can work together on research

You will not receive any compensation for participating in the interview.

You will receive a $\mathbf{\$ 2 5}$ gift card for your participation. Should you decide to withdraw from the interview part way through it, you will still receive the $\$ 25$ gift card. However, if you decide not to do the interview, you will not receive the $\$ 25$ gift card.

\section{What will happen if you decide NOT to participate?}

Nothing!

No one will be upset if you choose not to participate, including Katie, Erin, the other members of the research project, or your family or staff

It is your right to decide
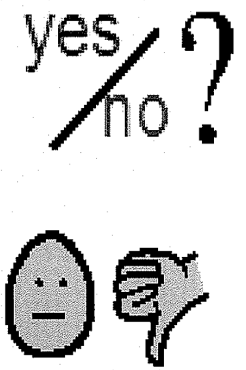

If you do not want to participate or if you want to

stop participating during the interview, you can say:

- I don't want to keep going.

- I would rather not participate.

- This won't work for me.

- I don't want to answer that question.

Syracuse University

EXPIRES SEP 1 92012

Evaluating CBPR: Individual Interview

Consent Form 4

September, 2011

Page 6 of 8 
What will happen after the information is collected?

- Katie and Erin will look at all of the information collected and write a summary of findings.

- The Steering Committee, Katie, and Erin will

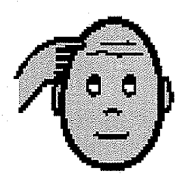
hold a meeting to talk about the findings.

- Katie and Erin may make changes to the summary and then hold a meeting with the Community Advisory Board (CAB) to talk about the findings.

\section{What should you do now?}

- Ask any questions

- Think things over

- Talk to a friend or family member, if you want to

- When you are ready, decide if you want to participate
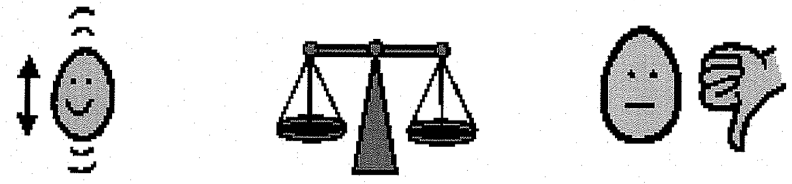

Syracuse University
IRB Approved

EXPIRES SEP 19202




\section{If you would like to participate}

Do you understand everything on this form?

Do you have any questions?

If you have questions or problems about participating in this study that you don't want to ask Katie, contact:

Institutional Review Board (IRB)

Syracuse University

315-443-3013

orip@syr.edu

If you have questions about the study, contact:

Dr. Katie McDonald

Department of Public Health, Food Studies \& Nutrition

Syracuse University

315-443-6140

kemcdona@syr.edu

- You may stop your participation in this study at any time, without anything bad happening.

- Please keep a copy of this form for your records.

- Please check whether you also agree to be audio-recorded: $\checkmark$ I agree to be audio-recorded $\quad$ I do not agree to be audio-recorded

\begin{tabular}{lll}
\hline Participant Name & Participant Signature & Date
\end{tabular}

\begin{tabular}{|c|c|c|}
\hline Researcher Name & Researcher Signature & Date \\
\hline \multicolumn{3}{|c|}{$\begin{array}{l}\text { Syracuse University } \\
\text { IRB Approved }\end{array}$} \\
\hline EXPIRES & SEP 19201 & $\begin{array}{r}\text { Consent Form } 4 \\
\text { September, } 2011 \\
\text { Page } 8 \text { of } 8\end{array}$ \\
\hline
\end{tabular}




\section{Appendix E: Empowerment in CBPR codebook outline}

\section{Empowerment in CBPR Codebook Outline}

1. Individual Empowerment

a. Empowered beliefs

i. Self-esteem

ii. Self-efficacy

b. Empowered behaviors

i. Independence and control related to decision-making

ii. Disability rights advocacy

iii. Seeking involvement

2. Environment (CBPR) and Facilitating Empowerment (unless otherwise mentioned)

a. Inclusion

b. Accessibility

i. Accessible meetings

ii. Accessibility outside of the meeting

c. Partnership

i. Co-learning/Learning

ii. Strength-based focus

iii. Trust

iv. Perceived empowerment

d. Power sharing 
i. Shared decision-making

ii. Shared leadership

iii. Influence

e. Barriers to empowerment

i. Inaccessible communication

ii. Inaccessible language

iii. Lack of project ownership

3. Changes to Empowerment Definition
a. No change
b. Negative change
c. Positive change 


\section{Appendix F: Empowerment in CBPR codebook}

\section{Description:}

\section{Individual-level Empowerment}

This refers to community member's understanding of what empowerment means to them in relation to how it looks in their own lives and how it has come to look within the CBPR project. Community members' words were used to assist with identification of whether or not a person is empowered within a CBPR process. This tree includes: 1) empowered beliefs and 2) empowered behaviors. This tree does not include any group, community, or environmental factors that influence empowerment. Example: When I am empowered, I have control over my life decisions.

\section{Empowered beliefs}

Description: This refers to an individual being comfortable with him or herself accepting faults and utilizing strengths. It does not behaviors one engages in when empowered.

Example: Empowerment is being comfortable with myself (defined). I am not good with the research part, but I am good at talking with people (within the project).

\section{Self-esteem}

Description: This refers to an individual having adequate self-worth and confidence about one's self as a whole. This does not refer to a belief in certain capabilities in specific situations; code confidence with self-esteem when it is general confidence.

Example: Empowerment is being confident with yourself (defined). I share what I know with the group because what I have to say is important (within the project).

\section{Self-efficacy}

Description: This refers to an individual believing in their ability to make valuable contributions. This also refers to an individual understanding their own strengths in relation to their work on the project. This does not refer to experiences that led to an individual gaining self-efficacy and is different from self-esteem because it reflects one's specific capabilities and not just a feeling of self-worth overall; code confidence with self-efficacy when it is specific to a certain self-identified quality.

Example: Empowerment is being confident in my representation of the deaf community (defined). I am capable identifying words that may not make sense to all people (within the project).

\section{Empowered behaviors}

Description: This refers to actions that are engaged in when a person is empowered. This does not refer to beliefs about empowerment.

Example: Empowerment is being involved (defined). I joined the project because it is important to be involved (within the project).

\section{Independence and control related to decision-making Description:}

This refers individuals being involved in and having control over decisions. This can take place with or without the support of another person. This does not refer to situations in which support is needed and not received.

Example: Empowerment is being able to do things for myself if I choose to (defined). I have control over decisions that are made throughout the project (within the project).

\section{Disability rights advocacy}

Description: This refers to being involved and working for disability rights within the disability community, including disability pride. This is does not refer to being involved in the community unrelated to disability rights.

Example: Empowerment is working in groups with other people with disabilities for our rights (defined). I try to represent [self-advocacy group] when I give my input (within the project). 


\section{Seeking involvement}

Description: This refers to an individual engaging in community exploration and seeking involvement within the group that does not include disability advocacy groups.

Example: Empowerment is about community exploration (defined). This project has encouraged me to seek involvement in other similar communities (within the project).

\section{Setting-level Empowerment}

Description: This refers to the aspects of a CBPR environment and how they can help or hinder an individual being empowered. This does not refer to individual aspects of empowerment. This tree includes: 1) inclusion, 2) accessibility, 3) partnership, 4) power-sharing, and 5) barriers to empowerment. This tree does not include any individual beliefs or behaviors about empowerment. Example: I am included in decisions that affect the direction of the project.

\section{Inclusion}

Description: This refers to project members' beliefs about inclusion and opportunities of being included. This includes an individuals opportunity to be involved and the group or individuals noting the value of inclusion. This does not take into account the level of importance of community members being included or how it may or may not have affected the project.

Example: It is important to here from the community about things that are important to them.

\section{Accessibility}

Description: This refers to the collaboration between the community and academic partners being understandable for all project members. This does not refer to inclusion or relationships within the partnership.

Example: [academic partner] sends me the meeting agenda in .rtf format before the meeting.

\section{Accessible meetings}

Descriptions: This refers to the meetings that community partners attend being accessible for them, including understandable language, materials, supports, structure, role definition, environmental factors, and other accommodations. This does not refer to things that happen outside of the meeting, including traveling to and from the meeting.

Example: [community partner] presents a slide of all the things we have done and need to do at the beginning of the meeting which helps me understand what we need to do at the meeting today.

\section{Accessibility outside of the meeting}

Description: This refers to accessibility of the partnership outside of the actual meetings, including traveling to the meetings, information about the meetings outside of actual meetings, and information about what happens in other meetings in relation to the project.

Example: [academic partner] walks with me from my apartment every meeting.

\section{Partnership}

Description: This refers to reasons why the partnership is necessary and implemented. It refers to community and academic partners' relationships within the project. This does not refer to powersharing qualities of the partnership.

Example: We work well together as a team.

\section{Co-learning/Learning}

Description: This refers to community and academic partners learning from each other. Use this code to also identify what projects are learning independent of mentioning what they feel others are learning from them. This does not refer to gaining knowledge in an exclusive way.

Example: I share my knowledge of self-advocacy with the group and I am learning about how research is conducted.

\section{Strengths-based focus}

Description: This refers to the individuals or the group understanding the different expertise that group members bring to the group. This also refers to project members' contributions being taken 
seriously. This is not learning for others expertise. It is understanding the strengths others bring to the project. It is not understanding the strengths oneself brings to the project.

Example: [community partner] is good with organizing and visualizing what we have been doing.

\section{Trust}

Description: This refers to individuals being comfortable working with, sharing ideas, and asking questions within the group.

Example: I feel comfortable sharing what I know because I trust other project members.

\section{Perceived empowerment}

Description: This refers to an individual feeling the project and/or people on the project have been empowering and inspiring. This does not refer to any other quality gained from work on this project or relate to whether or not an individual was empowered from another person's perspective.

Example: Certain project members inspire me to contribute.

\section{Power sharing}

Description: This refers to community and academic partners relinquishing power to each other when necessary and sharing ownership of the project. This does not include separating into individual or group expertise.

Example: Community and academic partners run the meetings.

\section{Shared decision-making}

Description: This refers to making decision together as a group. This does not refer to sharing leadership or ownership of the project.

Example: Decisions are not made with the input of both community and academic partners.

\section{Shared leadership}

Description: This refers to having a feeling of leadership within and ownership of the project, rotating responsibilities, and identifying as a researcher. This does not refer to shared decision-making. Example: I feel like [community partner] and [academic partner] lead the meetings.

\section{Influence}

Description: This refers to decisions being made that can affect the outcome of the project. This does not refer to individual expertise.

Example: I contributed to changes in the survey.

\section{Barriers to empowerment}

Description: This refers to people with disabilities being involved in the project but their ideas not being taken seriously or integrated into the work, this includes an inflated sense of control, no decision-making ability, lack of respect, and lack of trust. This does not refer to work that does affect change within the project.

Example: When I say my opinion, it is usually ignored.

\section{Inaccessible communication}

Description: This refers to feelings of not being listened to, respected, or taken seriously by other project members. This does not refer to lack of understanding in communication.

Example: I say things and I don't think people on the project are listening to me.

\section{Inaccessible language}

Description: This refers to not understanding what the project is about, what people are saying, or why decisions are being made. This does not refer to individuals not listen to, respecting, or taking project members seriously

Example: Sometimes I do not understand what individuals are talking about.

\section{Lack of project ownership}

Description: This refers to an individual not demonstrating feeling of ownership of the project and/or not identifying as a researcher. This does not refer to the inaccessibility of the project.

Description: No, I do not think of myself as a researcher. 


\section{Changes to Empowerment Definition}

Description: This refers to how one's empowerment definition has changed over time in direct relationship to their work on this project. This tree includes: 1) no change, 2) negative change, and 3) positive change.

Example: My definition of empowerment has not changed.

\section{No change}

Description: This refers to no change in one's definition of empowerment. This does not refer to a positive or negative change in one's definition of empowerment.

Example: My definition of empowerment has not changed.

\section{Negative change}

Description: This refers to a negative change in one's definition of empowerment as a result of one's work on this project. If this code is used, use above codes of empowerment to code the change if mentioned. This does not refer to no change or a positive change in one's definition of empowerment. The valence of change reflects the opinion of the coders.

Example: Yes, I think it cannot happen.

\section{Positive change}

Description: This refers to a positive change in one's definition of empowerment as a result of one's work on this project. If this code is used, use above codes of empowerment to code the change This does not refer to no change or a negative change in one's definition of empowerment. The valence of change reflects the opinion of the coders.

Example: Yes, I realize it can happen for people with disabilities. 
Appendix G: Empowerment in CBPR Member Check Summary

Empowerment in Community-Based Participatory Research with Persons with Developmental Disabilities:

Perspectives of Community Researchers

Erin Stack

Portland State University

June 13, 2012

1. Community-based participatory research or CBPR involves academic and community members working together to answer questions that are important to both groups.

2. Past researchers who have done CBPR have said community members are empowered or learn the importance of their ideas and having control over things important to them through CBPR.

3. But, community members have not been asked if they are empowered very much.

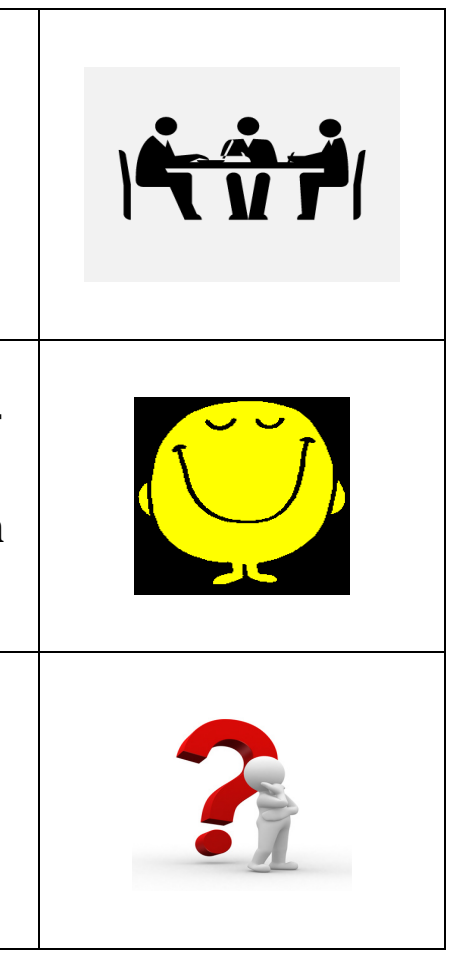

4. I wanted to learn:

1. About what empowerment meant to all people on the Partnering Project, especially community members.

2. If people on the Partnering Project were empowered from their work on the project.

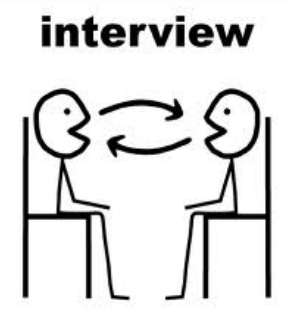

3. And, if there were parts of the project that helped or did not help people be empowered. 


\section{What is empowerment?}

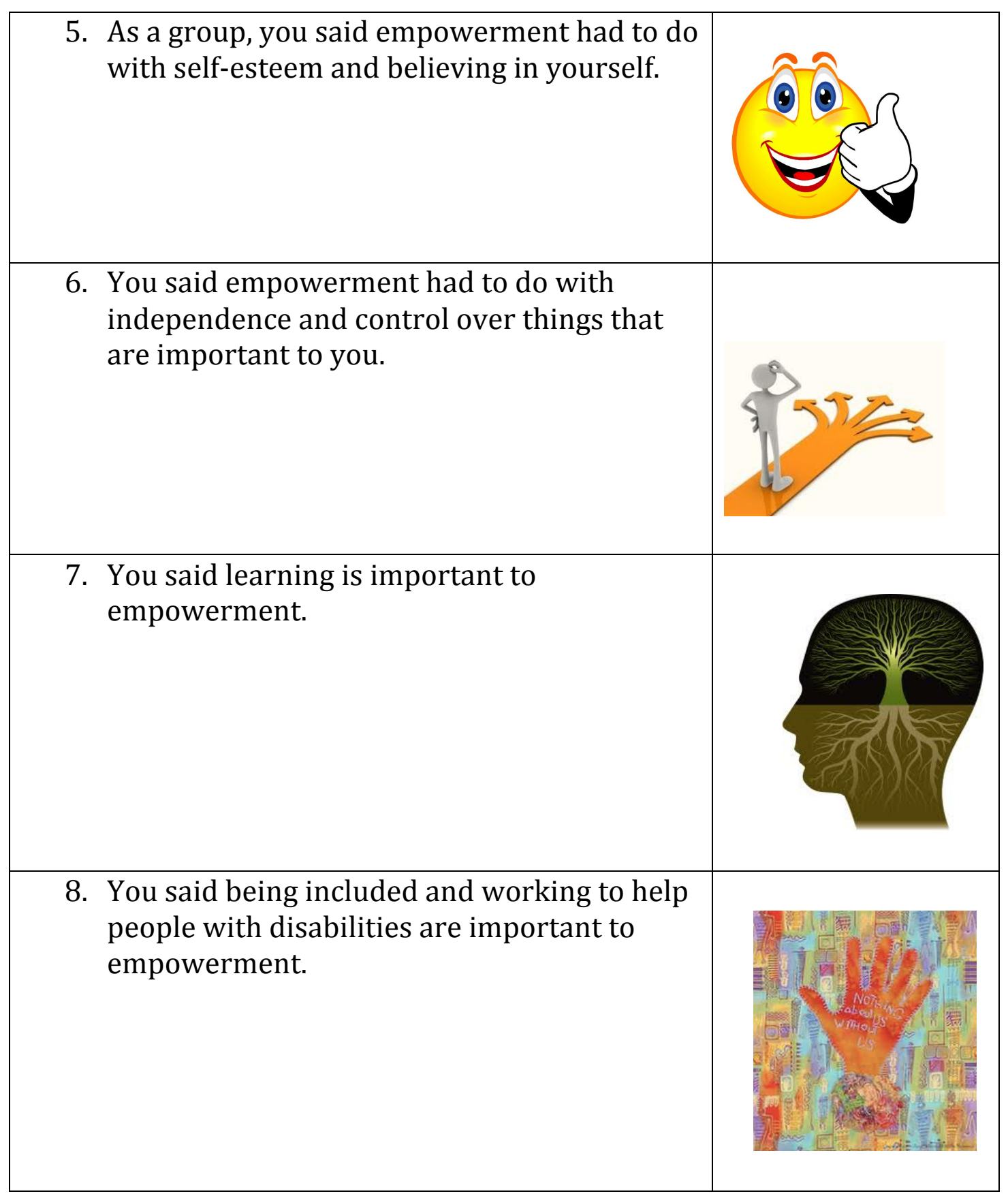




\section{What parts of the Partnering Project helped you be empowered?}

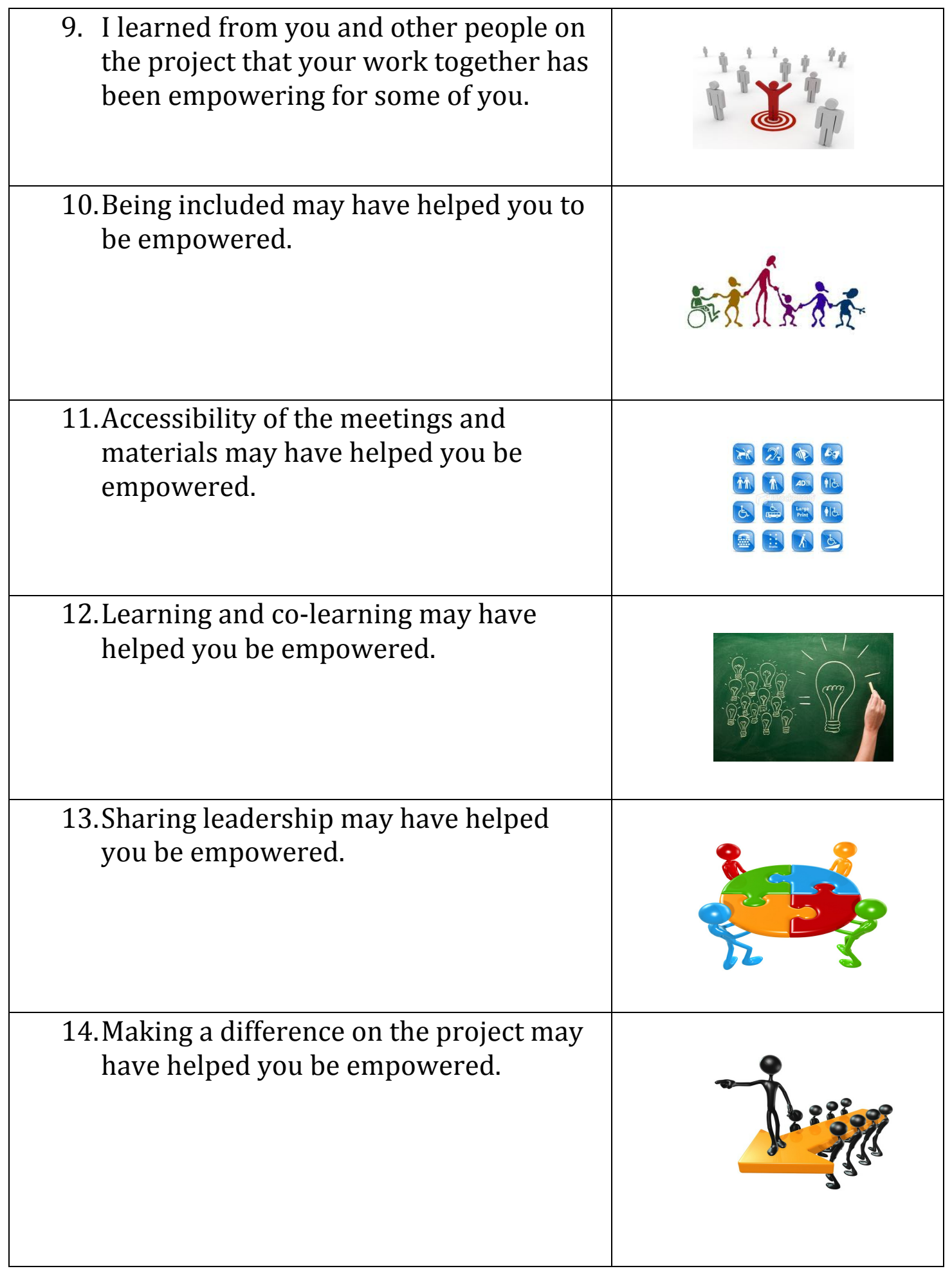




\section{What parts of the Partnering Project may have created obstacles or barriers to you being empowered?}

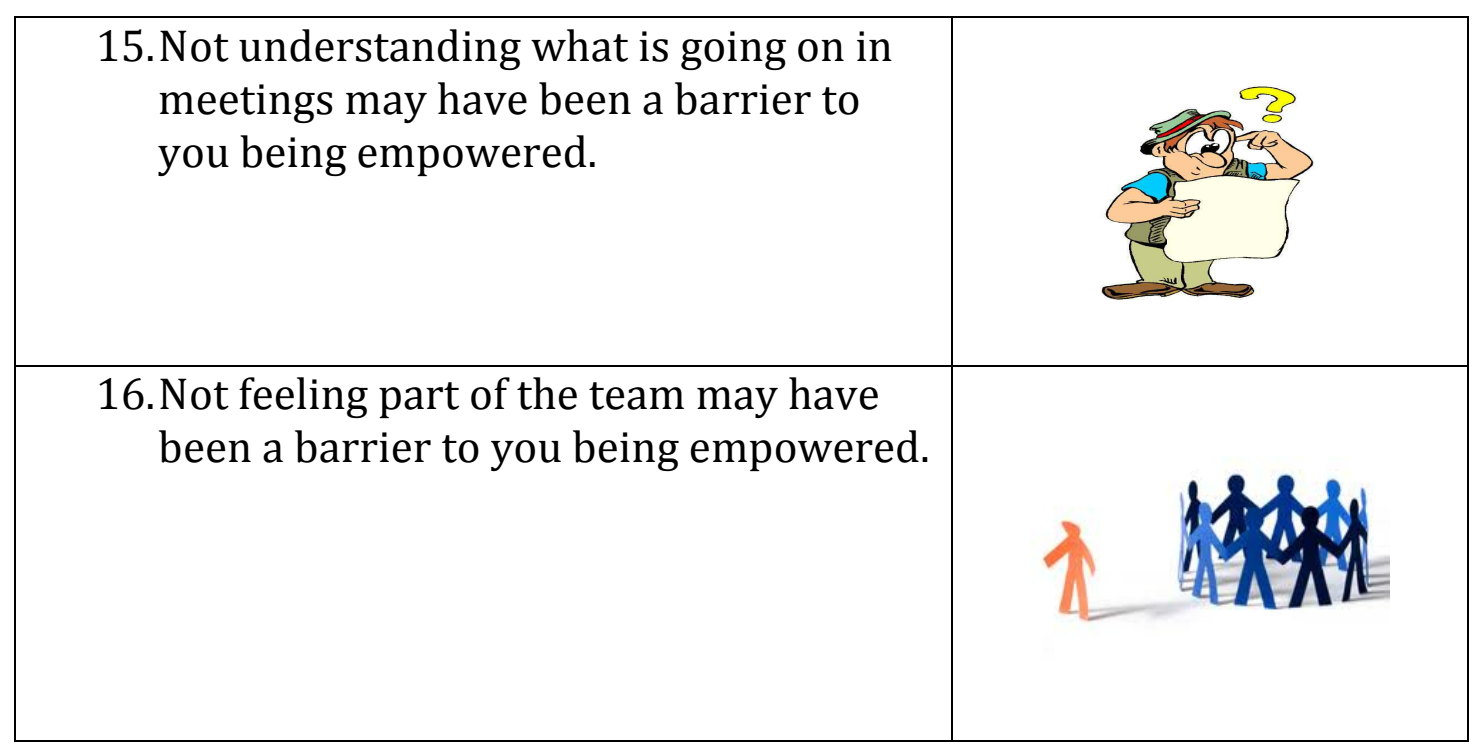

\section{Has what empowerment meant to you changed from your work on the Partnering Project?}

\begin{tabular}{|l|l|}
\hline $\begin{array}{l}\text { 17. Some of you feel the same about } \\
\text { empowerment as you did before the } \\
\text { project. }\end{array}$ \\
\hline $\begin{array}{l}\text { 18. Some of you feel better about } \\
\text { empowerment than you did before the } \\
\text { project. }\end{array}$ \\
\hline
\end{tabular}




\title{
Appendix H: Empowerment in CBPR Member Check Summary (Redo)
}

\author{
Empowerment in Community-Based Participatory Research with \\ Persons with Developmental Disabilities: \\ Perspectives of Community Researchers
}

\author{
Erin Stack \\ Portland State University
}

The following paper is called a member check. Member checks are done in research to make sure the things talked about in interviews are what people meant. They are also done because researchers make conclusions and suggest things for other projects based on responses, so researchers want to make sure those things are $\mathrm{OK}$ with the people they did interviews with.

I talked with you and other project members in the Fall and Winter of this year. I want to make sure you agree with my summary of what me and you and me and other project members talked about. I also want to make sure you are OK with the conclusions I make based on our talks. I want to make sure I am being true to the words and ideas that you and the group shared with me.

I need to know two things from you:

1. Did I get what you wanted to tell me correct?

2. Do you think the conclusions I made about why this project is important and my ideas suggestions for future CBPR projects are correct?

Let's go over the summary and tell me what you think. It can be good or bad. 


\title{
Empowerment in Community-Based Participatory Research with Persons with Developmental Disabilities: Perspectives of Community Researchers
}

\author{
Erin Stack \\ Portland State University
}

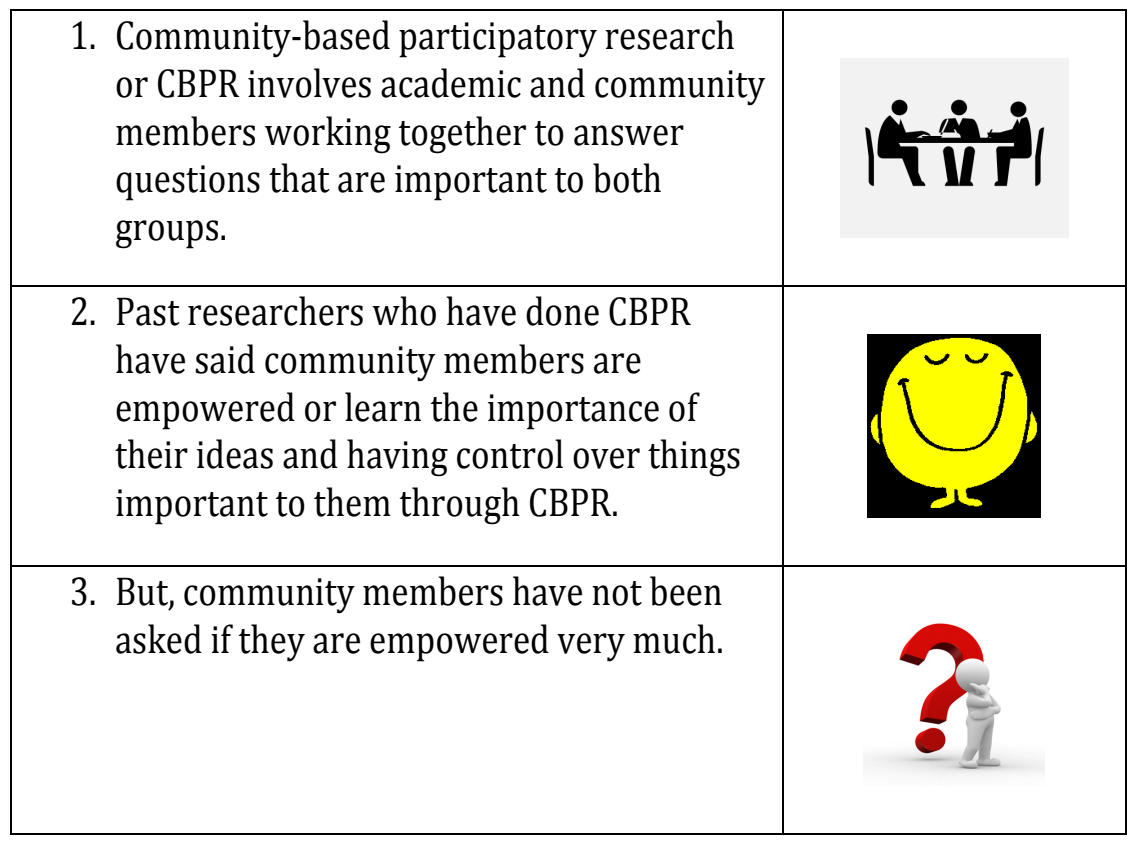

4. I wanted to learn:

1. About what empowerment meant to all people on the Partnering Project, especially community members.

2. If people on the Partnering Project were empowered from their work on the project.

3. If parts of the project helped or did not help people be empowered.

interview

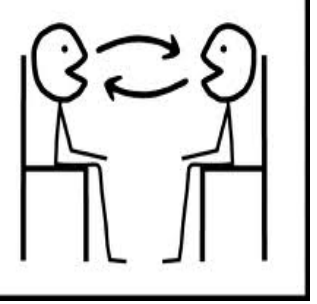

Empowerment in CBPR: Member Check

Page 1 of 6 


\section{What is empowerment?}

5. As a group, you said empowerment had to
do with self-esteem and believing in
yourself.
It just is kind of... being confidence in... yourself.
As far as how empowerment related to my life... it has to
do with self-esteem, self-consciousness, self-exploration.
6. You said empowerment had to do with
independence and control over things that
are important to you.
Ifeel empowered that I can control what my own thoughts
are, my own feelings, what I want to do with my life. I feel
empowered... that I can make my own choices.
7. You said learning is important to
empowerment.
In order for people to be empowered, any people, they
have to feel like they made the best choice with the
information they had available to them. You know, that is
empowering, giving people that information.

Empowerment in CBPR: Member Check

Page 2 of 6 


\section{What parts of the Partnering Project helped you be empowered?}

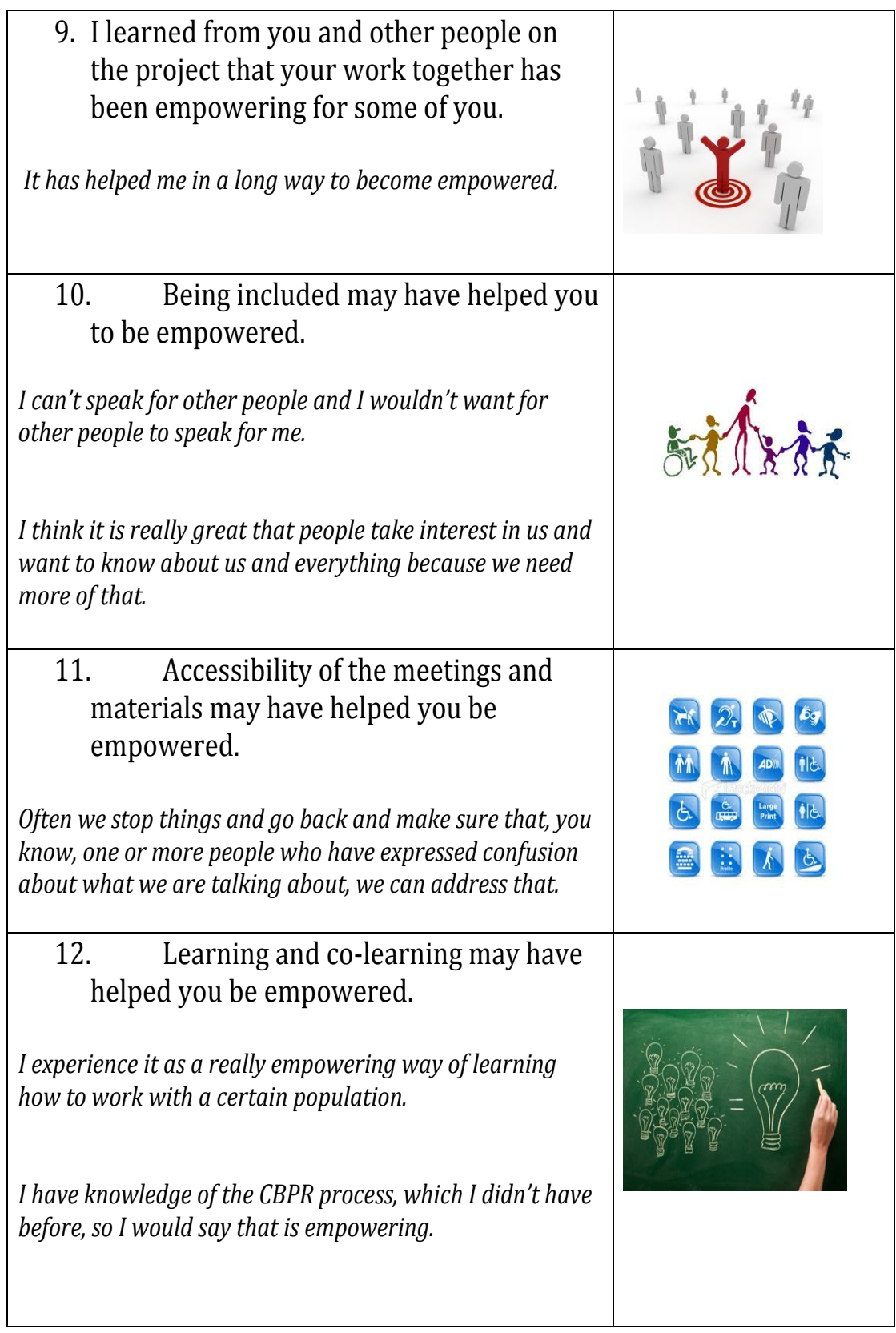

Empowerment in CBPR: Member Check

Page 3 of 6 


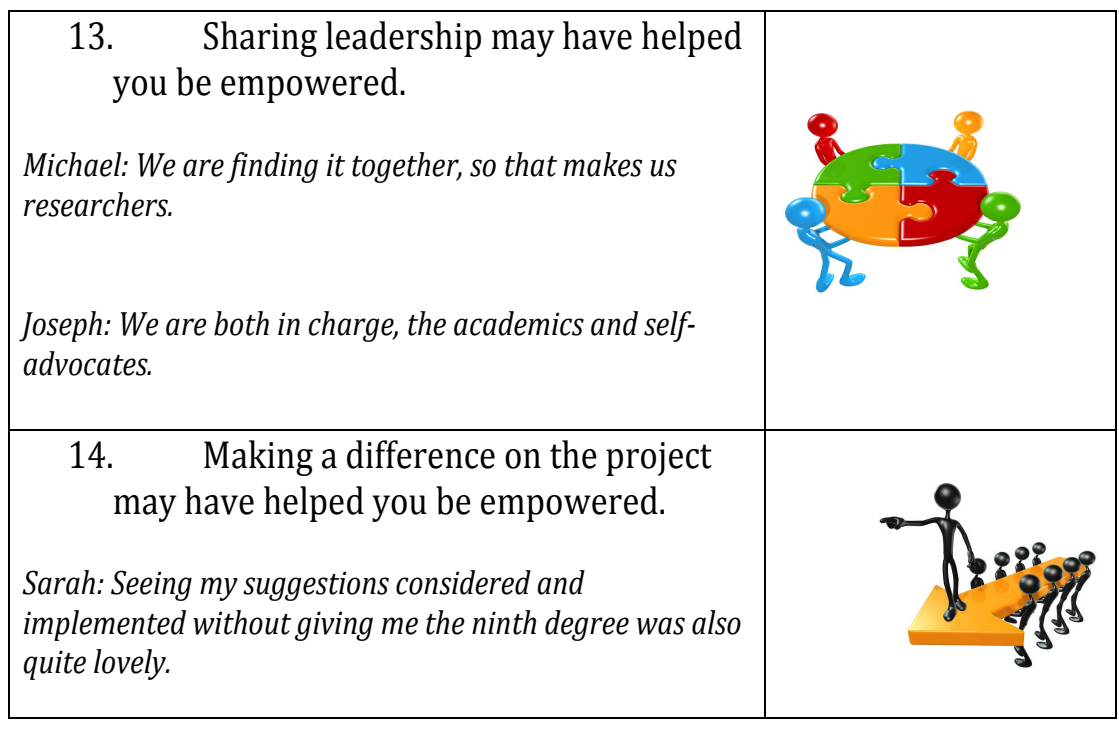

\section{What parts of the Partnering Project may have created obstacles or barriers to you being empowered?}

\begin{tabular}{|c|c|}
\hline $\begin{array}{l}\text { 15. Not understanding what is going on } \\
\text { in meetings may have been a barrier to } \\
\text { you being empowered. } \\
\text { I find it real hard sometimes when like [project members] } \\
\text { are talking and they have real hard words... That is really } \\
\text { frustrating to me. And I think with anyone, when you don't } \\
\text { understand something, it is pretty hard... When it gets } \\
\text { complicated, then I feel like, "Why am I here?" }\end{array}$ & \\
\hline $\begin{array}{l}\text { 16. Not feeling part of the team may } \\
\text { have been a barrier to you being } \\
\text { empowered. } \\
\text { No because I know what being a researcher is and I am } \\
\text { not doing that. }\end{array}$ & $M$ \\
\hline
\end{tabular}

Empowerment in CBPR: Member Check Page 4 of 6 


\section{Has what empowerment meant to you changed from your work on the Partnering Project?}

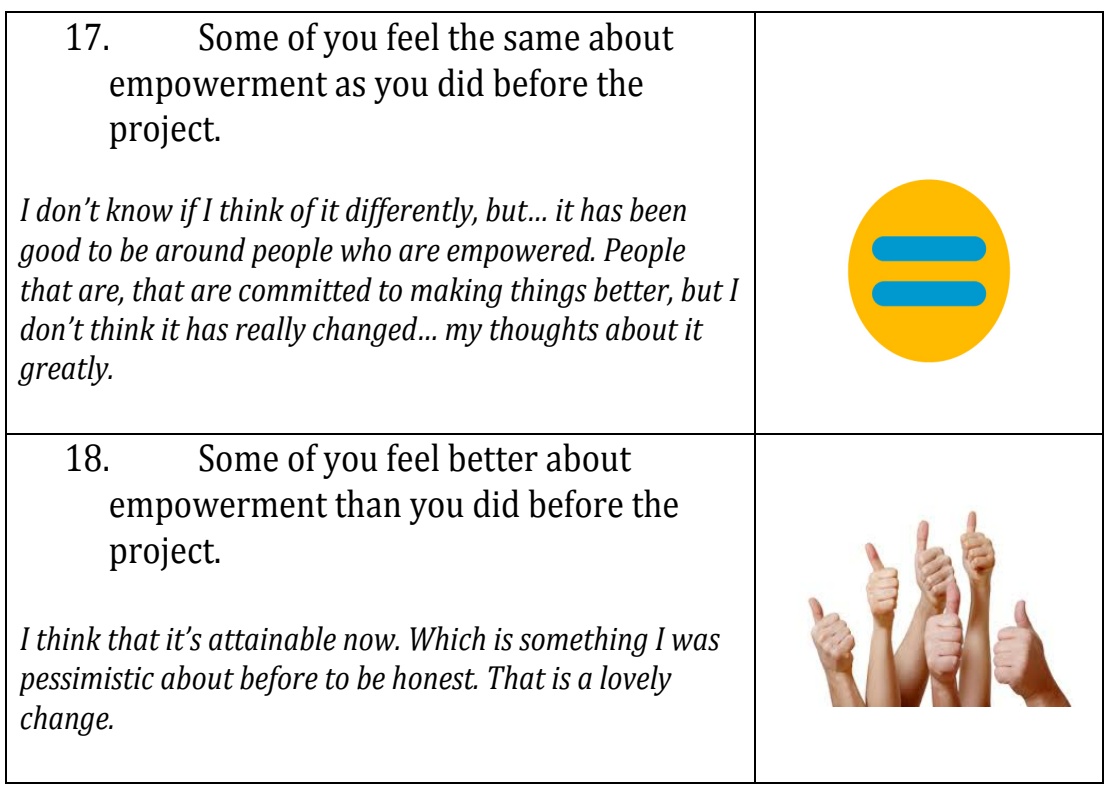




\section{Why is studying empowerment in CBPR important?}

\begin{tabular}{|l|}
\hline $19 . \quad$ To show others how CBPR can be \\
empowering for community partners. \\
\hline $\begin{array}{l}\text { will involve persons with developmental } \\
\text { disabilities on their research teams. }\end{array}$ \\
\hline $\begin{array}{l}\text { And persons with developmental } \\
\text { disabilities can benefit from being } \\
\text { included in CBPR and from the outcomes } \\
\text { of research together. }\end{array}$ \\
\hline
\end{tabular}

\section{My suggestions for future CBPR projects}

1. Focus on partnerships that provide an opportunity for community partners to be empowered.

a. This includes opportunities for community members to:

i. Be included

ii. Learn and share knowledge and skills

iii. Contribute because meetings are accessible

iv. And share leadership roles.

2. Have a reflection process so project members can share good and bad feelings about the work and be open to suggested changes in the partnership.

3. Have diversity of community members in the leadership roles on the project.

Empowerment in CBPR: Member Check 